UNIVERSIDADE DE SÃO PAULO

INSTITUTO DE PSICOLOGIA

DEPARTAMENTO DE PSICOLOGIA CLÍNICA

GERMANO HENNING

A terapia analítico-comportamental das habilidades sociais em grupo para adolescentes com uso do RPG e da gamificação 
UNIVERSIDADE DE SÃO PAULO

INSTITUTO DE PSICOLOGIA

DEPARTAMENTO DE PSICOLOGIA CLÍNICA

GERMANO HENNING

\title{
A terapia analítico-comportamental das habilidades sociais em grupo para adolescentes com uso do RPG e da gamificação
}

(Versão Corrigida)

\begin{abstract}
Dissertação apresentada ao Programa de Pós-Graduação em Psicologia Clínica do Instituto de Psicologia da Universidade de São Paulo como requisito para a obtenção do título de Mestre.
\end{abstract}

Área de Concentração: Psicologia Clínica

Orientador: Prof. Dr. Francisco Lotufo Neto 
AUTORIZO A REPRODUÇÃO E DIVULGAÇÃO TOTAL OU PARCIAL DESTE TRABALHO, POR QUALQUER MEIO CONVENCIONAL OU ELETRÔNICO, PARA FINS DE ESTUDO E PESQUISA, DESDE QUE CITADA A FONTE.

Catalogação na publicação

Biblioteca Dante Moreira Leite

Instituto de Psicologia da Universidade de São Paulo

Dados fornecidos pelo(a) autor(a)

Henning, Germano

A terapia analítico-comportamental das habilidades sociais em grupo para adolescentes com uso do RPG e da gamificação. / Germano Henning; orientador Francisco Lotufo Neto. -- São Paulo, 2021.

$112 \mathrm{f}$.

Dissertação (Mestrado - Programa de Pós-Graduação em Psicologia Clínica) -Instituto de Psicologia, Universidade de São Paulo, 2021.

1. treinamento de habilidades sociais. 2. psicoterapia de grupo. 3. role-playing game. 4. análise do comportamento. 5. terapia online. I. Neto, Francisco Lotufo, orient. II. Título. 

Nome: HENNING, Germano

Título: A terapia analítico-comportamental das habilidades sociais em grupo para adolescentes com uso do RPG e da gamificação

Dissertação apresentada ao Programa de Pós-Graduação em Psicologia Clínica do Instituto de Psicologia da Universidade de São Paulo para a obtenção do título de Mestre.

Aprovado em:

\section{Banca Examinadora}

Prof. Dr.

Francisco Lotufo Neto

Instituição:

USP

Julgamento:

Aprovado

Prof. Dr.

Antônio Serafim

Instituição:

USP

Julgamento:

Aprovado

Prof. Dr.

Denigés Regis Neto

Instituição:

PUC - SP

Julgamento:

Aprovado 
A minha família, que sempre me inspirou com os conhecimentos do universo acadêmico. Sem vocês, provavelmente não haveria a vontade e a inspiração para construir este caminho.

A minha equipe, que ajudou tanto a construir todo esse sistema... Sempre dizíamos que precisávamos de alguém para escrever sobre toda essa prática e, agora, aqui está!

Ao meu grande amigo e sócio Túlio Andrade; sem você, eu nunca teria tirado esse projeto do mundo das ideias. Toda a nossa experiência de vida está aqui... sim, este trabalho é nosso! E, sim, criamos um universo.

A todos, mães, pais e jovens do consultório, que sempre nos inspiraram com as imaginações mais intensas. Sem o universo lúdico de crianças e adolescentes não teríamos um mundo e nem heróis para narrar... Vocês são incríveis!

A minha esposa Mariana, que com seu humor, seus insights e o seu sossego, sempre trouxe calmaria para os meus nervos... 


\section{AGRADECIMENTOS}

Sou grato ao meu orientador, Prof. Francisco Lotufo Neto, que, com toda a objetividade e humildade, soube conduzir muito bem o seu orientando. Com certeza, devo lhe agradecer por ter evocado o meu lado como pesquisador. Será uma aprendizagem em que darei os créditos a você. Diga-se de passagem, os meus pais também lhe agradeceriam e muito.

Agradeço a equipe do consultório, Grupo D20, pelo apoio, coleta, discussão e, claro, o mais importante, a amizade. Faço questão de agradecer a vocês individualmente:

Túlio Andrade, a gente podia escrever um livro sobre a nossa relação! Somos sócios, moramos juntos e criamos o início desse universo! Essa dissertação é para você! Obrigado!

Raissa Benevides, por ser um dos membros mais antigos; a sua habilidade com as crianças é algo encantador, além da ideia inovadora das fichas de XP...

Renato Gallo, por ser um dos terapeutas mais esforçados que conheço... com certeza, a sua habilidade de lidar com pais é inspiradora, e a sua voz para o fim da Season VIII!

Reinaldo Rodrigo, a sua inteligência e o veganismo são um modelo para mim. A sua empatia com os animais é algo que admiro, e a ideia maluca do Ateneu...

Rodrigo Fuga, o seu espírito elétrico em ir atrás das coisas combina comigo... isso é ótimo, assim como as ideias práticas dos bots...

Lucas Moraes, um dos maiores mestres e ser mergulhado na cultura dos adolescentes... aliás, o seu conhecimento sobre RPG é incrível!

Maria Beatriz, a mais nova dos integrantes da equipe, que já mostrou o seu poder de síntese, temos orgulho de ter você na nossa equipe...

À minha mãe Leoni, pela preocupação e pelas consultorias; quanto às ideias... aprendi que filosofia é realmente útil... rs.

Ao meu pai, que tanto é a minha principal inspiração para perseverança, vontade e ética... sua moralidade e sua lealdade são umas das coisas mais valiosas que tenho! Obrigado por essa referência... agora, deixemos a conversa de política de lado... rs.

Agradeço à Banca da Qualificação, que fez críticas pertinentes e auxiliou na reestruturação da escrita final. Cláudia Oshiro e Denigés, as colocações feitas foram sensacionais. Obrigado!

Aos meus colegas profissionais que tanto apoiaram o trabalho ou me apresentaram outros trabalhos relevantes para o meu estudo... Saada, Daniel Del Rey, Daniela Tsubota, Mateus Brasileiro, Giovanna Andreozzi, Aliaska, a equipe Lupa, João Mariano, Gabi Parpinelli, 
Ceres, Fabrizia Dias, Georgia Menezes, Fabiana Davantel, Camila Colaneri, Juliana Gomes, Sheila Caetano, Caia Pacífico, Miguel Lebre, Ana Luiza, entre tantos outros.

O meu eterno agradecimento ao meu amigo desde a adolescência Maurício Takano, que tanto nos convida para participar de eventos! Obrigado!

Ao suporte de estatística: obrigado Alia Guirado por tantos encontros e discussão de dados, e à revisora Kika, que tanto cuida do meu português...

Obrigado aos meus irmãos: Fred, que, além do suporte de estatística, é uma inspiração de vida, o seu bandolim trouxe calma nas horas certas... Pri, você é uma das pessoas mais inteligentes que conheço! A minha inspiração de inteligência.

Obrigado a toda turma da pós-graduação de música, especialmente ao professor Ari Colares e ao Daniel Alfaro. Vocês foram uma pausa de semibreve no meio do solo... uma pausa necessária para descansar no mundo da arte...

Ao Mateus Brasileiro, o seu curso de Habilidades Sociais foi um divisor de águas para mim! Obrigado!

Um agradecimento especial à Tatiana Setuguti, que nos ajudou a construir a imagem do D20 e que acompanhou diversas histórias... Outro agradecimento ao pessoal do marketing: à Gabriela Ribeiro e à agência Bérgamo.

Nesse momento, cabe um agradecimento mais do que especial à Rosa Magaly, que tanto incentivou e me apresentou ao meu orientador.

E aos amigos Felipe, Bia, Amanda, Aline Mocoronga, Dija, Nego, Giovanni, Larissa, Samuca, Keny, Murilo, Rodrigo, Guga, Luiz Botelho, Zé, Juliana, Luís, Márcia...

E, para finalizar, um humilde agradecimento ao Stan Lee, que, provavelmente, sem os heróis criados por você, eu não teria muita imaginação para colocar no meu trabalho. 
Embora algum dia eu receba ingratidão Não deixarei de socorrer a quem pedir o pão Eu nunca soube evitar de praticar o bem Porque eu posso precisar também (Nelson Cavaquinho, Caridade, 1970) 


\section{RESUMO}

HENNING, G. A terapia analítico-comportamental das habilidades sociais em grupo para adolescentes com uso do RPG e da gamificação. 2021. Dissertação (Mestrado em Psicologia) - Instituto de Psicologia, Universidade de São Paulo, São Paulo, 2021.

Em busca de organizar e de contextualizar historicamente, a pesquisa propõe uma intervenção integrativa de diferentes áreas da psicologia, como treinamento de habilidades sociais e terapia de grupo, e do design, a gamificação, com uso do RPG de mesa. Como se trata de uma intervenção analítica comportamental de grupo, tem como premissa os usos da análise funcional e da prática controlada, para intervir individualmente no contexto do grupo e nas classes de respostas das habilidades sociais, utilizando os reforçadores do RPG e de outros aspectos da gamificação. Além do treino dentro do consultório, existem intervenções extraconsultório, de modo que as consequências estão diretamente ligadas às sessões de grupo. Portanto, o objetivo da pesquisa é avaliar os efeitos dessa intervenção, através de instrumentos e das técnicas clínicas da Análise do Comportamento. O método consistiu na amostra de dezesseis adolescentes entre 12 e 17 anos, distribuídos em cinco grupos, e os respectivos pais. A coleta de dados foi realizada através dos questionários de quatros instrumentos: IHSA, GCQ, CGI e TC-GAS. Além das sessões programadas da pesquisa, houve atendimentos individuais, intervenções fora do consultório e, com a pandemia, foi utilizada a plataforma online Discord. Os resultados sobre IHSA foram divididos em dois momentos, devido ao impacto da pandemia. A primeira comparação foi realizada entre seis sujeitos que realizaram sete sessões presenciais entre duas aplicações do IHSA, mostrando que houve um aumento da frequência de comportamentos socialmente hábeis e uma diminuição da dificuldade; porém, pelo tamanho da amostra, não houve diferença estatisticamente significativa. Já para os dezesseis sujeitos, o IHSA teve diferença significativa em duas categorias, indicando até uma piora na modalidade online. $\mathrm{O}$ instrumento GCQ descreveu o processo terapêutico de acordo com o perfil psicológico do grupo, indicando maior engajamento do que conflito e esquiva. Os participantes tiveram alto rendimento no instrumento TC-GAS para as tarefas solicitadas pelos pais. O CGI indicou que os pais participaram pouco da intervenção e não perceberam os rendimentos dos filhos a partir dos resultados da TC-GAS. Como resultado inesperado da pandemia, houve um aumento das interações sociais por conta do Discord, o que indica que a generalização do comportamento pode ser mensurável. Como parte da discussão, os resultados do IHSA foram analisados criticamente com relação à sua aplicação no contexto de pandemia e o GCQ no contexto de THS. Como conclusão, o estudo indica futuras pesquisas quanto à formulação de instrumentos de processo terapêutico para mensurar as habilidades sociais em grupo, implementação de THS protocolados junto com as intervenções propostas e com os pais, maior investigação sobre a gamificação aplicada na área clínica e as possibilidades de pesquisas sobre a generalização do comportamento e competências sociais através de plataformas online, como Discord.

Palavras-chave: Terapia Analítico-Comportamental. Treinamento de Habilidades Sociais (THS). Psicoterapia de grupo. Role-Playing Game (RPG), Gamificação. 


\begin{abstract}
HENNING, G. The analytical-behavioral therapy of social skills in groups for adolescents using RPG and gamification. 2021. Dissertation (Master's in Psychology) - Instituto de Pscicologia, Universidade de São Paulo, São Paulo, 2021.

In search of organizing and historically contextualizing, the research proposes an integrative intervention from different areas of psychology, such as social skills training and group therapy, and design, gamification, using table RPG. As this is a group behavioral analytical intervention, it has as premise the uses of functional analysis and controlled practice, to intervene individually in the context of the group and in the response classes of social skills, using stimuli from RPG and other aspects of gamification. In addition to in-office training, there are extra-consultative interventions, so the consequences are directly linked to group sessions. Therefore, the objective of the research is to evaluate the effects of this intervention, using instruments and clinical techniques of Behavior Analysis. The method consisted of a sample of sixteen adolescents between 12 and 17 years old, distributed in five groups, and their respective parents. Data collection was performed using questionnaires from four instruments: IHSA, GCQ, CGI and TC-GAS. In addition to the scheduled research sessions, there were individual consultations, interventions outside the office and, with the pandemic, the online platform Discord was used. The results on IHSA were divided into two moments, due to the impact of the pandemic. The first comparison was made between six subjects who carried out seven faceto-face sessions between two applications of IHSA, showing that there was an increase in the frequency of socially skilled behaviors and a decrease in difficulty; however, due to the sample size, there was no statistically significant difference. As for the sixteen subjects, the IHSA had a significant difference in two categories, indicating even a worsening in the online modality. The GCQ instrument described the therapeutic process according to the psychological profile of the group, indicating greater engagement than conflict and avoidance. The participants had a high performance on the TC-GAS instrument for the tasks requested by the parents. The CGI indicated that the parents participated little in the intervention and did not perceive their children's income from the results of the TC-GAS. As an unexpected result of the pandemic, there was an increase in social interactions due to Discord, which indicates that the generalization of behavior can be measurable. As part of the discussion, the results of the IHSA were critically analyzed with respect to its application in the context of a pandemic and the GCQ in the context of THS. As a conclusion, the study indicates future research regarding the formulation of therapeutic process instruments to measure social skills in groups, implementation of protocoled THS together with the proposed interventions and with parents, further research on the gamification applied in the clinical area and the possibilities research on the generalization of behavior and social skills through online platforms, such as Discord.
\end{abstract}

Keywords: Behavioral-Analytical Therapy. Social Skills Training (THS). Group psychotherapy. Role-Playing Game (RPG), Gamification. 


\section{LISTA DE ILUSTRAÇÕES}

Figura 1 - Diagrama representando o esquema geral de classes de comportamentos sociais pertinentes ou não pertinentes aos conceitos de HS e CS

Figura 2 - Porcentagem de estudos realizados em cada ambiente, ocorrência do arranjo de contingências e condições extra experimentais ou na presença de quem o comportamento seria observado

Figura 3 - Porcentagem de estudos que utilizaram treino de pais/cuidadores e tarefas para casa, e sua relação com a eficácia do procedimento

Figura 4 - Foto demonstrativa sobre o setting de uma mesa de RPG, em que há um mestre narrando e os demais jogadores com os seus personagens 42

Figura 5 - Cenário de um mapa ou cena narrada durante o RPG de mesa......................... 42

Figura 6 - Representação da intervenção TGS ............................................................. 54

Figura 7 - Cards dos equipamentos como armadura, espadas, escudos e outros ................ 61

Figura 8 - Foto das fichas de XP, cada uma apresenta um valor diferente ........................ 62

Figura 9 - Recorte de uma ficha do personagem de um dos participantes........................ 62

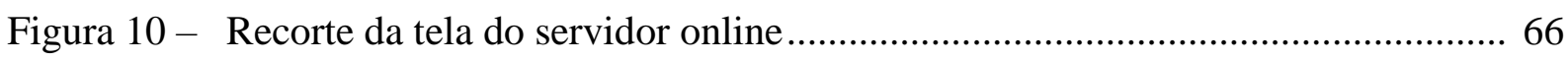

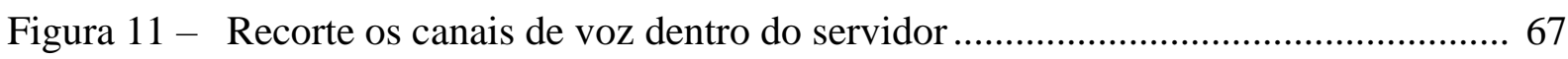

Figura 12 - BOT disponibiliza cartas de personagens de anime e os usuários podem guardar as cartas para sua coleção ............................................................................. 68

Figura 13 - Registro da quantidade de mensagem enviada e do tempo conectado em canais de voz com o XP dado para cada usuário

Figura 14 - Registro do número absoluto de mensagens a cada dia, enviada no servidor.... 69

Figura 15 - Representação das sessões em diferentes modalidades presencial ou online para cada sujeito da pesquisa ....................................................................... 70

Figura 16 - Representação da coleta dos instrumentos IHSA e GCQ para cada participante da

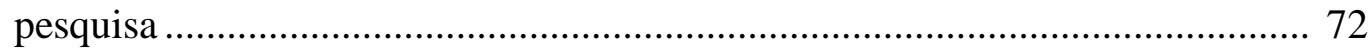

Figura 17 - Escore total da frequência e da dificuldade do IHSA ao longo das três avaliações pré, meio e pós-intervenção, e a indicação sobre a modalidade de atendimento da sessão entre os testes

Figura 18 - Escore de frequência e dificuldade para todas as categorias do IHSA para os seis sujeitos no pré, meio e pós-teste.

Figura 19 - Escore de cada grupo do instrumento GCQ e o intervalo de variância de cada categoria de engajamento, conflito e esquiva em todas as sessões 
Figura 20 - Frequência de resposta dos pais sobre a severidade da queixa a respeito dos AVD e HS dos filhos ........................................................................................... 79

Figura 21 - Frequência de resposta dos pais sobre a avaliação do processo terapêutico a respeito de AVD e HS dos filhos ............................................................... 80

Figura 22 - Porcentagem do tipo de tarefas requisitadas pelos pais nas TC-GAS, separadas em

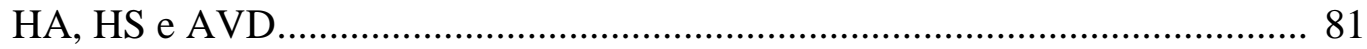

Figura 23 - Taxa de realização da tarefa por todos os participantes da pesquisa, separados em AVD, HA, HS, IND 81

Figura 24 - Porcentagem da realização de cada tipo de tarefa distribuída em cada grupo, com a linha média da taxa de realização de toda a amostra .................................. 82 


\section{LISTA DE TABELAS}

Tabela 1 - Resumo das características sobre as terapias de grupo quanto a ano, autor, frequência, número de participantes, perfil, método e os pontos de concordância com o setting da metodologia aqui proposta (amostra realizada de 1905-1950)

Tabela 2 - Progresso do nível do personagem através do acúmulo de XP e benefícios para cada nível

Tabela 3 - Cronograma do planejamento da coleta de dados durante as 12 sessões de grupo para cada inventário

Tabela 4 - Média, desvio-padrão, variância e nível de significância do escore total e as seis categorias da frequência e dificuldade para os 6 sujeitos nos 3 diferentes momentos da pesquisa pré (Ava 1), meio (Ava 2) e pós-intervenção (Ava 3) 73

Tabela 5-Teste de Wilcoxon pareado, média e desvio-padrão de cada categoria para frequência e dificuldades nos 2 momentos de teste (pré e pós) com os 16 sujeitos da pesquisa

Tabela 6 - Taxa de respostas dos pais dos participantes, agrupados pelos grupos terapêuticos, e o total das mensagens enviadas/respondidas a partir de 25/10/2019 até 13/03/2020 


\section{LISTA DE SIGLAS}

ABA Aplied Behavior Analysis

AC Análise do Comportamento

AVD Atividade Vida Diária

CGI Clinical Global Impressions

CS Competência Social

D\&D Dungeon \& Dragons

GAS Goal Attainment Scaling

GCQ Group Climate Questionnaire

GRQ Group Readiness Questionnaire

HA Habilidade Acadêmica

HS Habilidade Social

IHSA Inventário das Habilidades Sociais

PBE Prática Baseada em Evidência

RPG Role-Playing Game

TC Tarefas de Casa

TDAH Transtorno de Déficit de Atenção e Hiperatividade

TEA Transtorno do Espectro Autista

TGS Terapia de Gamificação da Socialização

THS Treinamento de Habilidades Sociais

TOD Transtorno de Oposição e Desafiador 


\section{SUMÁRIO}

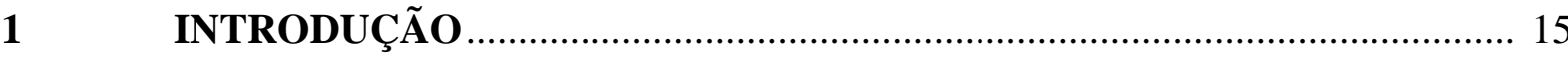

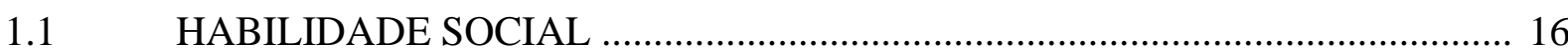

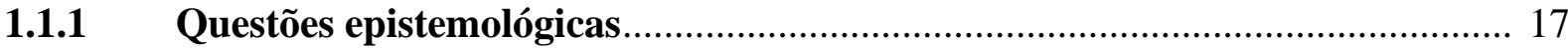

1.1.1.1 Contribuições da análise do comportamento ...................................................... 18

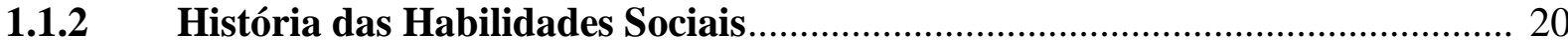

1.1.2.1 Os conceitos de habilidade social e de competências sociais ............................... 21

1.1.3 Classes de respostas das habilidades sociais ................................................ 26

1.1.4 Intervenção e planejamento da generalização.............................................. 29

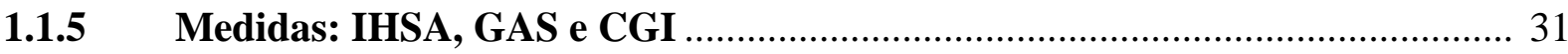

1.1.5.1 Inventário de Habilidades Sociais para Adolescentes (IHSA) .............................. 31

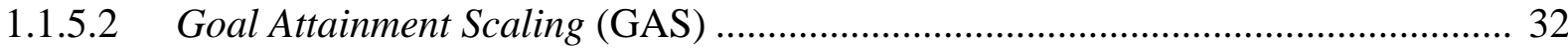

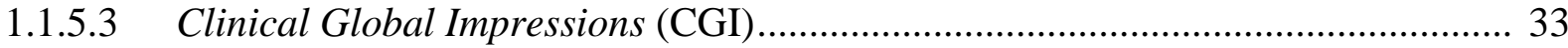

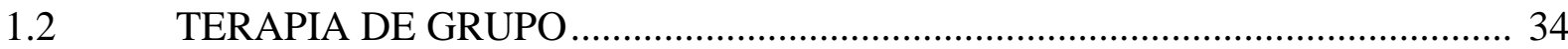

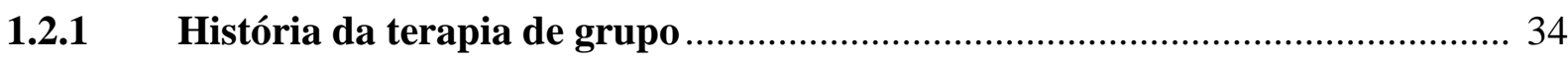

1.2.2 Group Climate Questionnaire (GCQ) ............................................................ 39

1.3 COMPREENDENDO RPG, CULTURA NERD E GAMIFICAÇÃO.................. 39

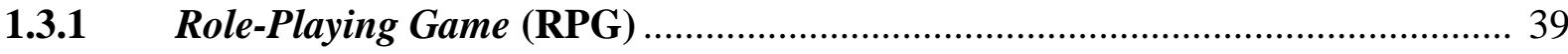

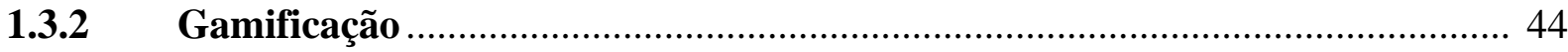

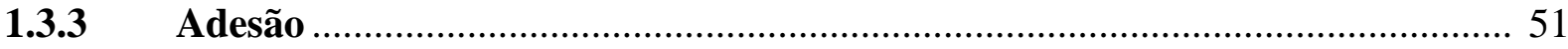

1.4 DESENVOLVIMENTO DO TERAPIA DE SOCIALIZAÇÃO GAMIFICADA (TSG) PARA TREINO DE HABILIDADES SOCIAIS EM GRUPO E GENERALIZAÇÃO DO COMPORTAMENTO.............................................. 52

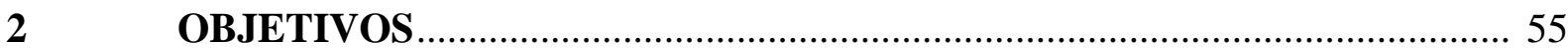

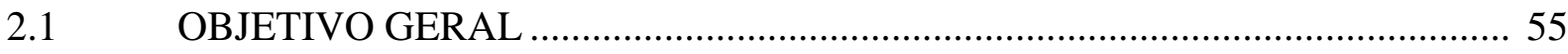

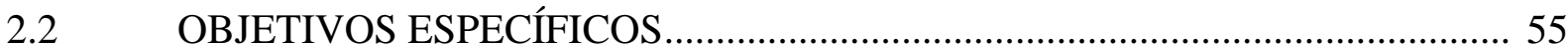

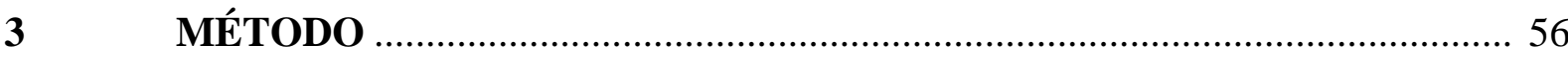

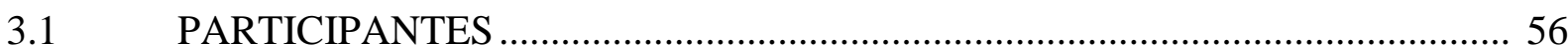

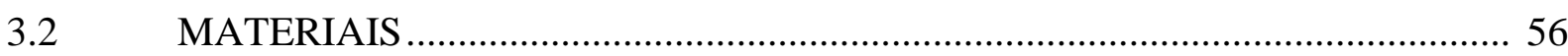

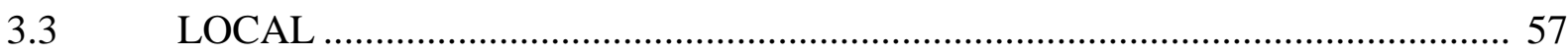

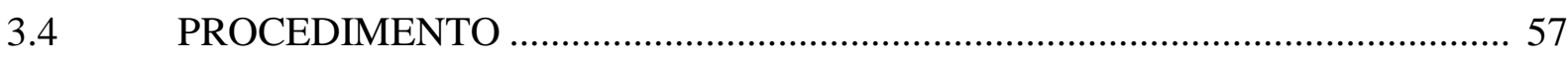

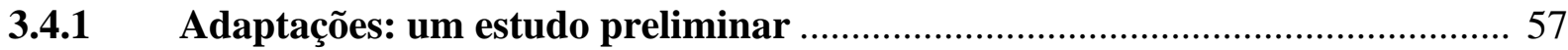

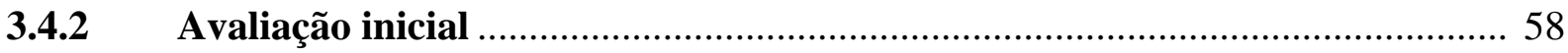


3.4.2.1 Primeira sessão de entrevista inicial (com os pais) ............................................. 58

3.4.2.2 Segunda sessão de entrevista inicial (com o cliente) .......................................... 58

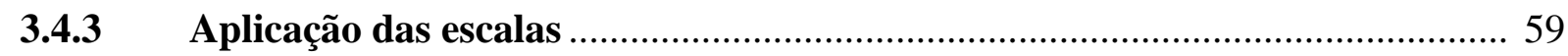

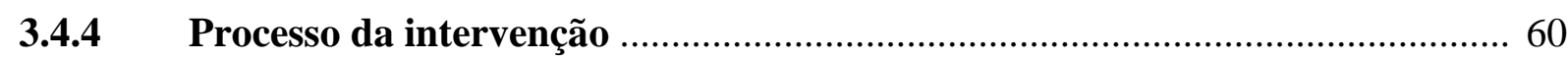

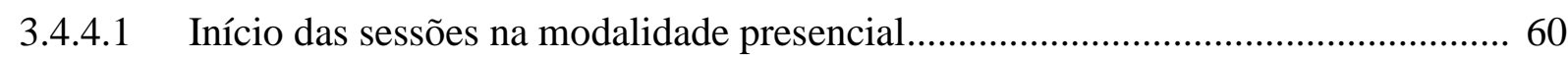

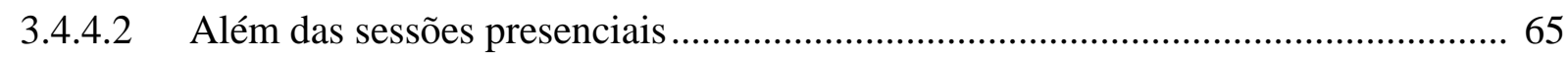

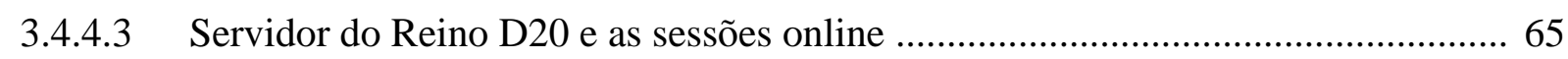

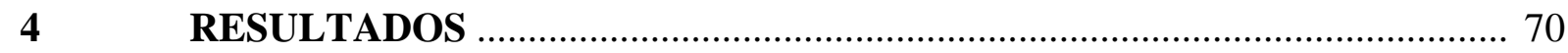

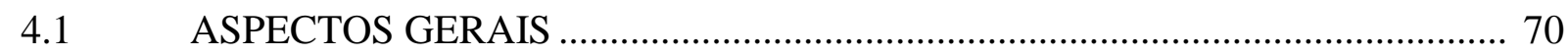

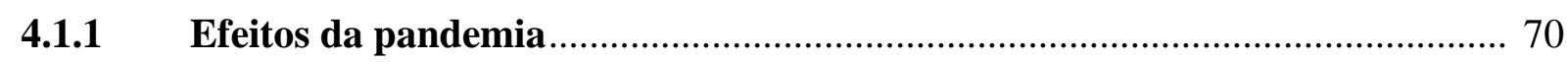

IHSA PARA OS SETE SUJEITOS E A AMOSTRA TODA .............................. 72

G.3 GCQ PARA OS CINCOS GRUPOS .............................................................. 75

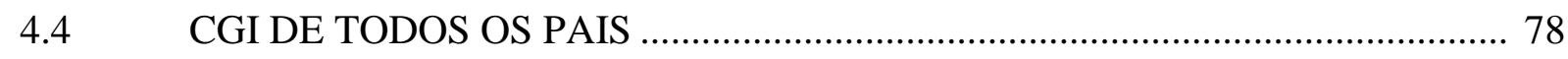

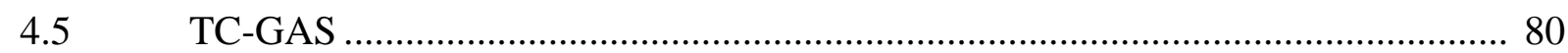

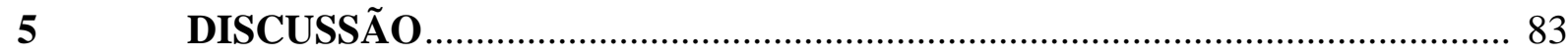

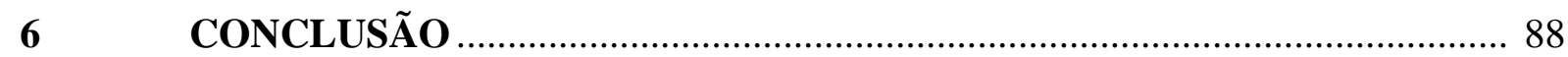

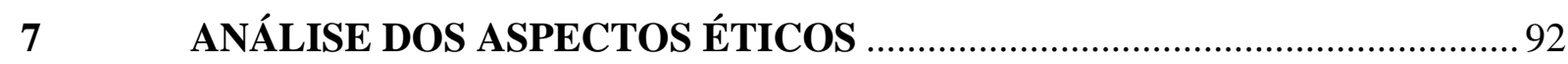

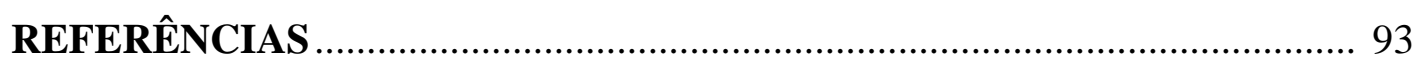

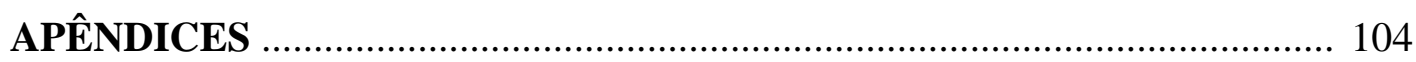




\section{INTRODUÇÃO}

Em 2013, iniciaram-se os primeiros grupos de terapia analítico-comportamental com foco nas habilidades sociais, utilizando Role-Playing Game (RPG) como ferramenta para intervenção, em uma clínica de São Paulo. Sem pretensão acadêmica e numa linha de "tentativa e erro", ao longo dos anos surgiu a necessidade de aproximação com algumas áreas da psicologia, e posteriormente do game design, para um melhor entendimento dessa prática psicoterapêutica. Esta dissertação é o resultado de uma pequena parte das intervenções grupais realizadas.

Para auxiliar o leitor, a intervenção em questão se baseia em quatro grandes áreas, além da linha teórica da Análise do Comportamento (AC), que guiou sua construção. São elas: a área das habilidades sociais (HS), da terapia de grupo (TG), do role-playing game (RPG) e da gamificação.

$\mathrm{Na}$ primeira parte, será apresentada a área das habilidades sociais, descrevendo sua história desde a origem até o desenvolvimento do seu conceito, as suas categorias e o Treinamento das Habilidades Sociais (THS). Também serão apresentados os inventários utilizados para a análise das habilidades sociais (pré e pós-intervenção) e a apresentação de outros questionários, adaptados para analisar o processo terapêutico dos grupos. Na parte final desse capítulo, serão apresentados a questão da generalização e os instrumentos de avaliação, tanto dos repertórios comportamentais em sessão como as mensurações no contexto natural, ou seja, além da sessão.

Na segunda parte, serão mostrados a história da terapia de grupo e alguns fatos curiosos sobre diversos fenômenos ocorridos dentro de grupos terapêuticos a partir de 1905. Muitos desses grupos envolveram observações curiosas sobre a importância da interação social, do ensaio comportamental e de algumas observações sobre manejo/setting terapêutico. Mesmo assim, os resultados desses grupos se aproximam em vários aspectos do setting terapêutico do atual trabalho. No final, será divulgado o questionário, traduzido e adaptado, Group Outcome Questionnarie, usado para mensurar o processo terapêutico de terapia de grupo.

$\mathrm{Na}$ terceira parte, será apresentada a área mais moderna, que é o impacto do RolePlaying Game, o desenvolvimento dos jogos eletrônicos e da tecnologia na sociedade, resultando numa área do design pouco conhecida na psicologia, a gamificação. O entendimento dessa grande área é relevante para o entendimento do perfil adolescente pós-moderno que, muitas vezes, nasce na era digital com jogos eletrônicos, assim como é inserido na cultura geek. 
Será possível, desse modo, entender a inserção do RPG como ferramenta motivacional para mudança do comportamento, resultando em maior adesão ao tratamento.

Através da interseção dessas quatro grandes áreas, espera-se esclarecer tanto a posição social quanto a histórica do método apresentado, denominado Terapia da Socialização Gamificada. Também será explicado como funciona o método e como foi realizada a análise de diferentes instrumentos com o objetivo de entender o processo terapêutico e de melhorar a adesão às práticas psicoterapêuticas de grupo.

\subsection{HABILIDADE SOCIAL}

O tema das HS é de interesse dentro tanto do contexto clínico quanto do popular. Uma das possíveis explicações sobre o interesse por esse tema aparece quando, retomando Aristóteles, Caballo (2003) afirma que os seres humanos são "animais sociais" e, sendo assim, a comunicação interpessoal é essencial para toda atividade humana. Esse comportamento social foi importante para manter a coesão da espécie, garantindo a sua sobrevivência, o que torna a prática humana difícil de desvincular do aspecto social (DEL PRETTE; DEL PRETTE, 2001b).

Outra observação importante a respeito das HS é a sua relação com a qualidade de vida e com os sintomas psiquiátricos, pois diversos estudos apontam uma melhora do quadro clínico quando elas são mais desenvolvidas (CARNEIRO, 2006; DEL PRETTE; FALCONE; MURTA, 2013; LIMA et al., 2016; ROCHA; BOLSONI-SILVA; VERDU, 2012). Além da questão clínica e dos sintomas psiquiátricos, alguns instrumentos de avaliação sobre quadros clínicos - como World Health Organization Quality of Life (WHOQOL), Outcome Questionnaire (OQ-45), Child Behavior CheckList (CBCL), Group Climate Questionnaire (GCQ), Inventário de Estilos Parentais (IEP) - possuem vários itens sobre relações interpessoais, relacionamentos amorosos e interações com os pais, entre outros.

Devido às HS serem um critério importante para avaliar o bem-estar ou a saúde mental, também constituem uma etapa comum em diversos tratamentos psicológicos em vários quadros clínicos, como ansiedade, depressão, esquizofrenia e delinquência (CABALLO, 2003; CARNEIRO, 2006; DEL PRETTE; FALCONE; MURTA, 2013; ROCHA; BOLSONI-SILVA; VERDU, 2012).

Além da saúde mental, o uso de técnicas e de treino das habilidades sociais aparecem em diversas áreas, como treinamento interpessoal em empresas, autoconhecimento, relacionamento conjugal, abordagem com fins para relacionamentos, técnica de vendas, dicas para fazer amigos e outros (CARDOSO; DEL PRETTE, 2017; DEL PRETTE; DEL PRETTE, 
1998; DEL PRETTE; DEL PRETTE, 2003; SCORSOLINI-COMIN; INOCENTE; MIURA, 2011).

\subsubsection{Questões epistemológicas}

Ao tratar as habilidades sociais fora do cenário popular e dentro da comunidade científica, espera-se uma definição do conceito, além de uma identificação sobre qual viés epistemológico foi construído esse conceito. Caballo (2003) afirma que ainda é um problema para o campo de investigação das habilidades sociais não ter uma teoria hegemônica, isto é, ainda não há uma definição universal sobre sua conceituação e os componentes das habilidades sociais.

Por mais que o fenômeno da socialização estivesse presente ao longo da história da psicoterapia de grupo (supondo ser evidente a socialização em uma dinâmica de grupo), Caballo (2003) aponta que há relatos de fenômenos das interações sociais ocorridos dentro de sessões ao longo da história desse tipo de psicoterapia, mas que, por alguma razão, tais fenômenos passaram "despercebidos” pelos terapeutas da época. Essas sessões terapêuticas poderiam ser consideradas THS, se forem levadas em conta as pesquisas e o desenvolvimento nos dias de hoje (CABALLO, 2003).

Embora a abordagem predominante dentro das HS seja cognitiva e comportamental (DEL PRETTE; DEL PRETTE, 2017), é difícil, ao longo da história das HS, descrever a posição das abordagens da psicologia, porque os conceitos de HS e de THS atravessam a história da psicologia desde 1949, com Salter (BOLSONI-SILVA; CARRARA, 2010), até os tempos de hoje.

Além da falta de abordagem psicológica hegemônica e de indícios de THS na história das terapias de grupos, a formulação do conceito das habilidades sociais e da prática do THS ainda foi influenciada por diferentes pontos de vista (evidências experimentais, antropologia, filosofia, fisiologia, linguística, matemática etc.), o que resultou em um paradigma ainda mais epistemológico e híbrido (BARBOSA; TERROSO; ARGIMON, 2014; CABALLO, 2003). Ainda assim, as produções acadêmicas das linhas cognitivas e comportamentais foram mais expressivas desde 1970 (DEL PRETTE; DEL PRETTE, 2017). 
1.1.1.1 Contribuições da análise do comportamento

Para a Análise do Comportamento, todo comportamento que tenha uma outra pessoa como ambiente relevante para ação analisada pode ser considerado um comportamento social (SAMPAIO; ANDERY, 2010).

Del Prette e Del Prette (2010) escreveram um ensaio com o objetivo de relacionar os conceitos atuais das habilidades sociais com a Análise do Comportamento. Segundo eles, a relação da $\mathrm{AC}$ se dá em três aspectos: (a) a contribuição do enfoque na função do comportamento para a definição das habilidades sociais e na avaliação da competência social; (b) a relação entre os três níveis de seleção, por consequências com os conceitos das habilidades sociais e competências sociais; e, por último, (c) as contribuições dos programas de habilidades sociais para o planejamento das práticas culturais com a sobrevivência e com a qualidade de vida na complexa sociedade contemporânea.

Segundo Del Prette e Del Prette (2010), Argyle foi um dos pioneiros da construção do campo teórico das HS; ele utilizou conceitos que poderiam ser chamados de princípios da Análise do Comportamento, e outros conceitos referentes ao cognitivismo, para explicar as interações interpessoais. Foram utilizadas definições como princípios de reforçamento e punição, da Análise do Comportamento, e percepção social, papel social, afiliação e categorização, do cognitivismo.

Posteriormente a Argyle, as definições da HS foram diversas e variadas, principalmente sobre em qual aspecto o estudioso define o que é HS (DEL PRETTE; DEL PRETTE, 2010). Para esses autores, como qualquer outro comportamento, as HS são um constructo, envolvendo relações funcionais entre as respostas de duas ou mais pessoas, em que, de forma dinâmica, as respostas de uma são antecedentes ou consequentes para a outra. Romanczyk e Gillis (2005) também acrescentam que o comportamento social é complexo e envolve uma interação dinâmica entre uma variedade de estímulos discriminativos e suas consequências.

Para Trower (1995), as HS contribuem para as competências sociais (CS), ou seja, o repertório das HS adquirido contribuem para o sucesso ou a consequência das interações interpessoais. Del Prette e Del Prette (2001a) estabeleceram três critérios como avaliação das CS: (a) a consequência da tarefa social, que pode ser dividida em reforçamento positivo ou negativo; (b) a aprovação social da comunidade verbal; e (c) manutenção ou melhora da qualidade da relação.

Skinner (1957) analisa e descreve o comportamento verbal a partir da análise dos estímulos antecedentes, a resposta e as consequências. Desse modo, a análise não fica restrita 
apenas à topografia do comportamento social, mas também à discriminação da função. Os operantes verbais (mando, ecoico, tato e intraverbal) auxiliam na identificação do comportamento-alvo e nas contingências potencialmente reforçadoras.

O desenvolvimento das práticas clínicas do treino das habilidades sociais deu-se a partir dos primeiros estudos de Salter (1949), Wolpe (1958, 1969) e Wolpe e Lazarus (1966), com foco no treino da assertividade. Por exemplo, Bornstein, Bellack e Hersen (1977) conduziram um estudo para demonstrar os efeitos do THS com uso de instrução, feedback, ensaio comportamental e modelação através de linha de base múltipla. Os sujeitos escolhidos para a pesquisa foram quatro crianças inassertivas, que apresentavam dificuldades em ter maior contato visual e em falar mais baixo e com pouca duração. Após as sessões, apresentaram ganhos comportamentais, mesmo após 2-4 semanas de follow-up.

Posteriormente, a terapia analítico-comportamental se destacou nos treinos de habilidades sociais, especialmente com Applied Behavior Analysis (ABA), tornando-se referência no desenvolvimento das THS em casos de Transtorno do Espectro Autista - TEA (McKINNON; KREMPA, 2002; ANDREOZZI, 2017).

McKinnon e Krempa (2002) escreveram um manual para guiar e criar intervenções para TEA. A intervenção proposta é baseada no modelo de treino sistemático e dividida em 10 módulos: treino de atenção conjunta (atenção ao outro, contato visual); contato inicial (cumprimento, respeitar o espaço do outro); dinâmica interpessoal (reconhecer interesses em comum, engajamento na conversa); autoconsciência (autorregulação, automonitoramento); conversação (iniciar e manter a conversa); perspectiva como falador (reconhecer e nomear emoções em si e no outro, demonstrar compaixão e se adaptar); pensamento crítico (resolução de problemas, planejamento); linguagem avançada (entender e compreender uma fala complexa, social pragmática, interpretar pistas sociais); amizade (fazer e manter amizade); e autonomia (independência dentro da comunidade e na vida cotidiana).

Desde o começo do programa, o registro do comportamento é fundamental para as intervenções analítico-comportamental, como registro de comportamentos na linha de base (para comparação com resultados futuros). McKinnon e Krema (2002) descrevem, a partir da coleta do Social Skills Checklist, que é possível determinar o melhor repertório do participante, determinar os comportamentos necessários para se desenvolver, criar um suporte de informações sobre o repertório inicial, metas para intervenção e ensino e determinar grupos baseados na necessidade complementar entre os membros.

Para realizar o registro, o terapeuta deve registrar os estímulos antecedentes, o comportamento-alvo (se foi independente ou com ajuda) e o processo de generalização, com 
destaque para settings, materiais e distratores do ambiente. Além dessas características do comportamento, também é importante registrar as dimensões desse comportamento, como frequência absoluta ou em um período de tempo, duração, latência, topografia e o comportamento emitido em cada local (por exemplo, comportamentos emitidos em uma cafeteria). No final do programa, há uma avaliação, para comparar o repertório inicial com o repertório final.

De modo geral, o treinamento das habilidades socias proposto por McKinnon e Kerma (2002) é um exemplo dentro da Análise do Comportamento Aplicada, mas não é hegemônico. Sendo assim, por mais que as lacunas teóricas das HS estejam resolvidam, o THS continua a evoluir e é utilizado em diversos tratamentos, independente da abordagem do terapeuta. Para Caballo (2003), a resolução dos problemas teóricos das habilidades sociais poderia melhorar a eficácia dos programas. Para entender as divergências sobre a questão teórica das HS e do THS, é preciso estudar a história do campo das habilidades sociais.

\subsubsection{História das habilidades sociais}

A origem dos estudos sobre as habilidades sociais supostamente teve diversas fontes, as quais provavelmente não são reconhecidas (PHILLIPS, 1985). Há registros de trabalhos que tentaram, de alguma maneira, desenvolver algum treino específico de habilidades sociais, embora esses treinos não focassem totalmente o desenvolvimento das HS. Segundo Phillips (1985), os primeiros autores são: Jack (1934), Murphy e Newcomb (1937), Page (1936), Thompson (1952) e Williams (1935).

Para Caballo (2003), há três fontes históricas e independentes que iniciaram um treinamento específico para a melhora das habilidades sociais. A primeira fonte é baseada na Terapia de Reflexos Condicionados, de Salter (1949), Wolpe (1958), Wolpe e Lazarus (1966), Alberti e Emmons (1970), entre outros. Curiosamente, Alberti e Emmons escreveram o primeiro livro sobre assertividade, com o título Your Perfect Right ("Seu perfeito direito"). A partir dos anos 70, houve programas de treino de habilidades sociais para reduzir déficits no repertório social. Vale a pena ressaltar que Wolpe (1958) foi o primeiro autor a utilizar o termo "assertivo".

A segunda fonte é no contexto da internação psiquiátrica, onde Zigler e Phillips (1960) notaram que adultos internados tinham menor duração de internação quanto melhor fosse a sua competência social. O histórico de CS anterior à internação sugeriu aos autores que as 
habilidades sociais fossem critério importante na regulação do paciente em sociedade. $\mathrm{O}$ tema das habilidades sociais passou a ter maior importância dentro das instituições psiquiátricas.

A terceira fonte citada por Caballo (2003) é o aumento de trabalhos sobre o treino das habilidades sociais na Inglaterra, onde Argyle (1994) apresenta um modelo de análise da performance sensorial-motor que pode ser útil para a análise do comportamento social ou da interação interpessoal. Esse primeiro modelo de treinamento das habilidades sociais impulsionou uma série de trabalhos na área (ARGYLE, 1967, 1969, 1974; ARGYLE; KENDON, 1967; TROWER; BRYANT; ARGYLE, 1978).

Percebe-se que os trabalhos sobre habilidades sociais têm sua origem dividida em dois polos: Estados Unidos (as duas primeiras fontes) e Inglaterra (a terceira fonte). No decorrer dos anos 70, houve uma sistematização e um processo histórico de transformações do nome "habilidade social" (CABALLO, 2003). Por exemplo, Salter (1949) utilizou o termo "personalidade excitatória" que, depois, Wolpe (1958) trocou por "comportamento assertivo". Lazarus (1971) trocou por "efetividade pessoal" e Liberman et al. (1975) por "competência pessoal". Embora a Inglaterra já utilizasse o termo "habilidades sociais", ele passou a substituir o termo "comportamento assertivo" no decorrer das publicações dos trabalhos ali realizados. A substituição efetiva do termo só foi realizada somente quando houve artigos com a proposta de mudar o termo "comportamento assertivo" para habilidades sociais (GALASSI; GALASSI; VEDDER, 1981; RATHUS; FOX; DE CRISTOFARO, 1979).

É interessante notar que, ao longo do desenvolvimento dos treinos de HS, que começou a partir da década de 50, a discussão teórica sobre o que define as habilidades sociais só veio a acontecer posteriormente, nos anos 80 .

1.1.2.1 Os conceitos de habilidade social e de competências sociais

A partir da década de 80 , houve um aumento significativo de programas sobre THS e, também, de discussões teóricas que, em geral, defendiam a demanda de ter uma teoria geral do relacionamento interpessoal e, consequentemente, um sistema de classificação de categorias das HS (BEDELL; LENNOX, 1997; SEGRIN, 1993; TROWER, 1995). Dentre esses trabalhos teóricos estão aqueles que discutem a definição das habilidades sociais.

Como discutido anteriormente, o campo da habilidade social não teve, em sua origem, uma linha teórica e um desenvolvimento gradual do conceito (CABALLO, 2003). Longe disso, teve dois polos (Estados Unidos e Inglaterra) que, além de algumas linhas teóricas da psicologia, influenciaram a formação do conceito; também houve contribuições e influências 
de outras áreas do conhecimento, como psiquiatria, antropologia, biologia e filosofia, para citar alguns (BARBOSA; TERROSO; ARGIMON, 2014).

Ao longo dos estudos teóricos, também existiu dificuldade em definir exatamente o que é um comportamento social hábil, pois ele depende de um contexto mutável (WILKINSON; CANTER, 1982). O comportamento social pode ser apropriado em um contexto e inapropriado em outro. Se considerarmos todas as variáveis para entender o que é apropriado ou inapropriado, entenderemos o porquê dessa dificuldade; pois as variáveis podem ser, por exemplo, a cultura geral ou a cultura específica de um certo local, a idade, o sexo, a classe social e a educação, entre outros. Também Meichenbaum e Grudson (1981 apud CABALLO, 2003) acreditam ser impossível uma definição exata sobre o que seja o CS, pois depende de um contexto. Mas, parece que, mesmo com essa dificuldade, "as pessoas sabem, de maneira intuitiva, o que são habilidade sociais" (TROWER, 1984).

Por não haver uma definição clara da topografia do que é comportamento social hábil, alguns autores, por influência do behaviorismo radical, defendem que o critério sejam as consequências, como Linehan (1984), por exemplo. Para a autora, existem três tipos de consequência: (a) eficácia para atingir os objetivos; (b) eficácia na relação interpessoal; (c) eficácia no respeito próprio.

Segundo Arkowitz (1981 apud CABALLO, 2003), a avaliação dos comportamentos sociais deveria considerar, em uma interação interpessoal, tanto o conteúdo do comportamento quanto a consequência. Espera-se que o comportamento social hábil produza maiores reforçadores do que punição. Então, em termos clínicos, é importante, segundo o autor, avaliar tanto a topografia quanto a consequência nas demais pessoas.

Após uma apresentação do processo histórico da definição do conceito das habilidades sociais, Caballo (2003) afirma que, ao longo da história, esse conceito se divide basicamente em dois aspectos: conteúdo (topografia da resposta) e consequências (reforço social). O conteúdo é a expressão do comportamento, como opiniões, sentimentos e desejos. Já as consequências referem-se ao reforço social a partir do comportamento do outro. Continuando, o autor afirma:

O comportamento socialmente hábil é esse conjunto de comportamentos emitidos por um indivíduo em um contexto interpessoal que expressa sentimentos, atitudes, desejos, opiniões ou direitos desse indivíduo de modo adequado à situação, respeitando esses comportamentos nos demais, e que geralmente resolve os problemas imediatos da situação enquanto minimiza a probabilidade de futuros problemas (CABALLO, 1996, p. 6). 
Alguns autores afirmam que habilidades sociais e competências sociais são debatidas como um elemento só (GRESHAM; ELLIOT, 2014; GRESHAM; ELLIOTT; METALLO, 2020; O’DONOHUE; FERGUSON, 2003; TROWER, 1995). McFall (1976) acredita que tal distinção é necessária, pois, em várias análises observa-se, por exemplo, que a pessoa parece saber o que fazer em uma tarefa interpessoal, mas isso não quer dizer que ele o faz (não é competente socialmente). Mesmo assim, para a literatura científica, não há um consenso na distinção entre os dois conceitos, e há uma parte de pesquisadores que utiliza tais conceitos separados (DEL PRETTE; DEL PRETTE, 2016; GRESHAM; ELLIOT, 2014; McFALL, 1976).

Del Prette e Del Prette (2016) diferenciam os conceitos de habilidades sociais e competências sociais, conceitos estes primordiais para entender o manual de THS por eles proposto. Porém, para compreender tal distinção, é necessário, antes, conhecer o conceito de comportamento social desejável e indesejável.

Os comportamentos sociais desejáveis, na maior parte das culturas ou subculturas, seguem uma qualidade de interação entre os indivíduos. Já o comportamento social indesejável apresenta conflito com os valores compartilhados na cultura. Segundo Del Prette e Del Prette (2016), para determinar se um comportamento é desejável ou indesejável é preciso observar as consequências dos comportamentos, ou seja, verificar se há prejuízo para interlocutor, grupo e comunidade.

A partir do comportamento social desejável, existem as habilidades sociais, que representam o conjunto das classes comportamentais e, por último, a competência social. Por outro lado, para os comportamentos sociais indesejáveis existe uma divisão de comportamentos ativos e passivos. Para cada uma dessas divisões existem as classes comportamentais; por exemplo: para comportamentos ativos, agredir e manipular; para comportamentos passivos, isolar-se e submeter-se. Como resultado, segundo os autores, em vez de competência social, surgem problemas e transtornos psicológicos.

O elo dos comportamentos ativos e passivos são os comportamentos externalizantes e internalizantes, vindos da denominação de Achenbach e Edelbrock (1979 apud DEL PRETTE; DEL PRETTE, 2016), que geralmente são associados a algum sintoma psiquiátrico ou problema comportamental. Em geral, os comportamentos indesejáveis ativos produzem consequências reforçadoras imediatas para o interlocutor, mas, não necessariamente, o mesmo efeito no outro ou no grupo. Por exemplo, um cliente com Transtorno Opositor Desafiador (TOD) emitirá respostas para satisfazer as suas vontades e não obedecer aos pais. 
Figura 1 - Diagrama representando o esquema geral de classes de comportamentos sociais pertinentes ou não pertinentes aos conceitos de HS e CS
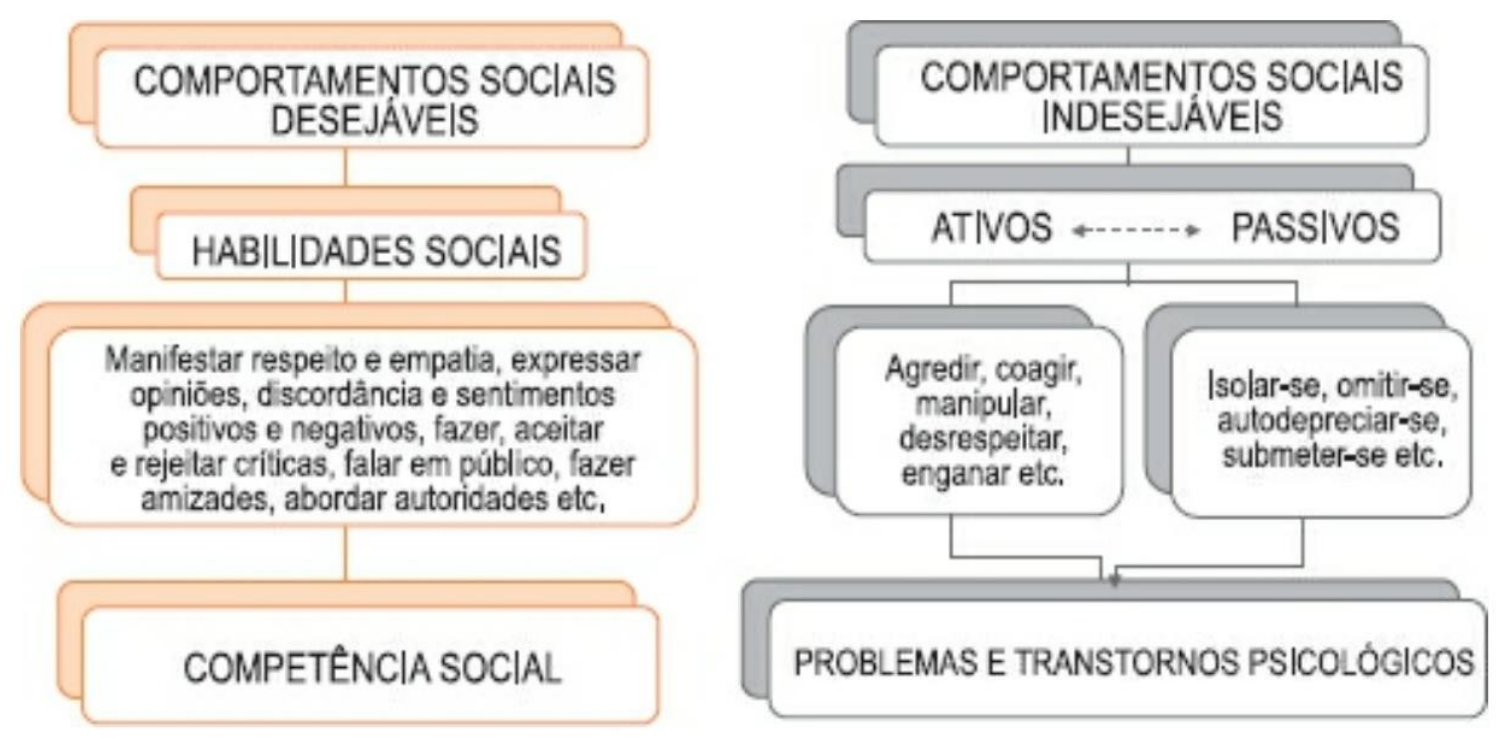

Fonte: DEL PRETTE; DEL PRETTE (2016).

Observando o diagrama, fica claro que os comportamentos indesejáveis e desejáveis são concorrentes entre si, pois as suas classes de comportamentos são distintas. Por exemplo, no caso da pessoa com TOD, citada anteriormente. Diante a uma ordem dos pais, ela poderá obedecê-los e emitir o comportamento de civilidade (comportamento social desejável) ou discordar e ser grosseiro (comportamento social indesejável). Nota-se que as consequências entre os dois comportamentos sociais não produzirão a mesma consequência reforçadora, ou seja, no caso do TOD, é provável que, com o passar do tempo, os comportamentos desejáveis tendam a ter a sua probabilidade diminuída, enquanto, no comportamento indesejável, seja mais provável de ser emitida. A consequência de não obedecer é mais satisfatória para o sujeito com TOD do que ter o próprio comportamento sob o controle de uma instrução verbal dos pais.

Considerando a distinção dos comportamentos sociais desejáveis/indesejáveis e ativos/passivos, segundo Del Prette e Del Prette (2016), a definição precisaria incorporá-los ao conceito de HS. Levando isso em consideração, então definem HS:

Habilidades Sociais refere-se a um construto descritivo dos comportamentos sociais valorizados em determinada cultura com alta probabilidade de resultados favoráveis para o indivíduo, seu grupo e comunidade, que podem contribuir para um desempenho socialmente competente em tarefas interpessoais (DEL PRETTE; DEL PRETTE, 2016, p. 24).

Interessante notar que, para os autores, as habilidades sociais não garantem um bom desempenho no contexto natural. Por isso, diferentemente de Caballo (2003), os autores não 
utilizam o adjetivo "hábil" para não confundir o leitor, pois, para eles, sujeito hábil é aquele que tem a competência social. Logo, a partir dessa premissa, houve a necessidade de também definir o que são as competências sociais.

É um constructo avaliativo do desempenho de um indivíduo (pensamentos, sentimentos e ações) em uma tarefa interpessoal que atende aos objetivos do indivíduo e às demandas da situação e cultura, produzindo resultados conforme critérios instrumentais e éticos (DEL PRETTE; DEL PRETTE, 2016, p. 37)

Em outras palavras, a competência social é a avaliação dos resultados produzidos pelo repertório social, tanto para o indivíduo quanto para o grupo, considerando curto e longo prazos, com critérios a partir da qualidade do desempenho e dos seus resultados.

Para avaliar os resultados, Linehan (1984) estabeleceu três critérios para avaliar um desempenho assertivo: atingir objetivos imediatos, manter ou melhorar a relação interpessoal e manter ou melhorar a autoestima. Curiosamente, a partir dessa linha de pesquisa, a mesma autora desenvolve estudos sobre habilidades interpessoais como base das habilidades básicas da Terapia Dialética Comportamental.

Seguindo a linha de Linehan (1984), Del Prette e Del Prette (2016) determinam cinco critérios para avaliar as competências sociais:

a) Consecução do objetivo;

b) Manutenção/melhora da autoestima;

c) Manutenção/melhora da qualidade da relação;

d) Equilíbrio de poder entre os interlocutores;

e) Respeito/ampliação dos direitos humanos interpessoais.

Essa distinção é importante para o presente trabalho, pois nota-se, ao longo da experiência clínica do pesquisador, que alguns clientes com queixas de déficit de habilidades sociais, muitas vezes, sabiam o que responder diante dos treinos em consultório, principalmente na terapia individual. Mesmo respondendo corretamente nas demandas em consultório, os mesmos clientes não produziam o reforço esperado no contexto natural (por exemplo, escola). Geralmente apresentavam um longo histórico de terapia de habilidades sociais e, portanto, sabiam o que responder "teoricamente" nas demandas sociais na terapia individual. Utilizando os conceitos de Del Prette e Del Prette (2016), pode-se dizer que eles tinham o repertório das habilidades sociais, mas, por alguma razão, não eram competentes socialmente no contexto natural, por não produzirem resultados esperados. 


\subsubsection{Classes de respostas das habilidades sociais}

A definição das categorias e das subcategorias das HS surgiu depois da discussão do conceito, dos THS e da ausência da linha teórica. Interessante é que, em sua obra, Caballo (2003) explicita toda a história das pesquisas que foram definindo as classes de respostas das HS e, também, as categorias que foram "rejeitadas" pela comunidade científica. Porém, para alguns autores, como Taylor (2013), ainda não há consenso sobre quais comportamentos são as classes de comportamento das habilidades sociais.

Historicamente, Lazarus (1973), a partir da experiência clínica, foi um dos pesquisadores importantes para iniciar a categorização das HS. Para ele, para ser considerado como HS, é necessário distinguir 4 tipos de respostas, que envolvem:

a) A capacidade de dizer "não";

b) A capacidade de pedir favores e de fazer pedidos;

c) A capacidade de expressar sentimentos positivos e negativos;

d) A capacidade de iniciar, manter e terminar conversações.

A partir dessa citação, Caballo (2003) descreve as categorias mais aceitas pela literatura e também as referências de cada classe de resposta:

1) Fazer elogios: (Furnham e Henderson, 1984; Galassi e Galassi, 1977a; Liberman e cols., 1977b; Michelson e cols., 1984; Rathus, 1975; Rinn e Markle, 1979).

2) Aceitar elogios: (Bucell, 1979; Furnham e Henderson, 1984; Galassi e Galassi, 1977a; Michelson e cols., 1986; Rathus, 1975; Rinn e Markle, 1979).

3) Fazer pedido: (Furnham e Henderson, 1984; Galassi e Galassi, 1977a; Gay e cols., 1986; Liberman e cols., 1977b, Michelson e cols., 1986).

4) Expressar amor, agrado e afeto: (Bucell, 1979; Galassi e Galassi, 1977a; Gambrill e Richey, 1975; Gay e cols., 1975; Michelson e cols., 1986; Rathus, 1975; Rinn e Markle, 1979; Tyler e Tapsfield, 1984).

5) Iniciar e manter conversação: (Bucell, 1979; Furnham e Henderson, 1984; Galassi e Galassi, 1977a; Gambrill e Richey, 1975; Gay e cols., 1975; Lange e Jakubowski, 1976; Liberman e cols., 1977b; Lorr e More, 1981; Michelson e cols., 1986; Rinn e Markle, 1979).

6) Defender os próprios direitos: (Furnham e Henderson, 1984; Galassi e Galassi, 1977a; Gay e cols., 1975; Lorr e More, 1980; Michelson e cols., 1986; Rathus, 1975; Tyler e Tapsfield, 1984).

7) Recusar pedidos: (Bucell, 1979; Furnham e Henderson, 1984; Galassi e Galassi, 1977a; Gambrill e Richey, 1975; Gay e cols., 1975; Lange e Jakubowski, 1976; Liberman e cols., 1977a; Michelson e cols., 1986; Rinn e Markle, 1979).

8) Expressar opiniões pessoais, inclusive desacordo: (Bucell, 1979; Furnham e Henderson, 1984; Galassi e Galassi, 1977a; Gambrill e Richey, 1975; Gay e cols., 1975; Lange e Jakubowski, 1976; Michelson e cols., 1986; Rathus, 1975; Rinn e Markle, 1979). 
9) Expressar incômodo, desagrado ou enfado justificado: (Furnham e Henderson, 1984; Galassi e Galassi, 1977a; Gambrill e Richey, 1975; Gay e cols., 1975; Lange e Jakubowski, 1976; Michelson e cols., 1986; Rinn e Markle, 1979).

10) Pedir mudança de conduta do outro: (Bucell, 1979; Furnham e Henderson, 1984; Michelson e cols., 1986; Rinn e Markle, 1979).

11) Desculpar-se ou admitir ignorância: (Bucell, 1979; Furnham e Henderson, 1984; Gambrill e Richey, 1975).

12) Enfrentar as críticas: (Furnham e Henderson, 1984; Gambrill e Richey, 1975; Lange e Jakubowski, 1976; Liberman e cols., 1977b).

(CABALLO, 2003, p. 8-9).

Nota-se que a lista das categorias descritas por Caballo (2003) não descreve exatamente o que seja cada categoria de comportamento, mas ele coloca várias referências no desenvolvimento de cada categoria. Portanto, o autor deixa claro quais os trabalhos de outros autores que auxiliaram no desenvolvimento de cada categoria das HS.

Outro trabalho relevante na literatura brasileira sobre o assunto é o de Del Prette e Del Prette (2017). O objetivo do manual é apresentar um protocolo de THS denominado Método Vivencial. Nos capítulos iniciais do livro, as classes e subclasses das HS são descritas e bem explicitadas, mas os autores não apresentam quais foram os trabalhos precursores de cada categoria.

Em todo caso, eis a lista dos comportamentos, apresentada tal como está no livro:

1. Comunicação. Iniciar e manter conversação, fazer e responder perguntas, pedir e dar feedback, elogiar e agradecer elogio, dar opinião, a comunicação tanto ocorre na forma direta (face a face) como na indireta (uso de meios eletrônicos); na comunicação direta, a verbal está sempre associada à não verbal, que pode complementar, ilustrar, substituir e às vezes contrariar a verbal.

2. Civilidade. Cumprimentar e/ou responder a cumprimentos (ao entrar e ao sair de um ambiente), pedir 'por favor', agradecer (dizer 'obrigado/a'), desculpar-se e outras formas de polidez normativas na cultura, em sua diversidade e suas nuanças.

3. Fazer e manter amizade. Iniciar conversação, apresentar informações livres, ouvir/fazer confidências, demonstrar gentileza, manter contato, sem ser invasivo, expressar sentimentos, elogiar, dar feedback, responder a contato, enviar mensagem (e-mail, bilhete), convidar/aceitar convite para passeio, fazer contatos em datas festivas (aniversário, Natal etc.), manifestar solidariedade diante de problemas.

4. Empatia. Manter contato visual, aproximar-se do outro, escutar (evitando interromper), tomar perspectiva (colocar-se no lugar do outro), expressar compreensão, incentivar a confidência (quando for o caso), demonstrar disposição para ajudar (se for o caso), compartilhar alegria e realização do outro (nascimento do filho, aprovação no vestibular, obtenção de emprego etc.).

5. Assertivas. Por se tratar de uma classe ampla com muitas subclasses, são aqui destacadas entre as mais importantes: Defender direitos próprios e 
direitos de outrem. Questionar, opinar, discordar, solicitar explicações sobre o porquê de certos comportamentos, manifestar opinião, concordar, discordar. Fazer e recusar pedidos. Expressar raiva, desagrado e pedir mudança de comportamento. Desculpar-se e admitir falha. Manejar críticas: (a) aceitar críticas (ouvir com atenção até o interlocutor encerrar a fala, fazer perguntas, pedir esclarecimento, olhar para o interlocutor, concordar com a crítica ou com parte dela, pedir desculpas); (b) fazer críticas (falar em tom de voz pausada e audível, manter contato visual sem ser intimidatório, dizer o motivo da conversa, expor a falha do interlocutor, pedir mudança de comportamento); (c) rejeitar críticas (ouvir até o interlocutor encerrar a fala, manter contato visual, solicitar tempo para falar, apresentar sua versão dos fatos, expor opinião, relacionar a não aceitação da crítica em relação à veracidade do acontecimento). Falar com pessoa que exerce papel de autoridade: cumprimentar, apresentar-se, expor motivo da abordagem, fazer e responder perguntas, fazer pedido (se for o caso), tomar nota, agendar novo contato (se for o caso), agradecer, despedir-se.

6. Expressar solidariedade. Identificar necessidades do outro, oferecer ajuda, expressar apoio, engajar-se em atividades sociais construtivas, compartilhar alimentos ou objetos com pessoas deles necessitadas, cooperar, expressar compaixão, participar de reuniões e campanhas de solidariedade, fazer visitas a pessoas com necessidades, consolar, motivar colegas a fazer doações.

7. Manejar conflitos e resolver problemas interpessoais. Acalmar-se exercitando autocontrole diante de indicadores emocionais de um problema, reconhecer, nomear e definir o problema, identificar comportamentos de si e dos outros associados à manutenção ou solução do problema (como avaliam, o que fazem, qual a motivação para mudança), elaborar alternativas de comportamentos, propor alternativas de solução, escolher, implementar e avaliar cada alternativa ou combinar alternativas quando for o caso.

8. Expressar afeto e intimidade (namoro, sexo). Aproximar-se e demonstrar afetividade ao outro por meio de contato visual, sorriso, toque, fazer e responder perguntas pessoais, dar informações livres, compartilhar acontecimentos de interesse do outro, cultivar o bom humor, partilhar de brincadeiras, manifestar gentileza, fazer convites, demonstrar interesse pelo bem-estar do outro, lidar com relações íntimas e sexuais, estabelecer limites quando necessário.

9. Coordenar grupo. Organizar a atividade, distribuir tarefas, incentivar a participação de todos, controlar o tempo e o foco na tarefa, dar feedback a todos, fazer perguntas, mediar interações, expor metas, elogiar, parafrasear, resumir, distribuir tarefas, cobrar desempenhos e tarefas, explicar e pedir explicações, verificar compreensão sobre problemas.

10. Falar em público. Cumprimentar, distribuir o olhar pela plateia, usar tom de voz audível, modulando conforme o assunto, fazer/responder perguntas, apontar conteúdo de materiais audiovisuais (ler apenas o mínimo necessário), usar humor (se for o caso), relatar experiências pessoais (se for o caso), relatar acontecimentos (incluir subclasses do item anterior), agradecer a atenção ao finalizar.

(DEL PRETTE; DEL PRETTE, 2017, p. 28-30).

As categorias descritas acima foram utilizadas como critério de intervenção/ comportamento-alvo dos participantes para a intervenção proposta na metodologia deste trabalho. Mas, essas categorias não são suficientes para estruturar nem uma intervenção completa de THS e nem o planejamento da intervenção. Assim, agora será apresentada a estrutura da intervenção e o planejamento da generalização. 


\subsubsection{Intervenção e planejamento da generalização}

Quando se trata das técnicas utilizadas no THS, encontram-se, na literatura, variadas técnicas. Foram encontradas intervenções com instruções, modelação, modelagem, ensaio comportamental, feedback verbal e vídeos, tarefas de casa, reestruturação cognitiva, solução de problemas, relaxamento e terapia de grupo (ANDREOZZI, 2017; BORNSTEIN; BELLACK; HERSEN, 1977; CABALlO, 2003; DEL PRETTE; DEL PRETTE, 1999; MCKINNON; KREMPA, 2002).

A intervenção pode ter diferentes objetivos, de acordo com cada demanda específica. $\mathrm{Na}$ literatura, foram encontrados diferentes treinos de habilidades sociais envolvendo casais (CORDOVA; JACOBSON, 1999), fobia social (MARKWAY et al., 1999), pânico e agorafobia (RANGÉ, 2001), prevenção de violência doméstica (SUGG et al., 1999), e vários outros.

Embora existam diversos programas de THS estruturados e publicados a partir do ano 2000, a maioria dos estudos não planeja de forma adequada a generalização (ANDREOZZI, 2017). Os poucos programas que utilizaram um planejamento de generalização tiveram foco em poucos settings e poucas pessoas. Os pais foram os responsáveis por avaliar os resultados da intervenção, através de medidas indiretas.

Andreozzi (2017) levantou e analisou dados de programas de THS com público TEA a partir de artigos de revisão e meta-análise publicados no período de 2006 a 2017 . A pesquisadora examinou 47 artigos encontrados nas bases de dados EMBASE, ERIC, MEDLINE e PsycINFO. Segundo ela,

... 47 dos resultados poderiam ser considerados efetivos ou parcialmente efetivos, embora houvesse limitações quanto ao planejamento da generalização do comportamento-alvo e da medida de sua manutenção após o término da intervenção (ANDREOZZI, 2017, p. xii).

Das 47 pesquisas selecionadas pela autora, apenas 16 programas fizeram o planejamento da generalização. A metade desses 16 programas teve por objetivo promover a generalização com outras pessoas ou com outros ambientes.

Também é interessante notar o local de atendimento em que foi realizado o treino. A metade dos programas fizeram os seus treinos em contexto do centro de atendimento; $25 \%$ não informaram onde os treinos foram realizados e $12 \%$ dos programas fizeram sessões em casa. 
Figura 2 - Porcentagem de estudos realizados em cada ambiente, ocorrência do arranjo de contingências e condições extra experimentais ou na presença de quem o comportamento seria observado

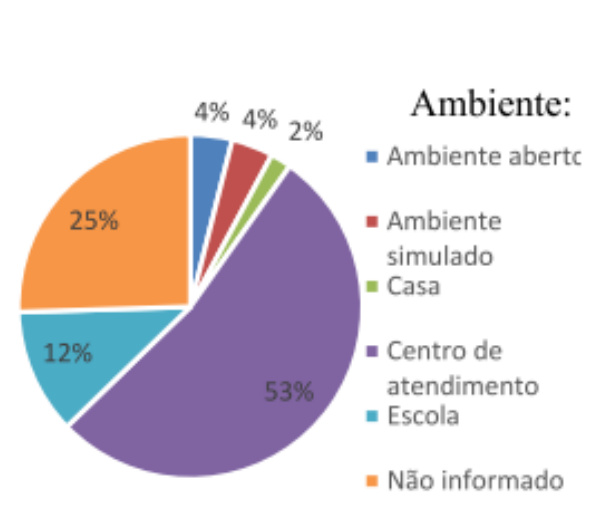
Houve planejamento para a generalização?

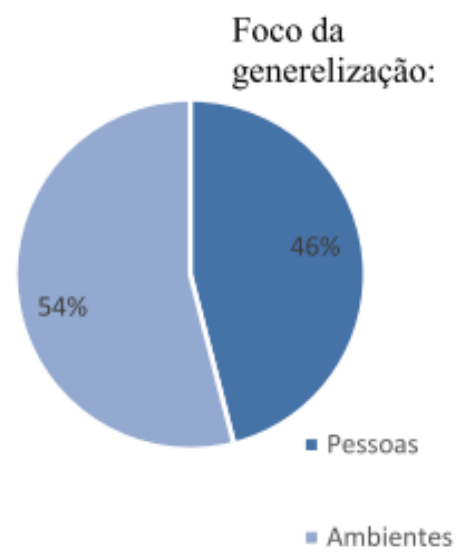

Fonte: Andreozzi (2017).

Alguns autores defendem que, para fortalecer a generalização, o treino de pais e as tarefas de casa auxiliam na manutenção e na generalização dos comportamentos trabalhados em sessão para fora do consultório, em especial nos estendidos para outros ambientes (INGERSOLL; GERGANS, 2007; McMAHON; LERNER; BRITTON, 2013).

Andreozzi (2017), em sua mesma pesquisa, apontou que 20 programas de THS não acrescentaram componentes adicionais para fortalecer o principal do programa; 11 programas utilizaram treinos com os cuidadores e outros 20 utilizaram as tarefas de casa como parte da intervenção, como consta na Figura 3:

Figura 3 - Porcentagem de estudos que utilizaram treino de pais/cuidadores e tarefas para casa, e sua relação com a eficácia do procedimento

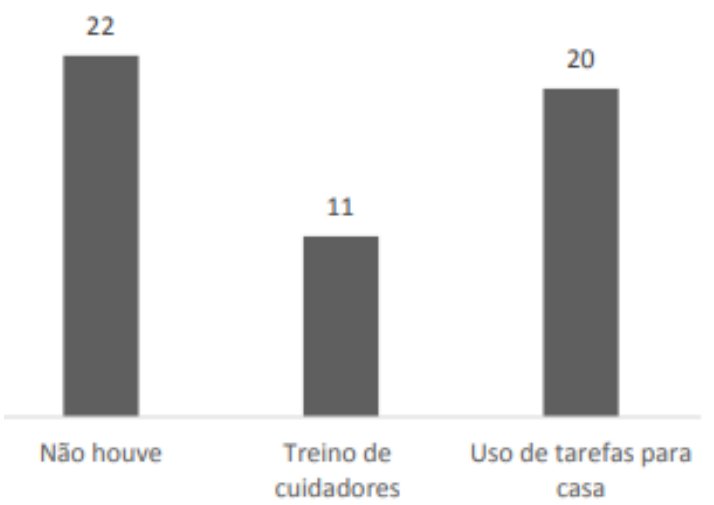

Componentes adicionais

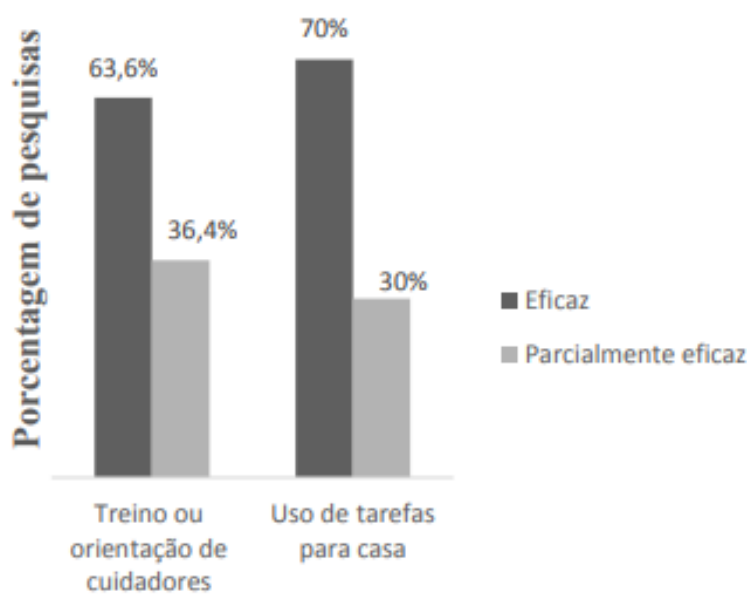

Componentes adicionais

Fonte: Andreozzi (2017). 
É interessante notar que, segundo os autores de cada pesquisa selecionada por Andreozzi (2017), a utilização de tarefas para casa eleva significativamente a porcentagem de eficácia do programa: $63,6 \%$ com o uso de treino dos cuidadores e $70 \%$ para o uso de tarefas para casa. Esse dado levantado por Andreozzi (2017) mostra que, do ponto de vista de eficácia, é importante que os THS planejem intervenções que possam indicar (a) generalização e (b) medidas para mensuração, através de escalas, observações diretas do comportamento (através de um observador treinado).

\subsubsection{Medidas: IHSA, GAS e CGI}

Devido à Prática Baseada em Evidência (PBE), nos últimos anos, o uso de escalas se tornou importante para medidas de mensuração para obter a eficácia de intervenções (STARLING, 2010). A avaliação (ou inventários) consiste em fazer um levantamento sobre os déficits e os excessos comportamentais, às vezes identificando as variáveis do ambiente que evocam tais comportamentos. Para a realização da avaliação, alguns modelos utilizam entrevistas (CABALLO, 2003), inventários (DEL PRETTE; DEL PRETTE, 2001), autorregistros (CABALLO, 2003) e observação direta do comportamento no ambiente natural (LÖHR, 2003).

Para este estudo, a análise dos dados sobre HS e a avaliação do programa com os pais utilizarão as seguintes escalas: Inventário de Habilidades Sociais para Adolescentes (IHSA), Goal Attainment Scalling (GAS) e Impressão Clínica Global (CGI).

$\mathrm{Na}$ sequência, será explicado cada inventário, apresentando um breve histórico, a aplicação, as subescalas envolvidas e, por último, alguns estudos que utilizaram esses inventários.

\subsubsection{Inventário de Habilidades Sociais para Adolescentes (IHSA)}

No cenário brasileiro, um dos inventários que mais se destacou na área, nas últimas décadas, foi o IHSA. Del Prette e Del Prette (2009) criaram um instrumento autoavaliativo sobre interações sociais do cotidiano. O inventário é composto por 38 itens, separados em 6 subescalas: empatia, autocontrole, civilidade, assertividade, abordagem afetiva e desenvoltura social. Para cada um dos 38 itens há a descrição de uma situação social e de um comportamento relacionado àquela situação; por exemplo: “Ao entrar numa festa de pessoas desconhecidas, você se apresenta para essas pessoas". 
O participante registra a frequência do comportamento e a dificuldade em emiti-lo, diante das 10 últimas situações semelhantes; se não houver nenhuma, o participante imagina o que faria. Os itens da frequência reagir são divididos em: (a) 0-2 vezes; (b) 3-4 vezes; (c) 5-6 vezes; (d) 7-8 vezes; e (e) 9-10 vezes. Para a validação do teste, a amostra foi aplicada em 1.172 participantes na faixa etária de 12 a 17 anos.

Um exemplo de uso desse instrumento foi a aplicação realizada por Leme et al. (2016). A amostra envolveu 2.291 alunos do Ensino Fundamental $\left(6^{\circ}, 7^{\circ}\right.$ e $8^{\circ}$ anos $)$ e do Ensino Médio ( $1^{\mathrm{o}}$ e $2^{\mathrm{o}}$ anos). Os resultados revelaram que os dados obtidos são fidedignos aos dados obtidos em 2006, durante a validação do teste. Para os autores, o IHSA é um bom instrumento para avaliar o repertório social dos adolescentes no contexto brasileiro.

Além do uso de avaliação do repertório, muitos estudos utilizam o IHSA como critério de avaliação da intervenção, o que envolve uma aplicação pré e pós-treino (PEREIRA-GUIZZO et al., 2018; RODRIGUES et al., 2021). A escolha desse inventário para o atual projeto é com o objetivo de utilizar um instrumento que seja validado pela comunidade científica brasileira, além de ter a possibilidade de comparação com outros estudos que utilizaram as avaliações de pré e pós-teste.

\subsubsection{Goal Attainment Scaling (GAS)}

O método GAS contrapõe-se às outras técnicas e programas protocolados, pois sua proposta é a possibilidade de construir uma avaliação contínua da melhora do paciente, o que se opõe à maioria das avaliações e programas dentro da saúde mental (STARLING, 2010). Essa maioria geralmente é fechada e estruturada em etapas, não passível de alteração. A crítica encontrada na literatura é exatamente a dificuldade de identificar esses sistemas protocolados de tratamento nos casos em que não há sucesso (STARLING, 2010).

Em 1968, Kiresuk e Sherman publicaram um artigo sobre Goal Attainment Scaling. A proposta do estudo foi descrever validar o método nos programas de saúde mental. Em 1969, o Instituto Nacional da Saúde Mental financiou estudos para desenvolver, implementar e disseminar o GAS pelo país (McDOUGALL; KING, 2007).

O método de GAS consiste em construir, junto com o paciente, as metas terapêuticas e o registro desses tais comportamentos. A partir de três grandes comportamentos-alvo, terapeuta e paciente estipulam quais são as metas necessárias e como mensurá-la. As variações de registro são de -2 a +2 , sendo -2 uma piora significativa e +2 uma melhora significativa (KIRESUK; SHERMAN, 1968). 
Starling (2010) realizou um estudo com objetivo de desenvolver e testar algumas metodologias clínicas a partir do modelo de prática clínica controlada. Tais dados produzidos podem ser reproduzidos e analisados por terceiros que estejam interessados na prática clínica. O método do estudo consistiu em análises de 38 clientes. Diversos instrumentos foram utilizados, entre eles, o GAS.

O resultado mostrou que o uso de GAS pode medir e também descrever eventos terapêuticos que auxiliam na possibilidade de um maior controle sobre a prática clínica. De tal maneira, ele também se aplica ao vínculo entre cliente e terapeuta.

$\mathrm{Na}$ literatura internacional, o GAS foi utilizado para casos de atrasos no desenvolvimento motor (BROWN; EFFGEN; PALISANO, 1998; PALISANO; HALEY; BROWN, 1992), paralisia cerebral (EKSTRÖM et al., 2005; STEENBEEK et al., 2005), hábito de estudo (KING et al., 1999) e tratamento pediátrico (McDOUGALL; KING, 2007). Já na literatura brasileira também são encontrados trabalhos que visaram a tradução do GAS para reabilitação (SANTOS, 2018) e uma análise mais detalhada na terapia analíticocomportamental (STARLING, 2010).

Para o presente trabalho, o GAS será adaptado para as Tarefas de Casa (TC), ou seja, TC-GAS refere-se aos registros dos clientes nos ambientes fora do consultório com metas construídas a partir do diálogo entre os pais e o cliente. Assim, o pesquisador fará a referência como TC-GAS, pois há influência e relação dos pais na elaboração das tarefas.

\subsubsection{Clinical Global Impressions (CGI)}

A escala Clinical Global Impressions (Impressão Clínica Global) é amplamente utilizada em pesquisas clínicas e na prática clínica há mais de 30 anos (BUSNER; STEVEN; TARGUM, 2007). É um instrumento que permite ao pesquisador ou clínico avaliar o processo dos sintomas dos transtornos ao longo do tempo, acompanhando as mudanças do quadro clínico durante o tratamento. O inventário é separado em dois primeiros blocos (gravidade e mudança), que contêm sete itens cada um, variando entre 0 (não avaliado) e 7 (piora).

Foram levantadas algumas pesquisas que utilizaram o instrumento para validação com vários estudos envolvendo transtornos psiquiátricos, como transtorno de ansiedade (BANDELOW et al., 2006; ZAIDER et al., 2003), transtorno depressivo (KADOURI; CORRUBLE; FALISSARD, 2007; SPIELMANS; McFALL, 2006;), transtorno psicótico (LEUCHT; ENGEL, 2006), transtorno bipolar (SPEARING et al., 1997), transtorno de personalidade esquizofrênica (HARO et al., 2003). 
Para o atual trabalho, o pesquisador utilizará CGI para avaliar, junto com os pais, a percepção deles sobre a melhora ou piora do comportamento dos filhos ao longo das sessões. Dessa forma, o GAS (chamado aqui como Tarefas de Casa) e CGI são questionários para envolver os pais no processo terapêutica e, segundo Andreozzi (2017), a participação dos pais e o planejamento da generalização são importantes para aumentar a eficiência do tratamento.

\subsection{TERAPIA DE GRUPO}

\subsubsection{História da terapia de grupo}

A história da psicoterapia de grupo não contribuiu diretamente para o desenvolvimento da área das habilidades sociais (CABALLO, 2003), pois esta modalidade de psicoterapia teve outros objetos de estudo e evoluiu para outros caminhos, o que e será explicado ao longo do item.

Porém, ao estudar, por curiosidade, sobre a história da psicoterapia de grupo, foram observados diversos momentos em que as intervenções, em sua maioria da linha psicanalítica, apresentaram observações sobre algum aspecto do setting terapêutico da terapia de grupo proposta neste trabalho, como frequência/duração das sessões, composição dos participantes, presença de dois terapeutas, entre outros. Além disso, as observações feitas sobre a importância da socialização foram predominantes na literatura, assim como sobre a "dramatização" ocorrida nas sessões. Portanto, o autor descreverá a história da psicoterapia de grupo para justificar e embasar a metodologia utilizada.

Bechelli e Santos (2004) descrevem a história da psicoterapia de grupo desde 1905 até os anos 90. Ao contrário da origem da terapia individual, o exato ponto de partida da terapia de grupo não é precisa. A atribuição da literatura americana atribui Joseph Pratt como o "criador" da psicoterapia de grupo. Pratt, em 1905, reunia, uma vez por semana, os pacientes com tuberculose, e os grupos tinham de 15 a 20 pacientes. O objetivo, naquela época, era a orientação para os cuidados em relação ao tratamento médico. O método utilizado por Pratt, segundo ele, era baseado em estratégia de persuasão e reeducação emocional e uso de registro do próprio comportamento e realização de tarefas diárias.

Após esse primeiro grupo, esse modelo foi utilizado para pacientes com outros quadros, como doenças mentais. Nesse momento, as reuniões (observe-se que não eram chamadas de sessões) tinham um foco mais educacional, como instruções e conselhos, além de dar apoio ao "grupo de pacientes que apresentava problemas, sintomas e doenças semelhantes" 
(BECHELLI; SANTOS, 2003). Segundo os autores, a semelhança dos sintomas (ou perfil) dos pacientes exercia papel adicional e positivo, que era o compartilhamento de histórias de sucesso e de melhora. Pratt considerava esses aspectos de perfil entre os pacientes como fatores terapêuticos: universalidade, aceitação e instalação de esperança.

Em 1920, Lazell utilizou o método de grupo para tratamento de esquizofrênicos internados. Seu método consistia em aulas de diversos temas e, como resultado, ele percebeu que alguns pacientes tinham um progresso positivo dentro do quadro usado por ele. "Muitos participavam das discussões e procuravam encontrar soluções para seus problemas, reconheciam que outros se encontravam na mesma condição e, conseqüentemente, seu estado não deveria ser tão grave como imaginavam”. Mesmo após as aulas, mantinham diálogo sobre o assunto, o que contribuía para uma melhor interação (BECHELLI; SANTOS, 2003).

Entre 1909 e 1912, Marsh utilizou o método de Lazell para pacientes “psiconeuróticos”. Eram grupos de 200 a 400 participantes e a participação era voluntária com diversas atividades, como canto, música e aulas. O interessante é notar que os pacientes contavam sobre os seus problemas, o que fez Marsh concluir que o trabalho de grupo auxiliava na reeducação, na sociabilidade e na atividade ocupacional, facilitando o engajamento no tratamento individual. Diferentemente de Lazell, Marsh incluiu diversos diagnósticos e não apenas grupos psicóticos, como no caso de Lazell. Burrow, um dos fundadores da American Psychoanalytic Association, também observou o aumento da interação entre os pacientes quando eles compartilhavam os pensamentos com o restante do grupo (BECHELLI; SANTOS, 2003).

Paralelamente a esses três profissionais, na Europa, Moreno formou os seus primeiros grupos entre 1910 e 1914. Os primeiros grupos foram com crianças nos parques de Viena, onde eles improvisavam representações. Para Moreno, a espontaneidade é importante para o processo criativo e "vitalizador da vida" (apud BECHELLI; SANTOS, 2003). Posteriormente, em 1921, ele criou, junto com grupo de atores, o Teatro de Improvisação, que tinha por premissa que a maioria dos sintomas psicológicos era a falta de espontaneidade e que a encenação, se fosse intermediada por um terapeuta, poderia trazer benefícios. Esse Teatro de Improvisação foi o início da psicodrama. Essas vivências consistiam em situações conflituosas da vida do participante. Em 1932, Moreno propôs o termo psicoterapia de grupo em uma reunião da American Psychiatric Association. Nos anos 20, também em Viena, Adler fundou o Centro de Aconselhamento para Pais e Filhos, com a proposta de, além do tratamento para o adolescente, incluir a família.

Os psiquiatras da Áustria e da Rússia utilizavam o termo Terapia Coletiva e tratavam vários quadros clínicos, como transtorno obsessivo-compulsivo, retardo mental, desajustes 
sexuais e alcoolismo. Um fato interessante, porém não relevante para este trabalho: Metzl criou um grupo específico para alcoólatras que, posteriormente, foi o precursor do grupos de alcoólicos anônimos.

Burrow foi um dos pioneiros a adotar as sessões de grupo dentro do consultório particular. Só em meados dos anos 50, outros tratamentos começaram a ter sessões de grupo nas clínicas particulares. Dreikurs realizou sessões de grupo em sua própria casa (BECHELLI; SANTOS, 2003).

Nos anos 30, como a psicanálise era muito predominante do zeitgeist ${ }^{1}$, Schilder (1936) e Wender (1940), ambos citados em Bechelli e Santos (2003), compuseram grupos de 6 a 8 pacientes do mesmo sexo. No início, esses grupos eram fechados, ou seja, não podiam entrar novos integrantes. Depois, os grupos passaram a ser abertos, com a possibilidade de admissão de novos integrantes. Para participar dos grupos, havia uma entrevista inicial. Para Wender, os grupos funcionavam como uma família, ou seja, simbolicamente, os pacientes consideravam o terapeuta como figura paterna e os pares como irmãos. Schilder apontou que os grupos funcionavam como uma troca de informações, ideias e sentimentos que ajudavam um ao outro, como se os grupos auxiliassem a liberar conflitos emocionais e a reorganizar a personalidade, aumentando o ajustamento social.

Ainda de acordo com o estudo de Bechelli e Santos (2003), Slavson colocou a terapia de grupo como atividade-chave em uma instituição para crianças e adolescentes, e teve um enorme papel no movimento da psicoterapia de grupo nos Estados Unidos. Fundou, em 1948, a American Group Psychotherapy Association e, em 1951, a revista International Journal of Group Psychotherapy. Em 1933, foi a vez de Lewin fundar o Centro de Pesquisa para Dinâmicas de Grupo na Universidade de Michigan e desenvolver estudos experimentais sobre relacionamento humano.

Nos anos 40, Loeser iniciou a psicoterapia de grupo e, pela falta de informações na literatura científica, conduziu uma série de estudos para responder algumas questões sobre as diferenças de grupos homogêneo/heterogêneo, grupos mistos/mesmo gênero, atuação ativa ou passiva do terapeuta, entre outras questões pertinentes. Ele e os seus colaboradores perceberam oito pontos:

a) Importância de preparar o participante antes da sessão;

b) A mistura dos gêneros tinha algumas vantagens;

1 * zeitgeist é um termo alemão que significa o espírito do tempo, ou seja, o conjunto intelectual e cultural do mundo, em uma certa época. 
c) Os níveis socioeconômico, raça, religião, idade e profissão não afetavam a composição dos grupos;

d) O número indicado de participantes era de 7 a 10;

e) A frequência ideal era duas sessões por semana, com duração do processo terapêutico ilimitada;

f) Grupos homogêneos facilitavam o processo terapêutico, sem a necessidade de novos integrantes;

g) O resultado era melhor quando tinha acompanhamento junto com terapia individual;

h) O papel do terapeuta deveria focar na interação entre os participantes e, à medida que houvesse progresso terapêutico, os pacientes assumiam algumas funções dos terapeutas.

Como características de suas sessões, elas não eram planejadas, pois os integrantes conduziam o curso da sessão. Não era necessário ser psicanalista, mas seria importante o terapeuta ter familiaridade com os conceitos. Pela primeira vez na história da terapia de grupo o autor enfatiza a necessidade de ter um coterapeuta.

A partir da década de 50, houve diversos novos terapeutas e várias abordagens com a proposta da terapia de grupo. Outra terapia que deixa clara a importância das interações interpessoais para a melhora do quadro clínico é a Terapia Interpessoal (TIP), criada em 1970 por Gerald Klerman (MELLO, 2004). Inicialmente, ela foi criada para tratar casos de depressão maior e, posteriormente, passou a ser utilizada em casos de ansiedade, bipolaridade, estresse pós-traumático, entre outros. Quanto ao setting, a TIP pode ser feita tanto em grupo quanto no contexto individual. A Terapia Interpessoal estabelece relação entre os sintomas de depressão e os problemas interpessoais atuais para o paciente, focando mais nos relacionamentos atuais do que em relações do passado. Essa intervenção é separada em três fases: início (surgimento dos sintomas e diagnóstico), fase intermediária (realização da intervenção com objetivo resolutivo) e final (encorajamento e reconhecimento dos ganhos terapêuticos). Desta maneira, o terapeuta atua no início da formação dos sintomas e nas questões sociais associadas à depressão; por exemplo, o terapeuta pode fazer uma relação entre os sintomas de depressão com quatro áreas interpessoais, como luto, disputa de papéis interpessoais, transição de papéis e déficits interpessoais.

Quanto ao número de publicações, é notável o crescimento na área da psicoterapia de grupo. Por exemplo, no período 1906-1945, houve 228 artigos publicados; em 1946-1950, foram 536; e em 1951-1955, 876 trabalhos. De 1977 a 1981, 400 revistas científicas publicaram artigos sobre o assunto. 
A seguir, um resumo sobre as principais características dos estudos relevantes e que, de certa maneira, coincidem com alguns propostas do setting do presente trabalho.

Tabela 1 - Resumo das características sobre as terapias de grupo quanto a ano, autor, frequência, número de participantes, perfil, método e os pontos de concordância com o setting da metodologia aqui proposta (amostra realizada de 1905-1950)

\begin{tabular}{|c|c|c|c|c|c|c|}
\hline Ano & Autor & Frequência & $N^{o}$ & Perfil & Método & $\begin{array}{l}\text { Observação / } \\
\text { Concordância }\end{array}$ \\
\hline 1905 & Pratt & Semanal & $15-20$ & $\begin{array}{l}\text { pacientes com } \\
\text { tuberculose }\end{array}$ & Aula & $\begin{array}{c}\text { Orientação, } \\
\text { realização de TC, } \\
\text { aceitação e } \\
\text { esperança }\end{array}$ \\
\hline 1920 & Lazell & & & esquizofrênicos & Aula & $\begin{array}{c}\text { Esperança no } \\
\text { outro, participação } \\
\text { dos outros para } \\
\text { ajudar }\end{array}$ \\
\hline $\begin{array}{c}1909 \\
- \\
1912\end{array}$ & Marsh & & $200-400$ & psiconeurótico & Aula & $\begin{array}{l}\text { Outras atividades, } \\
\text { sociabilidade, } \\
\text { reeducação, } \\
\text { aumento de } \\
\text { interação quando } \\
\text { participavam }\end{array}$ \\
\hline $\begin{array}{c}1910 \\
- \\
1914\end{array}$ & Moreno & & & adolescentes & Interação & $\begin{array}{l}\text { Dramatização, } \\
\text { importância da } \\
\text { espontaneidade }\end{array}$ \\
\hline $\begin{array}{c}1920 \\
- \\
1929\end{array}$ & Adler & & & adolescentes & Interação & $\begin{array}{l}\text { Aconselhamento } \\
\text { para pais e filhos }\end{array}$ \\
\hline 1950 & Burrow & & & não psicóticos & Interação & $\begin{array}{l}\text { Sessões em clínica } \\
\text { particular }\end{array}$ \\
\hline $\begin{array}{c}1930 \\
- \\
1939\end{array}$ & $\begin{array}{l}\text { Wender, } \\
\text { Schilder }\end{array}$ & & $6-8$ & & Interação & $\begin{array}{c}\text { Mesmo sexo, } \\
\text { início da entrevista } \\
\text { inicial, concepção } \\
\text { de família, vínculo } \\
\text { entre os } \\
\text { participantes }\end{array}$ \\
\hline $\begin{array}{c}1940 \\
- \\
1949\end{array}$ & Loeser & $2 \mathrm{x}$ semana & $7-10$ & & Interação & $\begin{array}{l}\text { Preparar sessão } \\
\text { anteriormente, } \\
\text { grupo homogêneos, } \\
\text { terapeuta com foco } \\
\text { na inteiração, } \\
\text { atendimento } \\
\text { individual junto } \\
\text { com grupo, duração } \\
\text { ilimitada, } \\
\text { coterapeuta }\end{array}$ \\
\hline
\end{tabular}

Fonte: Bechelli e Santos (2004). 
Assim, a proposta deste autor é conduzir o leitor para as observações feitas ao longo da história da psicoterapia de grupo e que, em uma época muito diferente da do século XXI, houve diversas observações e convergências sobre algum aspecto do setting terapêutico.

Também é notável como o fenômeno da socialização esteve sempre presente e, muitas vezes, foi apontado como um dos principais fatores para a melhora do quadro clínico. Para isso, algumas medidas são utilizadas na literatura e serão descritas na sequência.

\subsubsection{Medidas: Group Climate Questionnaire (GCQ)}

Uma outra categoria de avaliação sobre eficácia de intervenções clínicas é através de avaliação de processo terapêutico, que consiste em avaliações sistemáticas durante toda a intervenção, em vez de somente uma na pré e uma na pós-intervenção.

O GCQ é um inventário de autoaplicação que tem por objetivo coletar informações da percepção dos indivíduos sobre o clima do grupo terapêutico em cada sessão, ou seja, descrevendo o progresso clínico a partir de gráficos de linha (MacKENZIE, 1983). O inventário consiste em doze itens, em que o cliente pontua o quanto concorda e se ocorreu durante a sessão de grupo (por exemplo: Não ocorreu, Extremamente). Esses doze itens são divididos em três subescalas: engajamento, esquiva de mudanças comportamentais e conflitos interpessoais. Então, no decorrer das sessões, o terapeuta pode avaliar como foi o processo terapêutico daquele indivíduo, ao longo das sessões, através de gráficos lineares.

Nas pesquisas de processo clínico, essa escala é uma das mais utilizadas nas modalidades terapia de grupo e evolução dos sintomas (BURLINGAME; FUHRIMAN; JOHNSON, 2003; KIVLIGHAN; GOLDFINE, 1991; MacKENZIE et al., 1987).

\subsection{COMPREENDENDO RPG, CULTURA NERD E GAMIFICAÇÃO}

\subsubsection{Role-Playing Game (RPG)}

Huizinga (1996) afirma que a atividade lúdica sempre esteve presente nas culturas e é mais antiga que a própria cultura, pois os animais apresentam o comportamento de brincar mesmo sem ter cultura. Uma importante característica da atividade lúdica é a simulação de uma situação real, como uma luta, e, muitas vezes, não apresenta uma ameaça ao outro, mesmo tendo o reconhecimento de um vencedor e de um perdedor. A possibilidade de se envolver em uma atividade lúdica e praticar tais comportamentos pode resultar em melhora de diversos aspectos 
cognitivos, como criatividade, imaginação lógica, aquisição da leitura, raciocínio e reflexão crítica, entre outros (FORTUNA, 2011).

O Role-Playing Game (RPG) é definido como um jogo de interpretação de papéis, no qual jogadores interpretam personagens, criando uma narrativa construída colaborativamente com outros jogadores. Geralmente, os RPGs são jogos cooperativos e sociais, por mais que existam alguns competitivos. Dos diversos jogos que existem (de cartas, eletrônicos, de tabuleiros, esportes etc.), Chung (2013) sugere que o RPG de mesa estimula mais a criatividade do que outros tipos de jogos.

O primeiro livro de RPG foi publicado em 1974, com o lançamento do jogo Dungeons \& Dragons - D\&D (ARNESON; GYGAX, 1974), inspirado a partir de jogos de tabuleiro e de estratégia de guerra. O setting do jogo tradicional é uma mesa, na qual os jogadores se sentam em volta; uma dessas pessoas tem a função de mestre (narrador da história) e os outros, a de jogadores. Cada jogador cria um personagem único e a progressão acontece de acordo com o decorrer das aventuras. Os autores recriam o jogo em um universo fantasioso, inspirado em diversas mitologias que impactaram a cultura das crianças e dos adolescentes. O cenário do jogo é dentro da fantasia épica. Sobre o sistema do $D \& D$, há diversos dados, com 4, 6, 8, 10 , 12 e 20 lados, e cada um é utilizado de acordo com a ação exigida.

Após a publicação do primeiro sistema de RPG, surgiram outros sistemas, que utilizam diversas regras, contextos (por exemplo, ficção científica), tipos de personagens, vários sistemas de dados e outros aspectos. Cada um com a sua particularidade, de modo que essa pluralidade de sistemas e temas possibilita que diferentes pessoas possam encontrar o jogo que mais lhe agrade.

No presente estudo, o sistema TSG utilizou e se inspirou em um dos sistemas brasileiros mais populares, o Tormenta RPG (CASSARO; SVALDI; CALDELA, 2013). O cenário apresentado no Tormenta RPG é fantasia medieval, porém existem elementos de outros universos simbólicos e históricos, como armas do Império Romano, pistoleiros do Velho Oeste norte-americano, vikings, samurais, ninjas e robôs (do mundo futurista) (TANCINI, 2018).

Além dessas possibilidades de criação de personagens de diferentes universos, o sistema conta com uma progressão de pontos ganhos a cada aventura. Em cada nível atingido, o personagem também desbloqueia novas habilidades, tornando-se um personagem mais forte e versátil para diversas situações no jogo. Como exemplo sobre a progressão do nível e as habilidades adquiridas, através do Experience Points (XP). A Tabela 2 demonstra como. Os XP são pontos são necessários para a evolução do personagem, ou seja, a cada nível é exigido um número de XP para que o personagem avance para um novo nível. 
Tabela 2 - Progresso do nível do personagem através do acúmulo de XP e benefícios para cada nível

\begin{tabular}{|c|c|c|c|c|c|}
\hline $\begin{array}{c}\text { Nível de } \\
\text { Personagem }\end{array}$ & $\begin{array}{l}\text { Pontos de } \\
\text { Experiência }\end{array}$ & $\begin{array}{l}\text { Graduações } \\
\text { em Perícias }^{2}\end{array}$ & Talentos ${ }^{3}$ & $\begin{array}{l}\text { Aumento de } \\
\text { Habilidade }^{4}\end{array}$ & $\begin{array}{c}\text { Bônus na } \\
\text { CA, } \\
\text { Resistência e } \\
\text { Dano }^{5}\end{array}$ \\
\hline $1^{\circ}$ & 0 & $+4 /+0$ & 1 & - & +0 \\
\hline $2^{\circ}$ & 1.000 & $+5 /+1$ & - & 1 & +1 \\
\hline $3^{\circ}$ & 3.000 & $+6 /+1$ & 2 & - & +1 \\
\hline $4^{\circ}$ & 6.000 & $+7 /+2$ & - & 2 & +2 \\
\hline $5^{\circ}$ & 10.000 & $+8 /+2$ & 3 & - & +2 \\
\hline $6^{0}$ & 15.000 & $+9 /+3$ & - & 3 & +3 \\
\hline $7^{\circ}$ & 21.000 & $+10 /+3$ & 4 & - & +3 \\
\hline $8^{\circ}$ & 28.000 & $+11 /+4$ & - & 4 & +4 \\
\hline $9^{\circ}$ & 36.000 & $+12 /+4$ & 5 & - & +4 \\
\hline $10^{\circ}$ & 45.000 & $+13 /+5$ & - & 5 & +5 \\
\hline $11^{\circ}$ & 55.000 & $+14 /+5$ & 6 & - & +5 \\
\hline $12^{\circ}$ & 66.000 & $+15 /+6$ & - & 6 & +6 \\
\hline $13^{\circ}$ & 78.000 & $+16 /+6$ & 7 & - & +6 \\
\hline $14^{\circ}$ & 91.000 & $+17 /+7$ & - & 7 & +7 \\
\hline $15^{\circ}$ & 105.000 & $+18 /+7$ & 8 & - & +7 \\
\hline $16^{\circ}$ & 120.000 & $+19 /+8$ & - & 8 & +8 \\
\hline $17^{\circ}$ & 136.000 & $+20 /+8$ & 9 & - & +8 \\
\hline $18^{\circ}$ & 153.000 & $+21 /+9$ & - & 9 & +9 \\
\hline $19^{\circ}$ & 171.000 & $+22 /+9$ & 10 & - & +9 \\
\hline $20^{\circ}$ & 190.000 & $+23 /+10$ & - & 10 & +10 \\
\hline
\end{tabular}

Fonte: Tabela elaborada por Cassaro Svaldi e Caldela (2013).

Mesmo que as possibilidades de ações dos personagens sejam quase infinitas, há um sistema complexo de regras que auxilia o mestre a determinar se a ação do personagem/jogador é ou não possível (SALDANHA; BATISTA, 2009). Por exemplo, uma cena em que há um

${ }^{2}$ Bônus em algumas ações escolhidas do personagem. Por exemplo, ao realizar algum teste de percepção, o personagem de nível 10, deve somar +13 com o número do dado, ou seja, o personagem evolui ao passar dos níveis.

${ }^{3}$ Talentos são habilidades únicas e especiais do personagem como, por exemplo, ataque giratório.

4 As habilidades são atributos básicos como força, destreza, inteligência, constituição, sabedoria e carisma.

${ }^{5}$ Bônus na defesa, na resistência ou dano do personagem. 
guerreiro e um grupo de monstros. $\mathrm{O}$ jogador do personagem guerreiro diz ao mestre que quer pegar a sua espada e golpear todos os monstros com o seu ataque giratório. $\mathrm{O}$ mestre, ao consultar as regras do jogo, determinará se é possível ou não realizar tal ação. Se for possível, o mestre pode determinar a probabilidade de sucesso de conseguir realizar tal ação, pedindo ao jogador para que role o dado de 20 lados e que supere um número $\mathrm{x}$.

Esse sistema de nível e progressão do personagem, grosso modo, aplica-se a qualquer outro tipo de classe de personagens, como magos, ladinos, clérigos, paladinos, druidas etc. Cada um tem a sua particularidade, sua raça inicial, e o personagem se torna ainda mais único dentro daquela mesa e aventura. Por exemplo: um anão (raça) e paladino (classe). Uma amostra do setting de uma mesa de RPG pode ser vista na Figura 4. Já na Figura 5 observa-se que o mestre pode utilizar mapas, miniaturas dos personagens, e mais recursos que representam a cena do jogo, facilitando sua compreensão.

Figura 4 - Foto demonstrativa sobre o setting de uma mesa de RPG, em que há um mestre narrando e os demais jogadores com os seus personagens

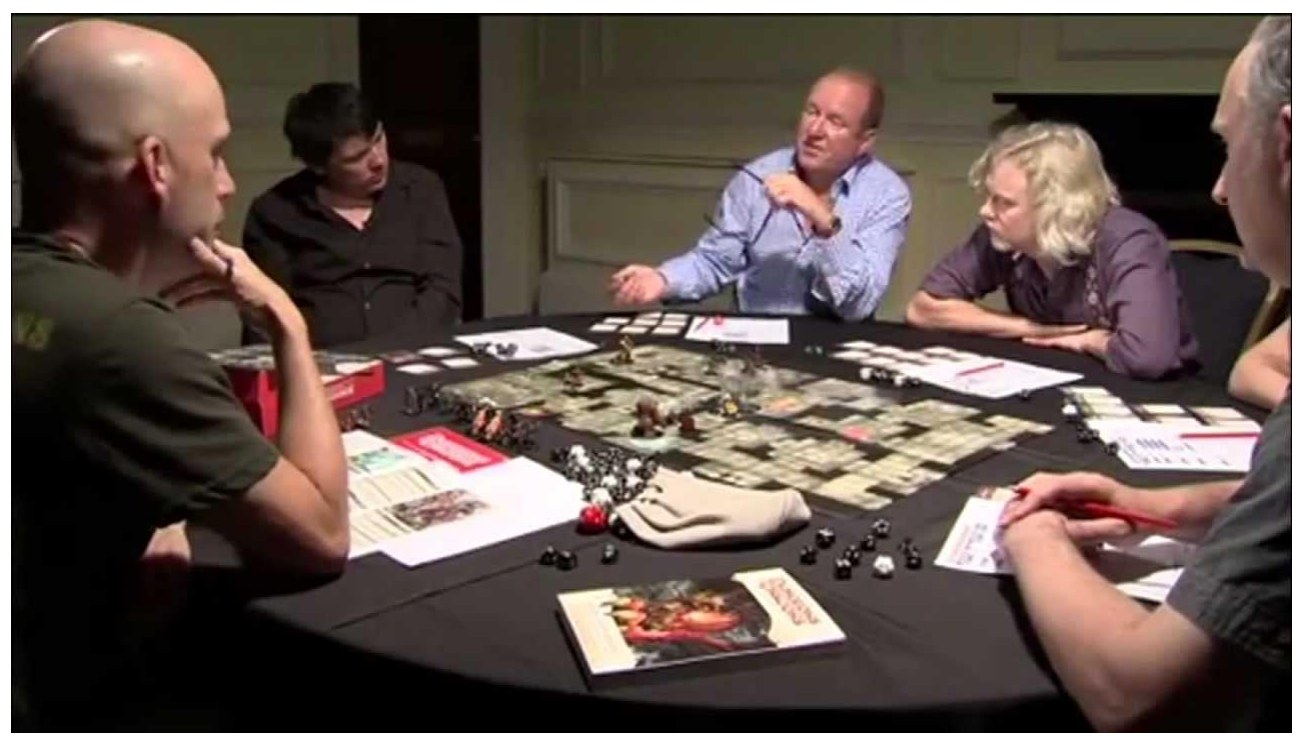

Fonte: https://i.ytimg.com/vi/-FeiNEsLElA/maxresdefault.jpg

Figura 5 - Cenário de um mapa ou cena narrada durante o RPG de mesa 


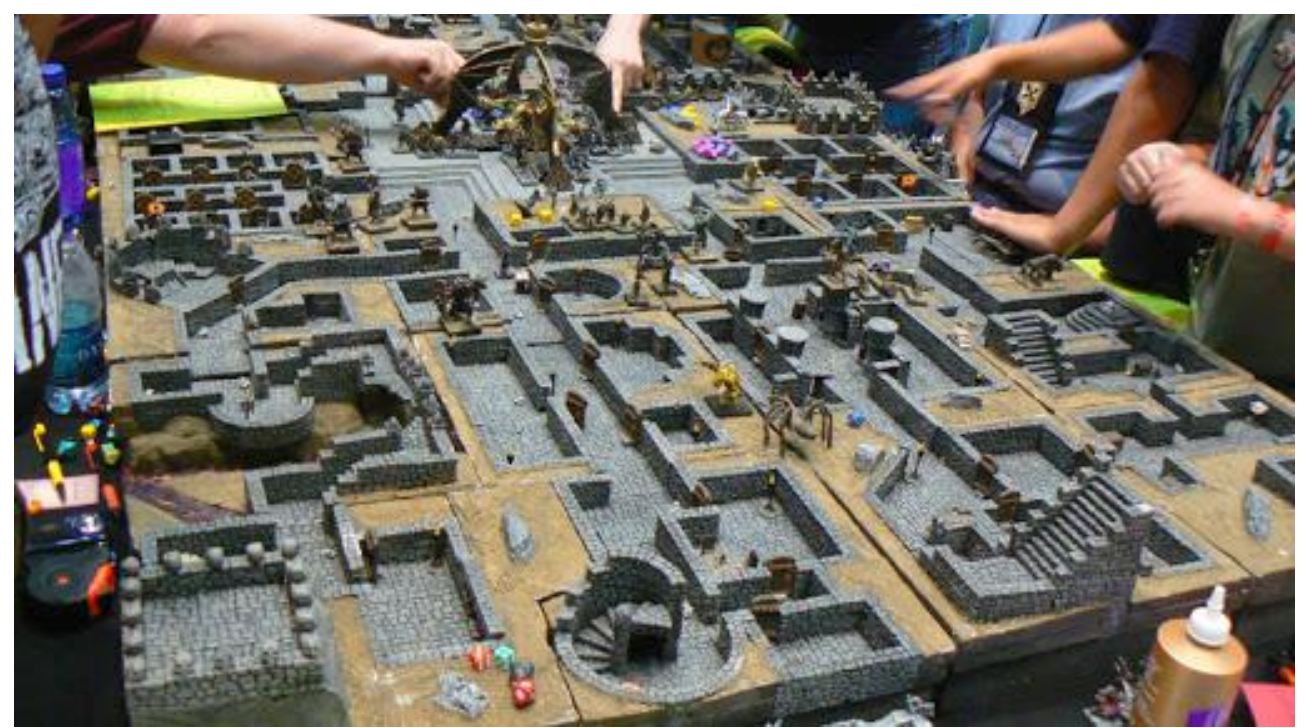

Fonte: https://lh3.googleusercontent.com/proxy/lipYD5eNEVj_KTbx9 2-KmUIf7SbZf GIlkSiTYjZ1J-JR1rvRwYOF_SD zJo884_j4iIl0HD71BCtn8OIR0E7pqDC29MBvhz7D WpsEN6-Q

Todo esse contexto fictício e imaginativo influenciou diversos jovens pelo mundo. Garcia (2017) afirma que, mesmo após 40 anos de publicação e em sua quinta edição, $D \& D$ continua influenciando jovens do mundo todo através de variantes dos jogos de tabuleiros e jogos eletrônicos. E continua a inspirar vários outros através da cultura pop.

Devido ao seu aspecto motivacional, o RPG foi utilizado em diversas áreas como educação (GARCIA, 2017; HORTA, 2005; JAQUES, 2016; KLIMICK; BETTOCHI, 2003; LIMA; NOMURA; VELASCO, 2012; RANDI; CARVALHO, 2013), na psicoterapia (ARAUJO; OLIVEIRA; CEMI, 2011; LIMBERGER; SILVA, 2013), na formação profissional (SOARES et al., 2015), na análise do impacto na cultura pop (SALDANHA; BATISTA, 2009).

Quando se trata de psicoterapia de grupo e habilidades sociais, foi encontrado apenas um artigo na literatura, dentro de uma intervenção estruturada sobre o uso do RPG na terapia de grupo para o desenvolvimento das habilidades sociais com sujeitos TEA. Kōhei (2019) realizou dois estudos sobre promoção da comunicação social e entretenimento com grupo de crianças e adolescentes com Transtorno do Espectro Autista através do RPG de mesa. O primeiro estudo foi realizado com um grupo de quatro crianças; analisou o número de verbalizações sem direcionamento para alguém (p. ex., falar sozinho) e comparou com as falas direcionadas para alguém. A análise foi realizada apenas sobre a primeira e a última sessão. Os resultados mostraram uma melhora significativa durante as 14 sessões com aumento estatisticamente significativa das verbalizações direcionadas para uma pessoa, e uma diminuição de falas sozinhas.

O segundo estudo foi realizado com uma amostra de 51 participantes (41 meninos e 10 meninas), e verificou o efeito de cinco sessões na qualidade de vida desses sujeitos. Foi aplicado 
o inventário de Qualidade de Vida (QOL) como pré e pós-teste, e os dados mostraram que houve impacto na QOL e relatos de melhora, como: "Depois de experimentar o RPG de mesa, eu gosto de conversar mais do que antes". As subescalas do questionário da qualidade da atividade apontaram um maior aumento principalmente na "qualidade da emoção" e "amigos".

A discussão do estudo de Kōhei (2019) aponta algumas características sobre o uso do RPG de mesa como ferramenta para treinar habilidades sociais:

(a) Atividades de lazer e hobby são importantes para criar laços de amizade entre crianças e jovens com TEA. A simples conversa sobre algum hobby já facilita a interação entre os participantes;

(b) O uso de RPG de mesa tem um funcionamento diferente do de uma conversa coloquial. Os elementos envolvidos no RPG, como regras e configurações das atividades, clareza dos objetivos e funções comuns e comunicação indireta por meio de um personagem, parecem facilitar as relações interpessoais entre crianças e adolescentes com TEA;

(c) O RPG pode promover rapidamente a melhora da qualidade de vida com o público TEA, mesmo sem um treino específico;

(d) Por mais que haja o estereótipo de que "jovens com TEA não são bons em comunicação ou odeiam atividades em grupo", se o ambiente propiciar interações espontâneas, a atividades de lazer proporcionam a melhora das interações sociais.

Portanto, esses achados sugerem que o uso do RPG de mesa tem potencial motivacional para o uso da terapia de grupo nos diagnósticos de TEA. Compreender aspectos mínimos dos elementos envolvidos no RPG pode auxiliar a motivação e, assim, aumentar a eficiência de adesão. $\mathrm{O}$ uso de elementos da gamificação podem tornar a tarefa mais tentadora, facilitando a generalização dos comportamentos-alvo.

Nesse sentido, a questão da gamificação será tratada a seguir, pois a intervenção proposta neste trabalho utiliza diversos elementos pertencentes ao RPG, que acabaram influenciando vários pilares da gamificação (CROCCO, 2016). A organização sistemática desses elementos motivacionais, que são encontradas no RPG e em outros tipos de jogos, são estudadas na área do game design e, portanto, podem ser analisadas à luz da gamificação.

\subsubsection{Gamificação}

A gamificação é um termo recente e contemporâneo, que utiliza elementos de jogos em diversos contextos diferentes que não são diretamente relacionados a eles (DETERDING et al., 
2011). A principal ideia da gamificação é tornar os jogos divertidos para os jogadores e, assim, aplicá-los em outras áreas, para motivar e engajar as pessoas (CHRISTIANS, 2018; CHOU, 2014).

É importante diferenciar gamificação de jogo. Para vários estudiosos (ÇEKER; OZDAML, 2017; CHOU, 2014; KIM; SHUTE, 2015). Kupchan (2000) afirma que o jogo é definido pelo uso de regras, jogadores, feedback para a maioria das ações do jogador, progressão e, muitas vezes, envolve o ganhar ou perder na situação. Para a maioria dos jogadores, o jogar envolve diversão, mas, por outro lado, para alguns jogadores envolve a dificuldade em si, como jogadores de jogos de Dark Souls, por exemplo. Ressalta, ainda, que o jogo é um sistema fechado em si (por exemplo, um jogo eletrônico ou um jogo de cartas) e a gamificação é um sistema que envolve interação externa (por exemplo, andar pela cidade usando o Waze).

Bernard Suits (1967), um dos principais estudiosos da área de jogos, definiu o jogo como se engajar em uma atividade diretamente ligada a um estado específico da coisa, que permite ações definidas por regras específicas, o que significa permitir regras que limitam as ações. As contidas em um jogo geralmente definem um vencedor, como vender, adquirir pontos e os parâmetros para definir o que é trapaça ou ilegal. Esse setting não interage com o mundo exterior. O jogo é uma experiência contida em si mesma, em que há vencedor/perdedor, gostar/odiar e performance boa/ruim. Portanto, o jogo é definido pela interação dele com o jogo em si, encapsulado em suas regras.

O aspecto motivacional é citado em diversos artigos da área (ÇEKER; OZDAML, 2017; CHOU, 2014; DETERDING et al., 2011; KIM, 2015) e é utilizado em diferentes áreas, como empresas, educação, jogos educacionais, entre outros (LANDERS, 2014). Para Chou (2014), a gamificação tem quatro grandes áreas de aplicação, como em um produto, um local de trabalho (dentro de empresas, por exemplo), marketing e estilo de vida (aplicativos, por exemplo).

Christians (2018) faz um levantamento detalhado sobre a história desse campo de estudo. Na conclusão do texto, o autor defende que a discussão sobre o uso da gamificação se estende para o campo da ética, pois ela pode ser utilizada como motivacional, mas também para uso abusivo. Ele acredita que, talvez, os primeiros "sistemas de gamificação" vieram muito antes da era dos jogos eletrônicos e da discussão do conceito. As instâncias iniciais envolvem um esquema de incentivo e sistema de "medalha". Ao longo da história, é raro não encontrar esses dois mecanismos. Por exemplo: o esquema de incentivo seria como um sistema de pontos; comumente utilizado em educação com crianças (ex. faz X tarefas para ganhar Y pontos para trocar por prêmios) ou fidelidade com empresas (ex. sistema de milhas nas companhias aéreas). 
Já o sistema de medalhas é a conquista de cargos, encontrada em inúmeras situações, como empresas, exército, esportes etc.

Charles Coonradt (1984) diz que, em um esporte, o feedback é coletivo e imediato a partir dos pontos, porém no trabalho não. O feedback em um posto de trabalho é vago e inconsciente e muito atrasado. Então, a proposta do autor é utilizar os mecanismos encontrados no esporte e aplicar no trabalho. Essa foi a primeira justificativa do uso de gamificação. $\mathrm{O}$ feedback cíclico dos esportes e dos jogos recreacionais são a chave para manter as pessoas motivadas.

Em 1978, foi criado um jogo com enorme impacto na gamificação, atualmente. Roy Trubshaw e Richard Bartle criaram um jogo chamado MUD1 (First Multi-User Dungeon Game). O jogo é feito em textos e a interface é difícil de operar, mas foi o primeiro jogo online que envolveu socialização e cooperação. Precursor dos jogos online, hoje em dia é importante para o uso da gamificação no setting online.

Em 1980, os benefícios da gamificação e dos jogos começaram a ser reconhecidos no contexto acadêmico. Thomas W. Malone descobriu propriedades que fazem os jogos eletrônicos intrinsicamente motivadores e não eram limitadas somente ao design dos jogos. Ele delineou como esses elementos podem ser analisados separadamente e aplicados a outras áreas, particularmente na educação. Esse trabalho é considerado o primeiro trabalho acadêmico sobre gamificação (MALONE, 1980).

A partir dos anos 80, inúmeras companhias adotaram sistema de fidelidade, acúmulo de pontos etc. A partir dos resultados das empresas que utilizaram sistemas de pontos, a divulgação das vantagens de seu uso se estendeu para a maioria das companhias.

Também os jogos eletrônicos foram expressivos, pelo lançamento da Nintendo, que, em 1990, já tinha se espalhado entre os americanos, sendo que 30\% das casas tinham esse videogame. Milhões de consoles foram vendidos e, por mais que a gamificação, enquanto conceito, não existisse, a divulgação dos seus elementos foi necessária. A Nintendo foi a responsável pela primeira geração de jogadores de videogame, a conhecida geração milênio. Essa proliferação do videogame foi responsável por "preparar" as pessoas a aceitar e apreciar os futuros jogos e os seus elementos. Em outras palavras, o sucesso da gamificação foi obtido através da aceitação desses elementos.

Os eletrônicos se tornaram cada vez mais populares e as pesquisas envolvendo esses jogos aumentaram significativamente. Bartle (1996), um dos desenvolvedores do MUD1, publicou um artigo sobre quatro perfis de jogadores quando estes participam de jogos sociais e o que eles esperam através da experiência. Os jogadores foram divididos em quatro categorias: 
socializador, explorador, empreendedor e assassino. Essas categorias não são mutualmente excludentes e podem variar de acordo com o momento, mas o impacto dessa categorização é que ela se tornou importante para a base da gamificação moderna.

Segundo Christians (2018), foi em 2002 que propriamente se deu o nascimento do termo "gamificação", marcando o início de uma era e o seu auge. Nick Pelling, um designer de jogos, foi contratado para desenvolver um jogo com interface de caixa de banco ou máquina de salgados, e utilizou o termo "gamificação", mesmo o termo sendo considerado "feio" (CHRISTIANS, 2018; LANDERS, 2018).

Em 2005, foi fundada a empresa Bunchball, uma das mais importantes em utilizar elementos de jogos para o aumento do engajamento em sites. Essa empresa foi responsável por desenvolver Dunder Mifflin Infinity, uma rede social gamificada em que os usuários podiam acessar o sistema como funcionários da empresa Dunder Mifflin. Os usuários (funcionários) podiam completar tarefas e desafios que, na realidade, era uma competição entre os usuários. Quem conseguisse terminar, poderia ganhar prêmios. Essa plataforma foi a primeira plataforma gamificada online.

No mesmo ano, surgiu uma plataforma online chamada Chore Wars, que, na realidade, é uma plataforma para motivar a realizar suas tarefas, com o tema de um jogo de fantasia, como World of Warcraft ou Caverna do Dragão. Em vez de o jogador completar missões matando dragões ou cumprindo missões épicas, ele teria que cumprir as tarefas domésticas. Cada tarefa possuía uma recompensa, que era definida pelo administrador. Depois de terminar a tarefa, o jogador poderia batalhar com o monstro e seu sucesso dependia do nível do jogador, ou seja, criou uma motivação entre a criança e os pais, pois, para cada tarefa, produzia um personagem cada vez mais forte. Essa plataforma foi importante para complexificar elementos simples, como aumento do nível e uma narrativa histórica.

Uma outra ferramenta significativa na história da gamificação é o Foursquare, que foi importante em criar mapas interativos, pois eram os usuários que enviavam informações para a Foursquare. Ao acessar o sistema, o aplicativo coletava informações do usuário. Uber e Snapchat foram empresas que compraram essas informações.

Em 2010, um outro marco na gamificação foi a apresentação de Jane McGonigal (autora de Reality is Broken), no TED Talk sobre o uso da gamificação para mudanças sociais com o título "Gaming can make a better world". Nesse seminário, ela argumenta que os usuários dos jogos eletrônicos como World of Warcraft passam muito mais tempo resolvendo os problemas da sociedade do jogo do que os problemas do mundo real. Assim, ela enxerga a possibilidade 
de utilizar esses elementos motivacionais para criar o senso de cooperação dos jogadores fora dos jogos (CHOU, 2014).

No mesmo ano, foi criada um dos maiores sucessos da gamificação: The Fitbit. Esse relógio é capaz de rastrear as atividades físicas do usuário, como passos, batimento cardíaco, velocidade e a rota realizada, entre outros. Dessa maneira, os usuários têm um volume maior de feedback, o que é um dos elementos da gamificação.

Para demonstrar como a gamificação estava sendo procurada, em 2012, Gartner previu que $70 \%$ das companhias adotariam ferramentas da gamificação já em 2014. Logo depois, duas empresas grandes, Amazon e Mozilla, lançaram plataformas como GameCircle e Open Badges, no intuito de ter leaderboards e conquistas.

Paralelamente a esses fatos, que demonstram a excitação com gamificação, houve outros eventos que evidenciaram alguns problemas da aplicação da gamificação. Christians (2018) afirma que o sucesso, nos meados de 2010, fez a gamificação ser aplicada em larga escala. No começo de 2014, houve um movimento afirmando que a gamificação não é tão eficaz quanto parece. Um dos casos explícitos foi a plataforma gamificada My Marriott Hotel que, em 2011, teve o objetivo de treinar empregados e atrair novos potenciais empregados. Nessa plataforma, os jogadores treinavam gerenciar a hospitalidade e aprendiam como satisfazer os clientes. Como resultado, a empresa concluiu que não precisava de um sistema gamificado para identificar os melhores funcionários, e o sistema de pontos isolou os usuários que não se adaptaram ao sistema. Nos aspectos motivacionais, não foi percebido maior engajamento por parte dos usuários. Segundo Christians (2018), várias questões surgiram no planejamento do desenvolvimento do projeto, como o foco na necessidade da empresa e na supervalorização do engajamento dos usuários. O jogo não foi bem detalhado e planejado, o que o levou ao fracasso.

O exemplo do fracasso de My Marriott Hotel representou o fracasso de várias aplicações em outras companhias e que, geralmente, envolveram o mesmo erro: a tentativa de gamificar um processo sem entender totalmente como a gamificação funciona. A aplicação dos elementos do game não tornam a atividade interessante, pelo contrário, se não for bem planejada e trabalhada, a atividade se torna chata.

Christians (2018, p. 22) diz:

The media reacted swiftly to the failures of gamification, and the trend was declared dead nearly overnight. In reality, the ideas were brought back to reality and the limitations of these tools were shown. In other words, adding a leaderboard and a point system to a problem does not fix the problem; it is not a miracle cure. This process needs to be done intelligently and with 
significant preparation. When rushed and not designed well, any application is destined to fail. No amount of points scored can change that.

A Gallup publicou que somente $31 \%$ dos trabalhadores americanos são engajados no trabalho, e o grupo dos mais desengajados é o dos milênios. Somente $29 \%$ gostam de trabalhar (HARTER, 2020). Se são eles a geração que estava condicionada aos jogos eletrônicos, ela não se engajou em trabalhos gamificados. E isso já havia sido percebido. Então, a partir de vários estudos, muitos departamentos de recursos humanos deixaram de utilizar gamificação.

Apesar disso, a gamificação se estabilizou e saiu do popular. Deixou de ser considerada mágica e operou por trás das cenas, variando nos degraus dos sucessos. Esquemas de incentivo continuam em todos os lugares e não se consegue usar o telefone sem alguma recompensa ou badges. São ondas entre interessantes e chatas, mas continua crescendo lentamente e evoluindo dia a dia.

Para Yu-kai Chou (2014), fundador da Octalysis Framework, a gamificação é muito mais do que PBL (Points, Badges e Leaderboard). O esquema do PBL está em praticamente tudo. Por exemplo: uma recomendação padrão para orientação de pais é usar sistema de pontos em que a criança, ao acumular um número x de pontos, poderá trocar por alguma premiação. Esse esquema, na literatura, sempre trouxe resultados, pois consegue tornar uma atividade diária chata, como lavar a louça, em uma atividade minimamente mais divertida.

Jogos têm a possibilidade de manter as pessoas engajadas, de construir relações entre pessoas, de desenvolver o potencial criativo, mas, por outro lado, também criam problemas, pois, ao desviar a atenção do real, as pessoas podem viver a vida sem aprimorá-la. Para Chou (2014), a motivação de um usuário "trabalhando" nas atividades de rotina diária e no contexto virtual com amigos é bem diferente. Esses usuários se mantêm "trabalhando" em atividades repetitivas (denominadas grunt work) no contexto virtual, que envolvem, por exemplo, coletar recursos e colocar no baú da guilda. Em outro contexto, são notavelmente desmotivados em atividades de casa, como fazer a lição, arrumar o quarto, tomar banho etc. Inclusive, sobre o grunt work, muitos usuários sacrificam horas de sono e comida para, simplesmente, realizar uma atividade repetitiva.

Outra crítica colocada por Chou (2014) é que a maioria dos interessados ou profissionais que trabalham com gamificação não possuem histórico com jogos eletrônicos, e muitos deles não gostam de jogar. Talvez essa falta de contato com o universo dos jogos explicaria o porquê de a maioria dos profissionais utilizar o PBL como estratégia principal das intervenções e, 
também, pelo contato dele ao longo de suas vidas, com o sistema de fidelidade ou programa de milhas.

No entanto, para Chou (2014), se você realizar uma pesquisa sobre razões e motivos que fazem o usuário de jogos eletrônicos continuar jogando, muito raramente eles falarão explicitamente sobre o PBL. Na realidade, a maioria relatará que outros aspectos são relevantes, como a história, o tema, jogar coletivamente, entre outros.

Ainda sobre a discussão a respeito dos fatores, os gráficos não são os aspectos mais relevantes para manter o jogador jogando (CHOU, 2014). Para exemplificar, jogos como MID1 eram realizados com base em textos e, no mesmo período de alguns jogos famosos, como Tíbia, havia diversas opções de jogos com recurso gráfico mais avançado.

Para Chou (2014), o planejamento da gamificação deve realizado em etapas; pensar no que poderia diminuir o prejuízo da gamificação (morte da era), mas aumentar sua aplicabilidade em diversas áreas, como o desenvolvimento de um produto (ex. aplicativo ou site), marketing e estilo de vida. Por que não planejar a gamificação e utilizá-la na terapia individual e de grupo, principalmente quando o cliente é criança e adolescente?

Uma das principais referências sobre gamificação é o justamente o livro Yu-kai Chou (2014). Nele, Chou apresenta a proposta da Octalysis e seus oito pilares:

1) Significado épico e o Chamado: É a sensação que o jogador tem de que está fazendo aquilo por uma causa maior (ex. salvar o planeta) ou que ele é O escolhido (ex. ele é o único que tem uma força sobrenatural). Um exemplo que se encontra no livro é o caso da Wikipédia, onde os usuários compartilham o conhecimento para um bem maior coletivo;

2) Desenvolvimento e Realização: Trata-se da progressão no jogo, ganhar ou desenvolver habilidades, superar desafios e o sistema de recompensas. Aqui se encontra, por exemplo, o PBL;

3) Fortalecimento da Criatividade e Feedback: Como o próprio nome diz, é o desenvolvimento da criatividade para solucionar problemas e testar novas soluções. O feedback é importante para manter o usuário interessado em continuar criando. Dois grandes exemplos são: Minecraft e Roblox;

4) Propriedade e Possessão: É a sensação de controle e de posse que os jogadores sentem quando jogam. Quando eles têm esse sentimento, esforçam-se ao máximo, pois são os donos. Por exemplo, o usuário passa muitas horas customizando o seu perfil nas redes sociais; 
5) Influência Social e Associações: Esse drive são todos os elementos sociais que motivam qualquer pessoa, como companheirismo, relacionamentos, aceitação, competição, pressão social e inveja. Por exemplo: a necessidade de jogar um jogo para não ser excluído do seu time ou para bater o recorde de algum amigo;

6) A Escassez e a Impaciência: É a motivação que rege a dificuldade de ter algo e não conseguir ter. A dificuldade em obter a recompensa faz o usuário se comportar repetidamente, até que consiga. Em outras situações, muitas vezes não há qualquer possibilidade de ter o que deseja, mas o usuário fica aguardando "ansiosamente" para ter. Exemplos: Dark Souls (um dos jogos mais difíceis da atualidade) e a liberação do Clubhouse para a comunidade (agora só pode acessar através de convite de outro usuário);

7) Imprevisibilidade e Curiosidade: É o caso de os usuários assistirem um filme ou série até o final apenas para saber o que vai acontecer. Existem vários livros e jogos com esse drive bem presente, como no caso do Red Dead Redemption (um dos jogos mais cinematográficos);

8) Perda e temor: É a motivação para "evitar algo negativo". Assim, o usuário joga com medo, para não perder tudo o que conquistou. Esse modo é chamado de hardcore, um modo que alguns jogos oferecem: se o usuário morrer, nunca mais poderá rodar aquele personagem novamente.

Alguns estudos traçam a relação entre o uso de elementos da gamificação para aumentar a motivação em diversos contextos, aumentando a adesão sobre alguma atividade humana e tornando-a mais agradável (BOWMAN; LIEBEROTH, 2018; CROCCO, 2016; GERDENITSCH et al., 2020; GROENING; BINNEWIES, 2019; MITCHELL; SCHUSTER; JIN, 2020; SPANELLIS; DORFLER; MacBRYDE, 2020; TREIBLMAIER; PUTZ, 2020).

\subsubsection{Adesão}

Quando se fala em adesão na psicoterapia, é difícil encontrar, na literatura, alguma taxa sobre o consultório particular. Não foi encontrado nenhum artigo sobre tal dado, apenas em contextos institucionais.

Taylor (2007) revela que a adesão para toda a área da saúde tem uma variação de 7\% a $85 \%$ em relação às recomendações efetuadas pelos profissionais da saúde. Quando envolve mudança de hábito, 50\% a 60\% tendem a não seguir. Quando são hábitos como o uso de cigarro, 
$80 \%$ não seguem. No pior cenário, o de fumantes com problemas cardíacos, $65 \%$ a $75 \%$ dos pacientes não mudam seus costumes.

Com relação aos tratamentos psicológicos, Wierzbicki e Pekarkik (1993) revisaram 125 estudos, constatando uma taxa de 46,86\% de abandono. Outros dois estudos, o de Lhullier, Nunes e Horta (2006) e o de Mantovani, Marturano e Silvares (2010), analisaram 5 anos de clínicas universitárias e chegaram à mesma taxa de $49 \%$. Outro estudo, de Viale-Val et al. (1984), afirma que a taxa de abandono, quando envolve adolescentes, é maior do que a de terapias com crianças ou adultos.

Portanto, a busca por novas estratégias e adaptadas ao adolescente contemporâneo é importante, quando a adesão na psicoterapia é um problema. Além disso, quando se trata de THS, de queixas ligadas ao uso de jogos eletrônicos e adolescente, é imprescindível que o terapeuta saiba se adaptar ao mundo do adolescente.

Neufeld et al. (2017, p. 163) afirmam sobre a importância desse aspecto:

Para tratar adolescentes, é preciso também estar disposto. Disposto a embarcar em seu universo e em suas questões, como, por exemplo, atualizar-se em relação a filmes, séries, jogos, tecnologias e músicas que são do interesse do paciente, a fim de, de alguma maneira, começar a compreender seu mundo. Além disso, muitas situações trazidas por um jovem podem parecer banais para um adulto, mas podem ter um significado muito importante para o adolescente. Essa empatia e essa disposição devem, acima de tudo, ser genuínas, do contrário, o processo terapêutico certamente estará prejudicado. Também o comportamento opositivo característico deve ser trabalhado com a validação dos pensamentos e das emoções do paciente, mas nunca de maneira confrontativa ou autoritária.

Logo, é nesse contexto das habilidades sociais, da terapia de grupo, do RPG e da gamificação que se apresenta a justificativa de desenvolver e aprimorar a prática psicoterápica. Essa prática envolve os elementos apresentados e discutidos na Introdução, visando trazer a criança, o adolescente e o jovem adulto ao seu universo. Desse modo, é importante ressaltar que, quando envolve desenvolvimento das habilidades sociais, tais técnicas apresentadas (por exemplo, a gamificação) têm o objetivo de aumentar a adesão na terapia de grupo e da individual. 
1.4 DESENVOLVIMENTO DO TERAPIA DA SOCIALIZAÇÃO GAMIFICADA (TSG) PARA TREINO DE HABILIDADES SOCIAIS EM GRUPO E GENERALIZAÇÃO DO COMPORTAMENTO

Diferentemente dos trabalhos encontrados na literatura sobre a uso do RPG nas terapias psicológicas, Kōhei (2019) - como vários outros autores - utilizou o RPG como ferramenta de intervenção, com foco no desenvolvimento de um repertório específico de falas direcionadas ao outro, com o objetivo de melhorar a qualidade de vida dos participantes. Porém, tal estudo carece de explorar as categorias das habilidades sociais, como apresentadas por Caballo (2003) e Del Prette e Del Prette (2017). Além disso, ambos os estudos não visaram registrar o processo terapêutico ao longo das sessões, lembrando que o estudo de Kōhei (2019) comparou a frequência dos comportamentos-alvo na primeira e na última sessão.

Não foram encontrados, na literatura, artigos que evidenciam o processo terapêutico na construção dos reforçadores lúdicos, os ganhos comportamentais ao longo das semanas, desenvolvimento de classes e de categorias de habilidades sociais e nem medidas de generalização envolvendo os próprios participantes e os seus cuidadores. Como apontado por Andreozzi (2017), é difícil encontrar intervenções com planejamento da generalização das habilidades sociais nos THS.

Diante desse cenário, Germano Henning e Túlio Andrade, em 2013, utilizaram o RPG para o desenvolvimento das habilidades sociais em grupo. A proposta inicial dos dois psicólogos era a de aplicar o RPG como ferramenta motivacional para diminuir a excesso comportamental em jogos eletrônicos. O primeiro grupo foi constituído de cinco participantes, entre 14 e 17 anos, e todos apresentavam diagnóstico de Transtorno de Oposição e Desafiador (TOD).

Em contexto experimental não científico, o potencial da ferramenta foi evidenciado, quando produziu diminuição das demandas de excesso comportamental e, ao mesmo tempo, aumentou as interações sociais, e até então a intervenção não tinha sido planejada com tal finalidade.

Em 2014, os terapeutas iniciaram mais três grupos, divididos por faixas etárias entre 9 e 15 anos, totalizando quatro grupos. Alguns diagnósticos constituíram tais grupos como Transtorno do Espectro Autista (TEA), Transtorno de Déficit de Atenção e Hiperatividade (TDAH), entre outros. No World Congress on Brain, Behavior and Emotions 2015, Henning e Andrade (2015) apresentaram o trabalho sobre os grupos terapêuticos, com título de "Developing Social Skills with group therapy using RPG". 
A partir de 2016, foram testados e experimentados diversos formatos e possibilidades de aumentar o valor motivacional do trabalho com uso do RPG. Assim, foi se desenvolvendo a Terapia da Socialização Gamificada (TSG), uma síntese histórica de inúmeras tentativas e erros, que resultou numa intervenção gamificada e lúdica com crianças, adolescentes e jovens-adultos.

A TSG pode ser definida como um universo simbólico e motivador onde, a partir da sua história pessoal, os jogadores-clientes incorporam os personagens-heróis e os seus reforçadores agregados. De outro lado, os mestres-terapeutas manipulam as contingências lúdicas e offgame, e utilizam uma ampla possibilidade de manejo, com reforçadores focando desenvolver individualmente as habilidades sociais e outros comportamentos-alvo, sem deixar explícito o setting terapêutico da prática psicoterápica.

Através desse universo lúdico, os participantes podem estabelecer vínculo com os demais integrantes, diminuindo a probabilidade de punições sociais (exemplo: rejeição ou julgamentos pelos pares) por comportamentos inadequados, presentes na sua história pessoal. Dessa forma, o grupo terapêutico pode auxiliar, através do setting terapêutico, e aumentar as chances de modelagem e generalização dos comportamentos aprendidos com seus pares.

Figura 6 - Representação da intervenção TSG, onde a parte destacada é a intersecção entre as diferentes áreas.

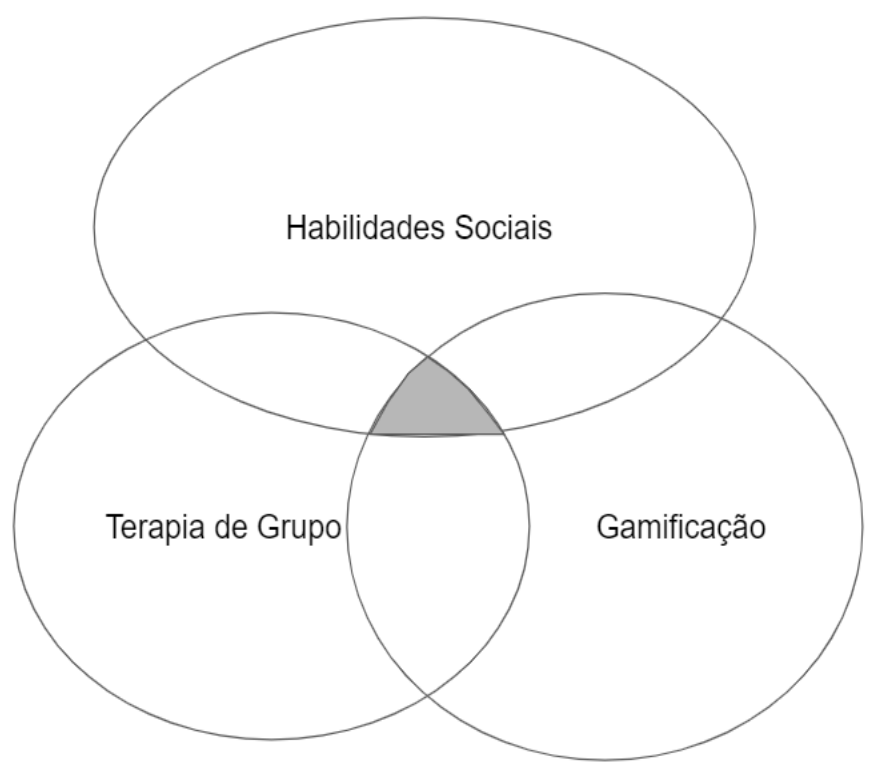

Fonte: Elaborada pelo autor.

Para a produção de evidências científicas, Petermann e Muller (2001), dentro da Prática Psicológica para Evidência, defendem a sistematização da intervenção e não uma intervenção padronizada. 
O THS possui diversos programas estruturados para ensino e refinamento das HS, porém não há intervenções com avaliação contínua de processo sobre a habilidade social. A proposta da avaliação contínua é coerente com a proposta do behaviorismo radical, pois um dos objetivos do terapeuta é observar e auxiliar diretamente o cliente com as variáveis do ambiente e descrever as contingências de mudança.

O uso de escalas e inventários apresentados anteriormente são primordiais para avaliar as mudanças e a melhora das habilidades sociais em intervenções dentro do consultório. Assim, torna-se útil entender as diferenças e os mecanismos para generalização e manutenção dos comportamentos fora do consultório. Dessa forma, será possível compreender e validar cientificamente a prática dos programas na abordagem analítico-comportamental, que apresenta resultados positivos, segundo observado através de relatos de cuidadores e do próprio cliente. Sua eficácia é reconhecida entre os profissionais da área clínica, sendo, muitas vezes, requerida como uma intervenção complementar às sessões individuais.

Não se sabe como e qual foi a construção do processo responsável para a mudança comportamental do cliente; logo, o presente projeto visa a compreender os mecanismos de mudanças, através da pesquisa de processo da intervenção de grupo, utilizando as avaliações no decorrer das sessões. 


\section{OBJETIVO}

\subsection{OBJETIVO GERAL}

O objetivo geral deste trabalho é avaliar os efeitos de uma intervenção integrativa utilizando o método nos aspectos da habilidade social e competência social em jovens de 12 a 17 anos.

\subsection{OBJETIVOS ESPECÍFICOS}

Os objetivos específicos do presente projeto são:

- Comparar os resultados da avaliação das habilidades sociais obtidos com GCQ e IHSA;

- Verificar se GCQ foi capaz de descrever o processo terapêutico do grupo;

- Examinar se a escala TC-GAS pode fornecer dados de generalização dos comportamentos treinados dentro da sessão terapêutica em outros ambientes;

- Quanto à adesão ao tratamento, verificar se TC-GAS é uma medida para os jovens e se CGI é para os cuidadores;

- Apontar os resultados observados no final da intervenção clínica sob olhar da gamificação. 


\section{MÉTODO}

\subsection{PARTICIPANTES}

Os participantes foram clientes de consultório particular, onde há estrutura e adaptação temática do grupo (cultura pop, RPG, games), conforme descrito na Introdução. Como é um estudo avaliativo do processo terapêutico de grupo para o desenvolvimento das habilidades sociais, a maioria dos participantes já era cliente e alguns já estavam em processo terapêutico de grupo ou individual.

Para a análise dos dados, participaram 21 clientes do gênero masculino, com idade entre 12 e 17 anos.

Os critérios de inclusão foram:

1) Interesse por elementos da cultura pop (desenhos animados, YouTube, videogame etc.), coletados a partir do inventário Lista de Interesses (Apêndice C);

2) Demanda, a partir da entrevista inicial com pais e/ou cliente, por déficit das habilidades sociais, independente, em partes, do diagnóstico.

Como critérios de exclusão, não participaram da pesquisa os participantes com as características:

1) Comportamentos autolesivos e heterolesivo, bem os que não tinham disponibilidade para realizar as sessões de grupo com duração de duas horas;

2) Por envolver alguns clientes TEA, não participaram os com autismo moderado e grave, devida à dificuldade de fala e de abstração;

3) Foram excluídos deste estudo os dados dos participantes que não quiseram preencher os questionários GCQ e IHSA, essenciais para a análise.

\subsection{MATERIAIS}

Foram utilizados: Termos de Consentimento Livre e Esclarecido - TCLE (Apêndice A); Livro Guia Básico do Jogador Tormenta - edição revisada; Livro Bestiário de Arton; fichas de personagens adaptadas pela equipe; Livro das Raças; três Livros Complementos de Classes de TRPG; oito kits de dados para RPG, cada kit contendo: um dado de quatro faces, um dado de seis faces, um dado de oito faces, um dado de dez faces, um dado de 12 faces e um dado de 20 faces; kit de miniaturas de personagens e monstros; folhas de papel sulfite; imagens 
transmitidas para um TV 55', para a facilitar narrativa; lápis; borracha; quadro branco; canetas para lousa branca; apagador; lápis de colorir e apontador.

Com a pandemia, os grupos migraram para a modalidade online, ou seja, cada participante utilizou o seu próprio computador ou celular para fazer as sessões de grupo.

\subsection{LOCAL}

A coleta foi feita no consultório do pesquisador, pela questão estrutural e temática da atividade do grupo. A sala possui diversos estímulos com a cultura pop, contendo uma mesa quadrada com 8 cadeiras.

Após o advento da pandemia, as sessões de grupo e a coleta de alguns instrumentos foram realizadas na modalidade online. Para isso, foi utilizada a rede social Discord, que é uma plataforma fechada, ou seja, apenas ingressavam no servidor quem tivesse convite para entrar.

\subsection{PROCEDIMENTO}

\subsubsection{Adaptações: um estudo preliminar}

Durante os meses de agosto e setembro de 2019, foi realizado um estudo preliminar para checar se os dados poderiam ser coletados a partir de uma tradução literal dos instrumentos.

Sobre a versão traduzida e literal do GCQ, a primeira etapa de tradução foi assim realizada: o pesquisador procedeu a versão para o português e a enviou para uma terceira juíza, que possui teste de proficiência em inglês e que morou nos Estados Unidos por 4 anos. Então, a juíza traduzia novamente para o inglês, de modo que a frase traduzida fosse igual à original. Ao concluir essa fase, o pesquisador aplicou o GCQ com os possíveis participantes da pesquisa, mas houve bastante obstáculos para o entendimento da amostra da clínica. Então, a partir das dificuldades para o entendimento, o pesquisador traduziu a versão para os adolescentes e, a cada versão, checava se os participantes entendiam o que estava escrito, até chegar à versão final.

Sobre o GAS, houve uma adaptação. Foi aplicado da mesma forma como descrita por Starling (2001), durante as sessões individuais. Os adolescentes não concluíram as 8 etapas para a construção do GAS, pois não sabiam com clareza as grandes áreas que gostariam de desenvolver. Portanto, a construção do GAS foi adaptada para o contexto no consultório. 
Os pais ajudaram a preencher as demandas e, no estudo preliminar, de fevereiro a outubro de 2019, elas foram divididas em três áreas: atividade vida diária (AVD), hábitos de estudos e habilidade social.

\subsubsection{Avaliação inicial}

A entrevista inicial foi dividida em duas sessões individuais de 50-60 min. A primeira sessão realizada com os pais e a segunda, com o cliente.

\subsubsection{Primeira sessão de entrevista inicial (com os pais)}

Na primeira sessão de entrevista inicial, o pesquisador coletou alguns dados gerais de anamnese, descritos no Apêndice B. As informações relatadas pelos pais foram sobre a queixa do cliente e, também, a respeito das dinâmicas familiar, escolar, de reforçadores e outros.

Após a coleta de dados, os responsáveis receberam uma explicação verbal e uma folha sobre o funcionamento dos grupos e as regras da intervenção. Nesse momento foram abordadas questões burocráticas e estruturais referentes a horários da coleta de dados e duração das sessões, dentre outras informações.

\subsubsection{Segunda sessão de entrevista inicial (com o cliente)}

Para a segunda sessão de entrevista inicial, dessa vez com o participante, o pesquisador buscou estabelecer um vínculo e utilizou as informações coletadas na sessão com os responsáveis para guiar a conversa e a avaliação com o participante. O pesquisador tinha o objetivo de:

a) apresentar e explicar o funcionamento do RPG ao participante;

b) aplicar a Lista de Interesses v2.09 (Apêndice C);

c) aplicar o IHSA-Del-Prette;

d) dar o início à construção da ficha do personagem e realizar uma dinâmica de curta duração.

Para a apresentação do RPG, os livros básicos do jogo foram apresentados ao participante, que pôde escolher livremente qualquer combinação de raça e classe para seu personagem. Antes de terminar a construção do personagem, o terapeuta, então, entregou a 
Lista de Interesses v2.09 ao participante, um questionário de autoaplicação fácil e simples. Após o término, o terapeuta revisou e fez algumas perguntas sobre as respostas escritas na folha.

Durante toda a entrevista, o terapeuta avaliou as habilidades sociais, utilizando as classes comportamentais descritas em Del Prette e Del Prette (2017).

Após essa revisão, o terapeuta aplicou o IHSA-Del-Prette. Finalmente, com o tempo restante da sessão, o terapeuta terminou a construção da ficha do personagem para fazer uma dinâmica de curta duração, simulando uma partida de RPG com o participante. Essa etapa tinha o objetivo de estabelecer uma operação motivadora para aumentar a probabilidade de o participante retornar para a próxima sessão de grupo.

Ao final da sessão, foi informada a viabilidade da participação do cliente no grupo e feita uma breve descrição sobre o perfil do grupo em que ele seria incluído.

Vale ressaltar que, se não foi possível concluir algum desses objetivos, o procedimento foi alterado para ser concluído antes da sessão de grupo.

\subsubsection{Aplicação das escalas}

Para a coleta dos dados, foram utilizadas 4 escalas para a análise dos dados quantitativos:

- Inventário de Habilidades Sociais para Adolescentes (IHSA): aplicado no começo, no meio e no final da pesquisa, em sessões individuais ou no final da sessão de grupo;

- Group Climate Questionnaire (GCQ): aplicada no final de cada sessão de grupo;

- Goal Attainment Scaling (GAS): construída nas sessões individuais e reformulada entre/ou nas sessões de grupo, considerando as ponderações dos pais;

- Clinical Global Impressions (CGI): enviado para os pais no dia da sessão de grupo, através do Google Formulário.

$\mathrm{Na}$ Tabela 3, está representado o planejamento inicial para cada instrumento e em qual sessão seria aplicado o instrumento. $\mathrm{O}$ " $\mathrm{x}$ " indica a previsão para a coleta do instrumento. 
Tabela 3 - Cronograma do planejamento da coleta de dados durante as 12 sessões de grupo para cada inventário

\begin{tabular}{|c|c|c|c|c|c|c|c|c|c|c|c|c|}
\hline Sessões de grupo & 1 & 2 & 3 & 4 & 5 & 6 & 7 & 8 & 9 & 10 & 11 & 12 \\
\hline $\begin{array}{l}\text { IHSA-Del-Prette - } \\
\text { sessão individual ou grupo }\end{array}$ & $\mathrm{x}$ & & & & & $\mathrm{x}$ & & & & & & $\mathrm{x}$ \\
\hline $\begin{array}{l}\text { CGI (pais) - durante as sessões de } \\
\text { grupo }\end{array}$ & $\mathrm{x}$ & $\mathrm{x}$ & $\mathrm{x}$ & $\mathrm{x}$ & $\mathrm{X}$ & $\mathrm{x}$ & $\mathrm{X}$ & $\mathrm{x}$ & $\mathrm{x}$ & $\mathrm{x}$ & $\mathrm{x}$ & $\mathrm{x}$ \\
\hline GCQ - final de cada sessão de grupo & $\mathrm{x}$ & $\mathrm{x}$ & $\mathrm{x}$ & $\mathrm{x}$ & $\mathrm{x}$ & $\mathrm{x}$ & $\mathrm{x}$ & $\mathrm{x}$ & $\mathrm{x}$ & $\mathrm{x}$ & $\mathrm{x}$ & $\mathrm{x}$ \\
\hline GAS - diariamente, durante a semana & $\mathrm{x}$ & $\mathrm{x}$ & $\mathrm{X}$ & $x$ & $\mathrm{x}$ & $x$ & $\mathrm{x}$ & $\mathrm{x}$ & $\mathrm{x}$ & $\mathrm{x}$ & $x$ & $\mathrm{x}$ \\
\hline
\end{tabular}

Fonte: Elaborada pelo autor.

\subsubsection{Processo da intervenção}

\subsubsection{Início das sessões na modalidade presencial}

As sessões eram planejadas previamente para cada participante, com o objetivo de intervir individualmente no comportamento-alvo (categoria das HS) de cada participante. Por mais que as intervenções fossem individualizadas, elas aconteciam coletivamente no grupo; por exemplo, ao decorrer da sessão, o comportamento-alvo de um participante era civilidade e o outro era assertividade. Os comportamentos-alvo poderiam ser comportamentos mais simples, como contato visual ou mais complexos como ser empático com o colega quando este era prejudicado na sessão.

Essas intervenções aconteciam ao mesmo tempo durante a sessão, e a frequência da possibilidade de treino de cada comportamento era por oportunidade, ou seja, em vez de ter uma quantidade limitada de treino por sessão, ela poderia ocorrer dependendo do terapeutamestre e do coterapeuta.

Como estímulo reforçador daquele comportamento-alvo emitido, os terapeutas tinham diversas possibilidades, como:

a) Fichas de XP (pontos para evolução do personagem): os terapeutas poderiam dar as fichas; no final da sessão, o participante contabilizava a quantidade de pontos que tinha conseguido e somava na ficha do personagem dele;

b) Equipamentos novos: por exemplo, uma espada, armadura, escudo e outros;

c) Bônus nos dados: para diversas ações, era exigido um número que o participante deveria tirar no dado. Então, como reforço, era dado um bônus, que era somado com o número da rolagem; 
d) Feedback dos terapeutas: além dos outros reforçadores, os terapeutas poderiam cumprimentar e parabenizar o participante que emitiu o comportamento-alvo. Por exemplo: "Cara, você mandou muito bem nessa cena!";

e) Feedback dos demais participantes: geralmente, quando o reforçador beneficiava os demais da equipe, os outros também elogiavam. Por exemplo: "Nossa, você mandou muito bem! Ajudou muito...";

f) Algum evento facilitador na história: quando era emitido algum comportamento adequado, às vezes o terapeuta podia mudar a direção do enredo para, justamente, reforçar aquele comportamento adequado. Por exemplo: "Por você ter sido empático com a senhora das poções, ela lhe contou o ponto fatal do monstro que vocês irão enfrentar!";

g) Bônus temporário em alguma habilidade do personagem: os terapeutas podiam dar um bônus de habilidade. Por exemplo, o personagem ganhava um bônus em destreza ou força, dependendo da situação daquele participante;

h) Dinheiro como reforçador generalizado: os personagens podiam ganhar dinheiro dentro do sistema do jogo ao emitir a resposta-alvo na sessão. Esse dinheiro possibilitava inúmeras utilidades para adquirir possibilidades.

Figura 7 - Cards dos equipamentos como armadura, espadas, escudos e outros

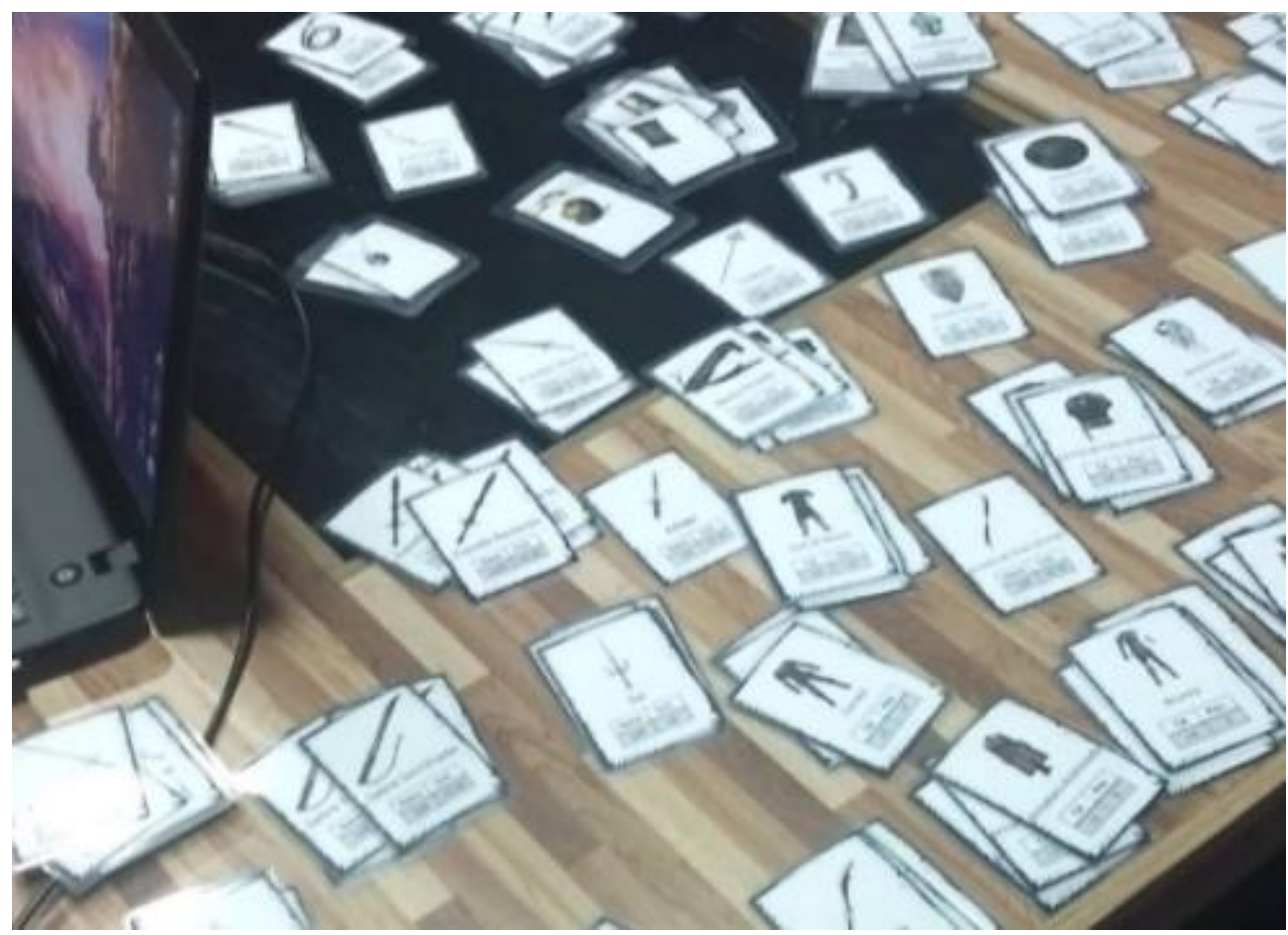

Fonte: $\mathrm{O}$ autor. 
Figura 8 - Foto das fichas de XP, cada uma apresenta um valor diferente

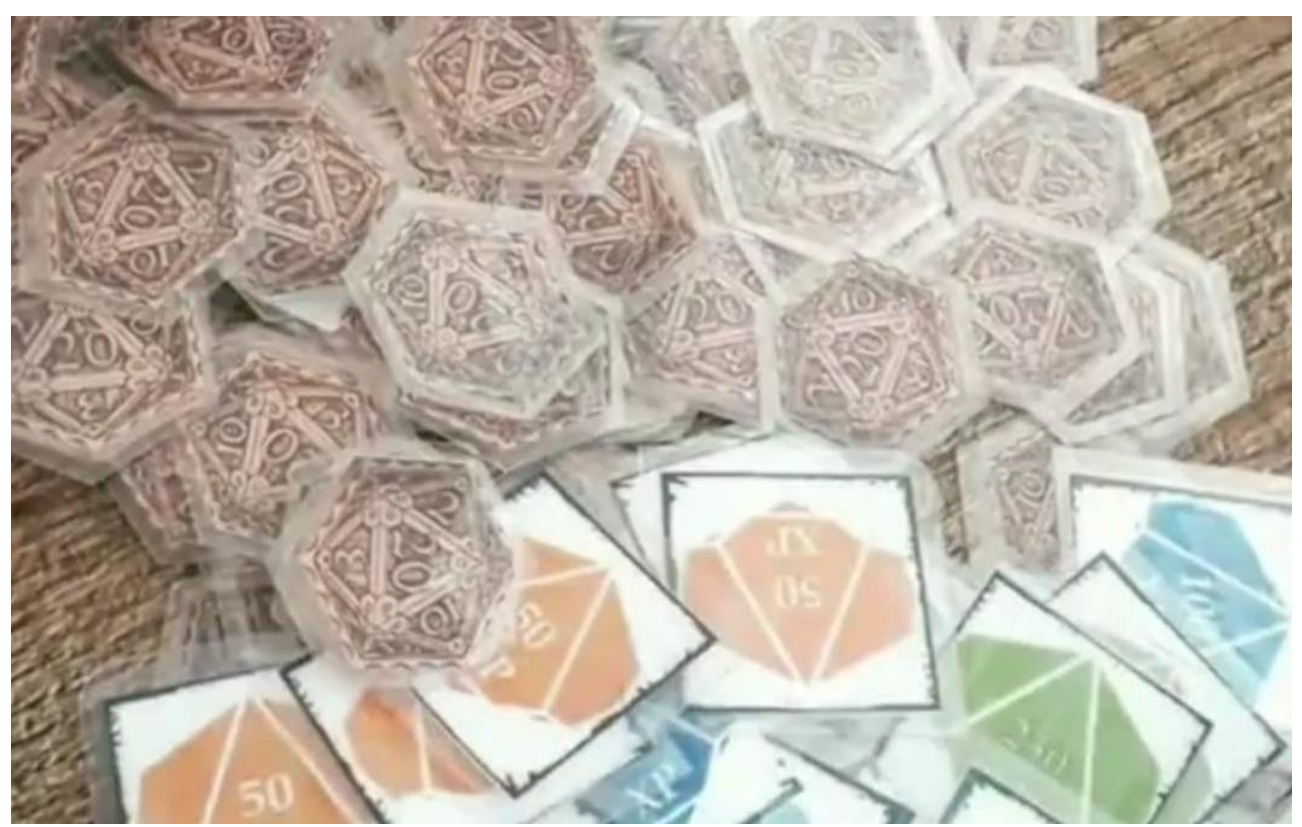

Fonte: $\mathrm{O}$ autor.

Figura 9 - Recorte de uma ficha do personagem de um dos participantes

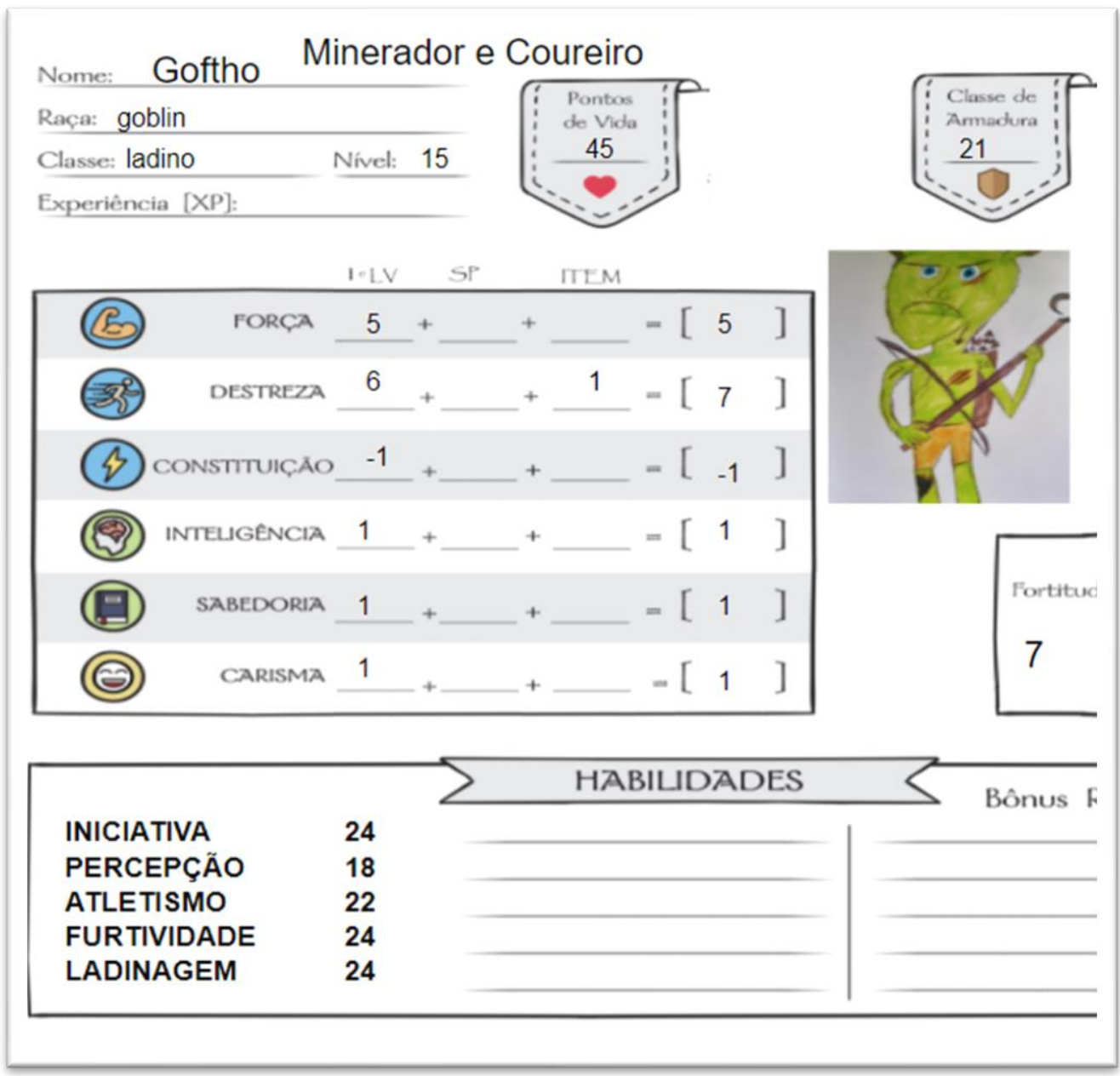

Fonte: $\mathrm{O}$ autor. 
Nas primeiras sessões, para os participantes novos à intervenção, houve a introdução deles no grupo. Geralmente, houve descrição dos personagens, relato do comportamento social do personagem (por exemplo, se era um personagem bravo, introvertido etc.) e um relato da biografia. A maioria dos participantes optou por escrever uma biografia do seu personagem em uma folha que ficava junto à sua ficha, guardadas em pastas individuais, além de desenhos representando o seu personagem (cf. Figura 9).

Como procedimento padrão, nas sessões iniciais de um participante, os participantes novos ganham fichas de XP, para participar da dinâmica do grupo. Como a história do jogo já estava em andamento, esse procedimento facilitava a interação deles. Já para os demais participantes do grupo, o comportamento-alvo de ouvinte também era reforçado, pois esses comportamentos compõem a categoria denominada Comunicação.

Geralmente, a técnica comportamental utilizada na maioria dos treinos foi:

a) Aproximação sucessiva: o terapeuta reforçava gradualmente classes de respostas mais próximas de um comportamento-alvo;

b) Modelagem das respostas: uma classe de resposta é modificada de acordo com a sucessão de critérios de reforço, tornando mais frequente uma resposta-alvo que, antes, era menos frequente ou inexistente;

c) Modelação entre os terapeutas ou participantes: o terapeuta ou outros participantes davam dicas verbais sobre o que deveria ser feito;

d) Encadeamento de respostas entre os participantes: em diversas situações, os terapeutas criavam um encadeamento de respostas entre os participantes para a resolução de um problema. Por exemplo, um participante faz uma ação (conversar com os guardas), enquanto um outro faz uma outra ação. O foco desses tipos de intervenções era a promoção do trabalho em cooperação;

e) Ensaio comportamental: o RPG é, por definição, um jogo de interpretação de papéis, portanto, a maioria dos treinos sempre envolveu a simulação de uma situação para efetuar tal treino. Por exemplo, o mestre podia dar uma situação de um evento e eles o encenavam ou o mestre treinava aquele participante específico para trabalhar algum repertório-alvo.

À medida que a apresentação do comportamento ficasse mais frequente, o nível da dificuldade dos treinos e da aventura aumentavam. Para a avaliação de tal medida, os terapeutas qualificavam o rendimento dos participantes e ajustavam a dificuldade, para evitar extinção do comportamento ou desmotivação com a atividade. 
Por mais que as sessões fossem anteriormente planejadas, com foco em treinar alguma classe de HS específica, ao decorrer das sessões de grupo o mestre-terapeuta e o coterapeuta buscavam identificar alguns comportamentos-alvos que pudessem aparecer durante a sessão. Por exemplo, um dos participantes estava interrompendo os outros durante a sessão, então, no meio da sessão, surgia algum item mágico que deixava o personagem silenciado, no sentido de que, qualquer coisa que ele dissesse, não teria efeito no jogo.

Além desses reforçadores utilizados durante a sessão para contingenciar alguma resposta-alvo, havia outros reforçadores generalizados que estavam além da sessão em si e que tinham um efeito motivacional entre os participantes:

a) Ranking entre todos os participantes, a partir do mais experiente: foi programado, em planilhas de Excel, um sistema que pudesse colocar todos os pontos de XP em esquema de ranking. Quanto mais alto, mais experiente era o personagem;

b) Criação de identidade da guilda: cada grupo constituía uma guilda; logo, eles montavam a apresentação da equipe dele;

c) Criação de um jornal para eles divulgarem notícias: cada grupo tinha a possibilidade de compartilhar histórias e acontecimentos da sessão para informar os outros grupos. O sistema das guildas era um contexto;

d) Criação de um diário das histórias: alguns dos participantes começaram a registrar histórias através da escrita e de desenhos;

e) Participação ativa em sugestões para a história principal da aventura: os participantes podiam sugerir algumas histórias para a guiar todos os grupos;

f) Sistema financeiro: foi criado um sistema de moedas dentro do RPG, ou seja, eles tinham salários, emprestavam dinheiro, podiam ajudar o outro etc.

A coleta de dados qualitativos foi realizada através da análise funcional, sendo o coterapeuta essencial para registro ou anotações sobre as dinâmicas e interações dentro da sessão.

Além desses treinos em sessão, podiam conversar entre si, ou seja, alguns enigmas exigiam conversas entre os participantes de outros grupos, que podiam ser através de participação na sessão, comunicação por WhatsApp ou cartas. 


\subsubsection{Além das sessões presenciais}

Paralelamente aos atendimentos do consultório, os terapeutas montaram intervenções para aumentar a intensidade do treino para além das sessões realizadas dentro do consultório. Para isso, houve uma série de intervenções com objetivo de aumentar a generalização dos ganhos comportamentais treinados em sessão.

a) TC-GAS: no início de cada sessão de grupo, era analisado o rendimento de cada participante individualmente, pelas suas TC-GAS e, em alguns casos, novas metas eram estabelecidas; os pais foram orientados a montarem as tarefas de casa junto com os filhos;

b) Encontros entre os participantes: os terapeutas construíram, junto com os participantes, uma escala de "vontades que o participante tem, mas não tem companhia para fazer". Por exemplo, cada participante respondeu à pergunta: "Em quais atividades fora do consultório que você gostaria de ter companhia?”. Com as respostas, os terapeutas fizeram filipetas com frases temáticas ao RPG. por exemplo: em vez de escrever Exalrode gostaria de ler gibis com alguém, os terapeutas escreviam Exalrode está tentando ler pergaminhos mágicos e precisa de ajuda para compreender as escritas arcanas. Um participante podia ajudar o outro colega, escolhendo a tal tarefa em sessão. Esses encontros entre os participantes intensificaram os encontros entre eles em momentos além dos atendimentos;

c) Eventos grandes além das sessões: para facilitar a generalização dos comportamentos aprendidos, a clínica também realizou eventos maiores, que envolviam todos os clientes da clínica, como ir ao Brasil Game Show, ao Comic Com, Idas a shoppings e parques. Nesses eventos, houve tarefas especiais e, ao realizar interações com as pessoas no local do evento, os participantes ganhavam os reforçadores mencionados anteriormente.

\subsubsection{Servidor do Reino D20 e as sessões online}

A partir do dia 16 de março de 2020, as sessões presenciais foram suspensas, devido à pandemia da COVID-19, o que impactou no planejamento das sessões. Assim, foi utilizada a plataforma Discord para a realização das sessões de grupo e individuais. Popularmente, ela é uma plataforma criada para atender aos usuários de jogos eletrônicos, então, para o público do consultório, foi mais fácil implementar essa ferramenta. 
O Discord permite que o usuário entre em servidores públicos e privados. O servidor público permite a entrada de qualquer usuário, e o servido privado requer um convite dos administradores, tornando o servidor mais seguro para os participantes.

Desse modo, os terapeutas criaram um servidor fechado, denominado Reino D20, onde todos os terapeutas da clínica eram os administradores e os usuários eram necessariamente clientes do consultório.

Uma vez no servidor, ele permite a criação de canais de voz e canais de texto. Os canais de texto são apenas para o envio de mensagens por texto; já os canais de voz permitem a comunicação por voz em tempo real, além da possibilidade de ligar câmera e compartilhar a tela.

Não há limite para criação de canais de voz ou de texto, ou seja, o servidor foi organizado por temas para cada canal de voz e de texto. Assim, os usuários podiam saber qual era o tema para cada canal, podendo identificar o canal de seu interesse. Por exemplo, algum canal onde se discute sobre animes, memes ou eventos do RPG.

Figura 10 - Recorte da tela do servidor online

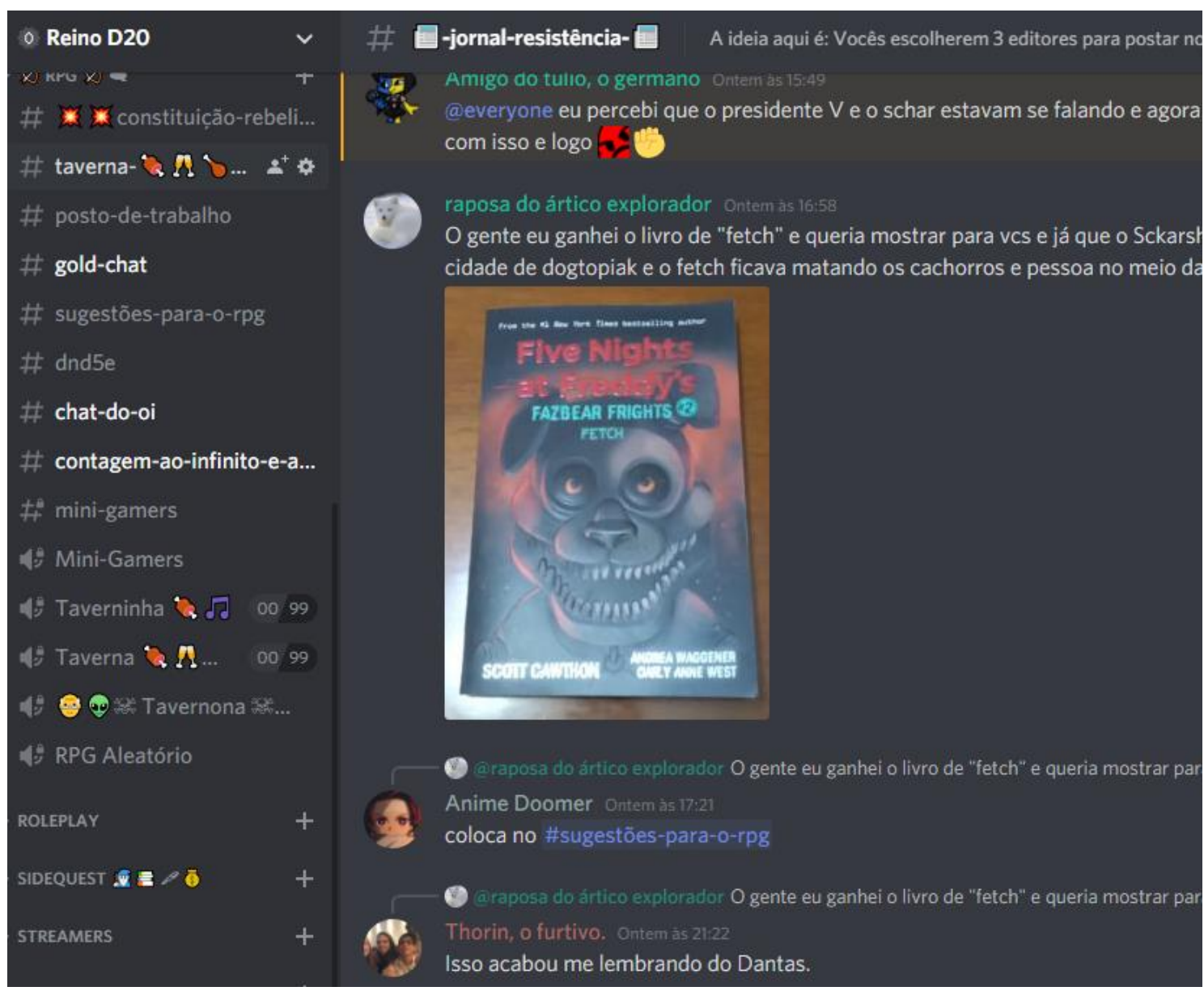

Fonte: O autor. 
Quando os usuários estavam em canais de voz, eles ficavam visíveis para outros usuários, conforme a Figura 11:

Figura 11 - Recorte os canais de voz dentro do servidor

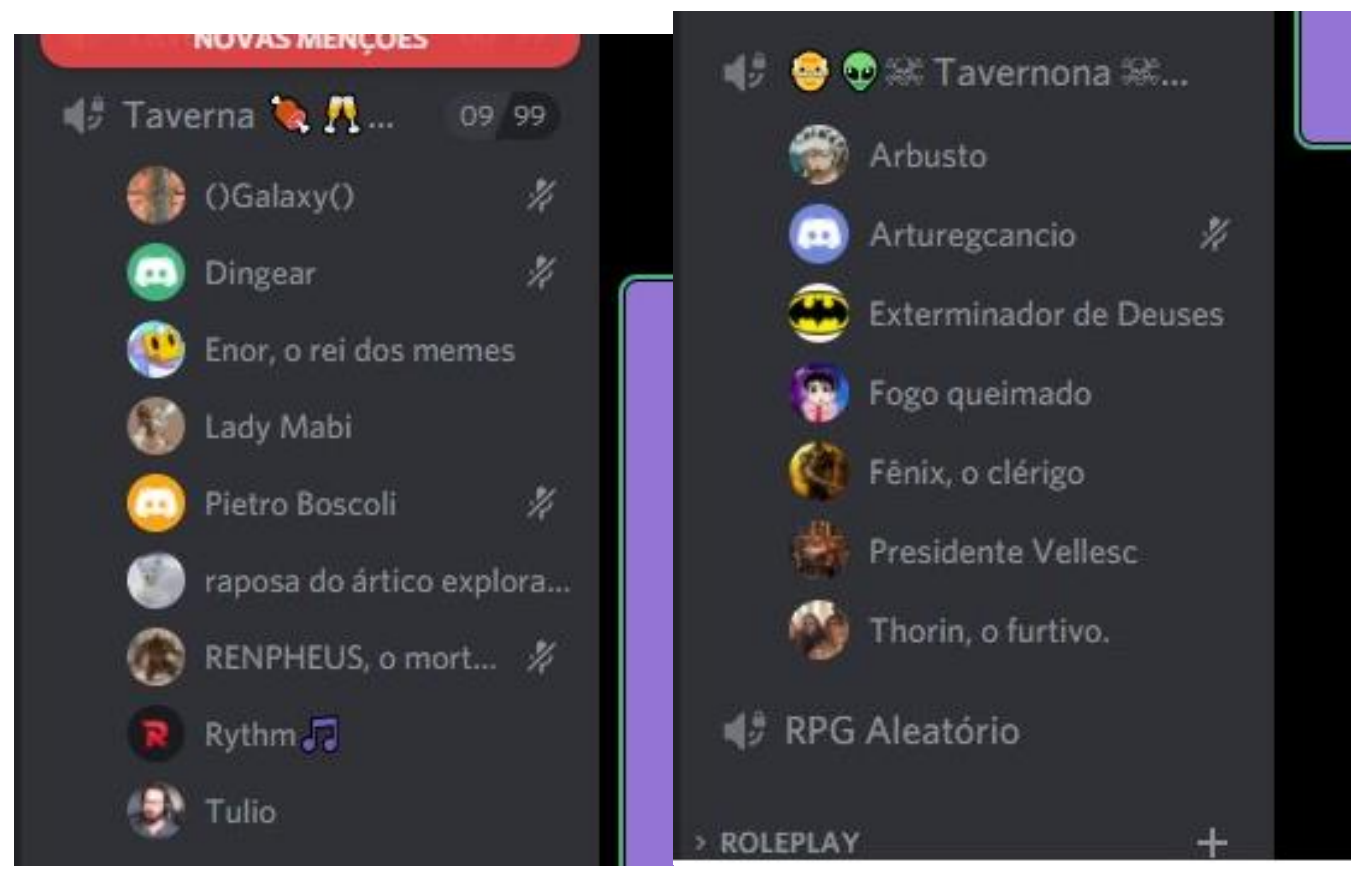

Fonte: $\mathrm{O}$ autor.

Dessa forma, o servidor possibilitou a realização das sessões de grupo e, para facilitar a adesão à plataforma, foram inseridos 14 BOTS, que são robôs que automatizam processos dentro de um servidor. Desta forma, os BOTS permitem uma infinidade de aplicações, pois automatizam processos, tornando o servidor mais atrativo. Por exemplo, os BOTS foram separados em três funções: estimular a interação social, aumentar o valor do RPG e registrar as frequências dos comportamentos sociais.

As funções de cada tipo de BOTS podem ser assim descritas:

a) Estimular as interações sociais: jogos por texto - Gartic, Pokémon -, coleção de cartas de personagens de animes, música em canais de voz, criação de enquete e outros;

b) Aumentar o valor do RPG: dar XP para cada mensagem ou minuto de voz, rolagem de dados, dar nomes de personagens de RPG, consultar regras do RPG, sistema financeiro, outros;

c) Registrar comportamentos sociais: quantificar todas as mensagens enviadas de cada usuários e de cada canal, fazer gráficos e registrar a quantidade de usuários online e offline. 
Figura 12 - BOT disponibiliza cartas de personagens de anime e os usuários podem guardar as cartas para sua coleção

Karuta $\checkmark$ BOT Ontem as $16: 49$

This drop has expired and the cards can no longer be grabbed.
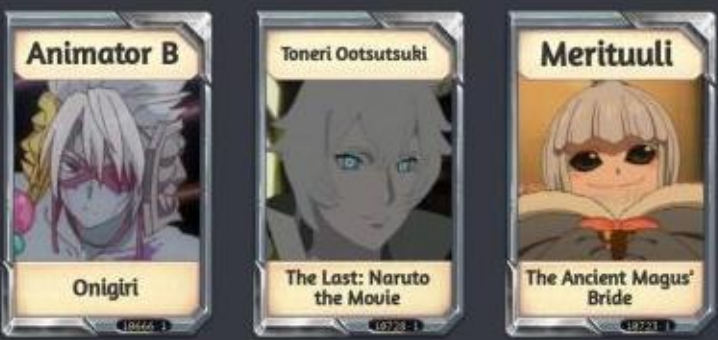

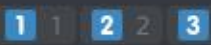

@ Amigo do tulio, o germano took the Toneri Ootsutsuki card wq2z28 ! W

\section{Karuta $>$ BOT}

This drop has expired and the cards can no longer be grabbed.
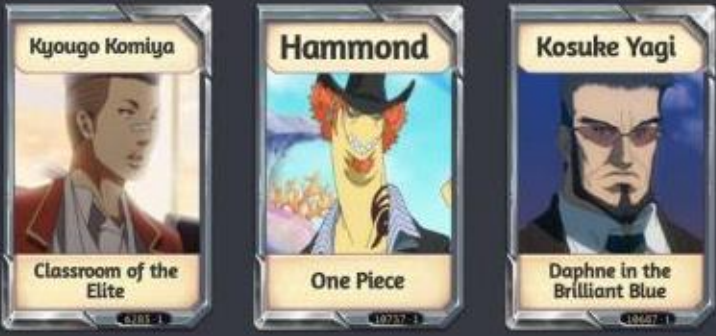

\begin{tabular}{l|l|l|l|l|l|l|l|l|l|l|l|l}
1 & 1 & 2 & 3 & 3
\end{tabular}

Amogos Ontem às 1789

k!drop

Fonte: $\mathrm{O}$ autor.

Figura 13 - Registro da quantidade de mensagem enviada e do tempo conectado em canais de voz com o XP dado para cada usuário

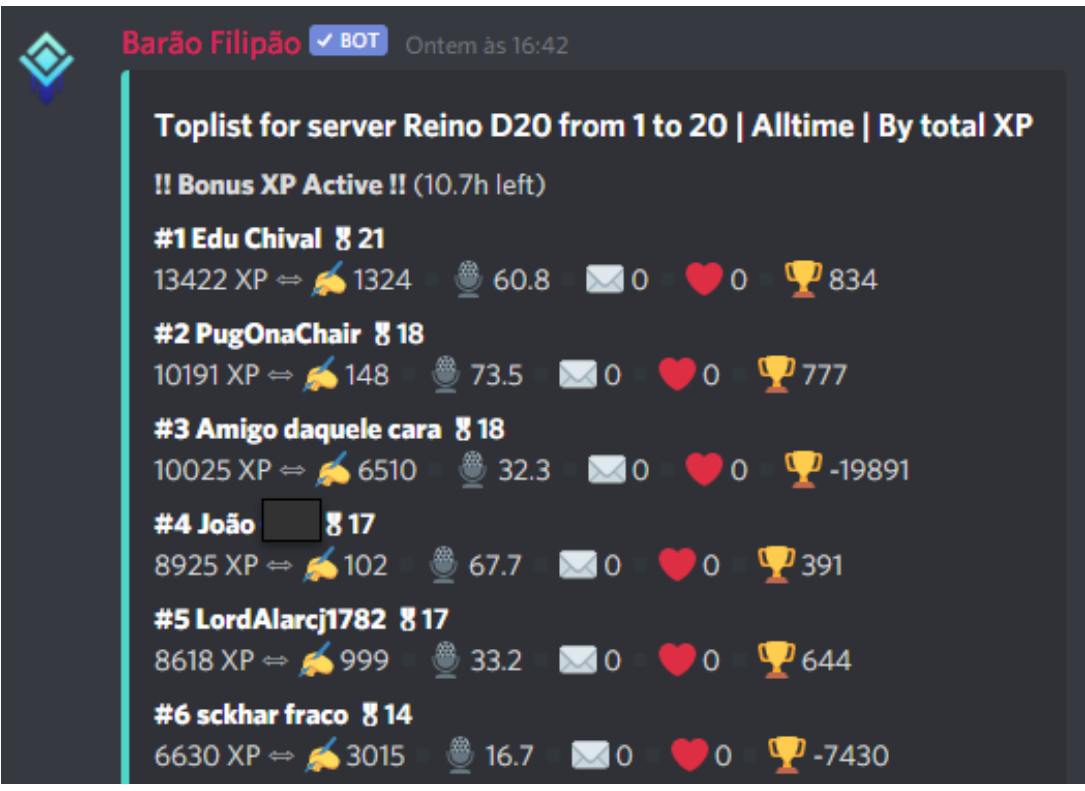

Fonte: $\mathrm{O}$ autor. 
Figura 14 - Registro do número absoluto de mensagens a cada dia, enviada no servidor

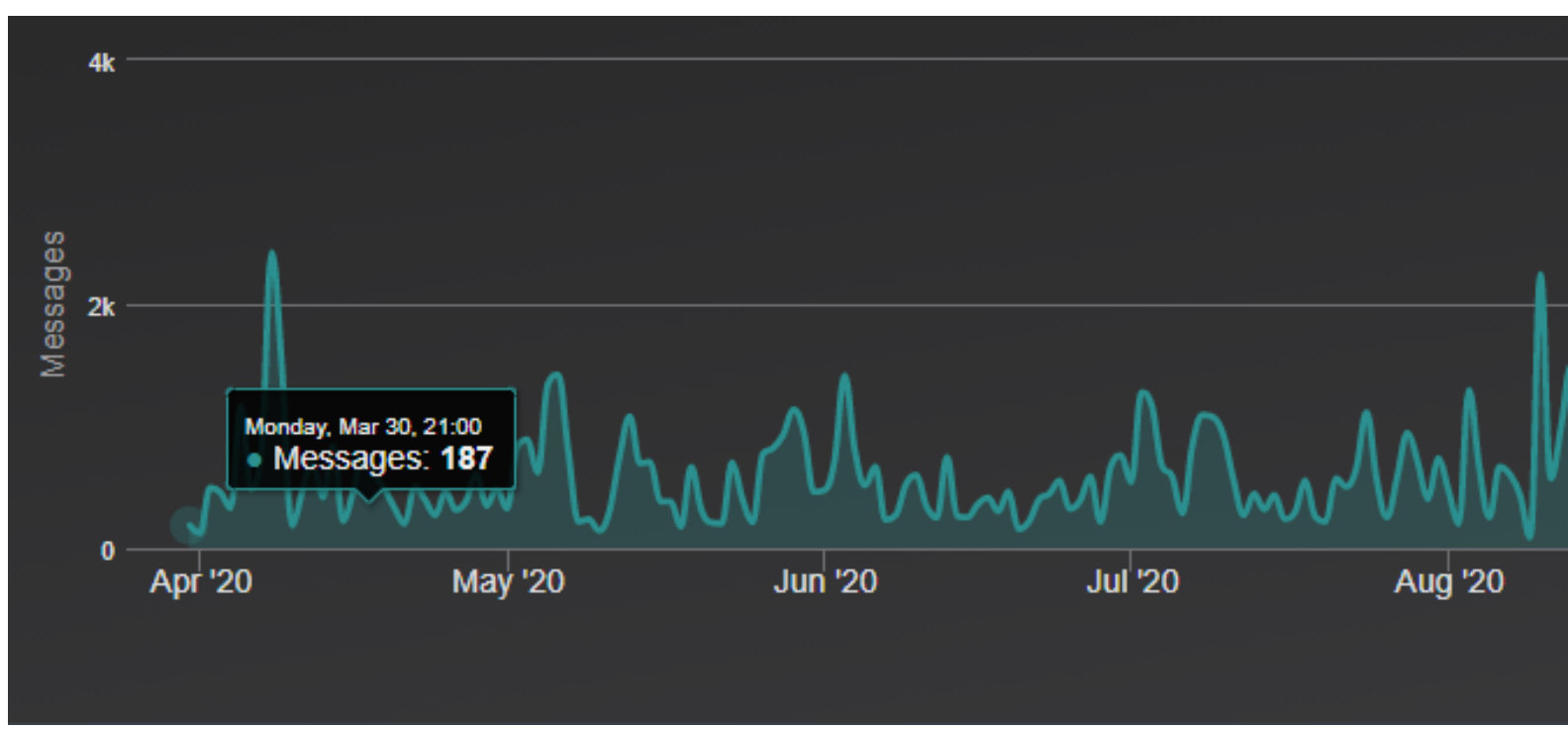

Fonte: $\mathrm{O}$ autor.

Vale ressaltar que, diferentemente do presencial, o servidor ficava ligado continuamente, e os participantes tinham a possibilidade de conversar entre si todos os dias. Como suporte oferecido pela clínica, existem profissionais que acompanham o servidor para, justamente, auxiliar as interações sociais durante a semana.

No momento da sessão de cada grupo, os participantes se conectavam para a realização da sessão; o mestre compartilhava a tela e, semelhante à modalidade presencial, os usuários assistiam ao cenário para realizar os treinos planejados. Algumas vezes, os participantes não ligavam a câmera, por dificuldades de manuseio com a plataforma ou por questões pessoais.

Dessa maneira foram conduzidas as sessões até o encerramento da pesquisa. 


\section{RESULTADOS}

\subsection{ASPECTOS GERAIS}

\subsubsection{Efeitos da pandemia}

O cronograma da pesquisa foi impactado pela pandemia e as sessões presenciais foram interrompidas a partir do dia 16 de março de 2020. A interrupção aconteceu na sétima sessão para sete sujeitos, enquanto para outros foi na quinta sessão. Além da parada, houve um período de pausa nas intervenções até que houvesse maiores informações sobre a duração da quarentena (se voltariam para o presencial ou não) e, também, um período de testes até que se desenvolvesse uma adaptação das sessões dos grupos para modalidade online.

Assim, a coleta de vários instrumentos foi interrompida, sendo realizada apenas a coleta do IHSA do pós-teste. De todas as sessões possíveis de serem realizadas para todos os sujeitos, no total de 162 sessões, houve 81 sessões na modalidade presencial e o restante na modalidade online, ou seja, exatamente $50 \%$ das sessões programadas foram realizadas no contexto virtual.

A Figura 15 apresenta um diagrama demonstrativo de cada sujeito e qual a modalidade de sessão realizada:

Figura 15 - Representação das sessões em diferentes modalidades presencial ou online para cada sujeito da pesquisa

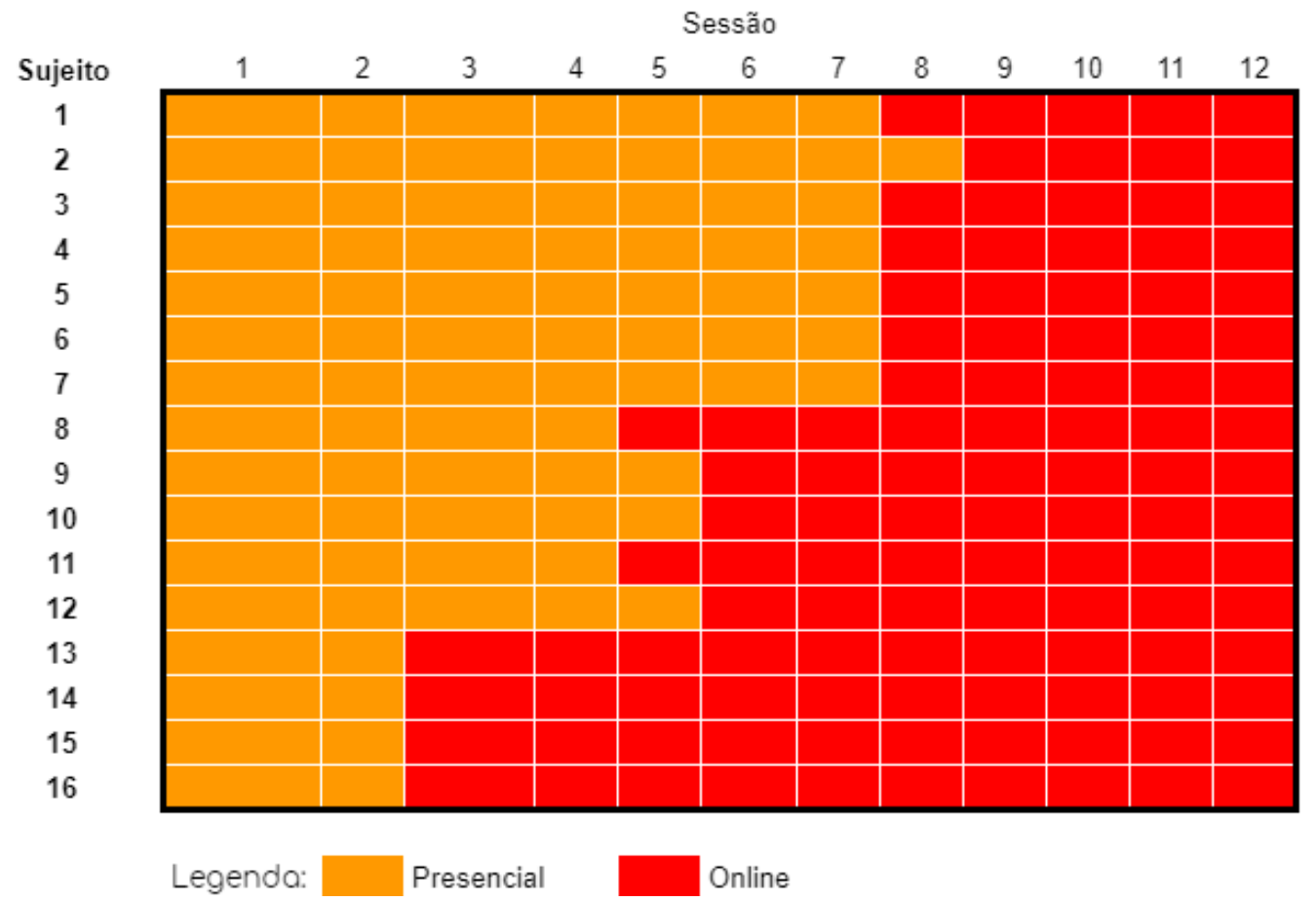

Fonte: $\mathrm{O}$ autor.

* Note-se que o sujeito 2 esteve em 8 sessões, pois ele fez uma sessão em outro grupo. 
Na sequência, os instrumentos interrompidos e a justificativa para a interrupção da coleta:

- GCQ: esses questionários apresentam itens que exige a observação do comportamento dos demais participantes, o que o tornou limitado na modalidade online. Por não ser presencial, algumas vezes os participantes desligavam a câmera, para otimizar a conexão, além de problemas sistemáticos com fones e microfones. Então, devido à mudança do setting terapêutico presencial para o online, houve o encerramento da coleta do instrumento GCQ;

- IHSA: houve a terceira coleta para todos os participantes, mesmo após do início da pandemia, pois, como o instrumento é respondido a partir do autorrelato de situações vividas, é aplicável e válido. A coleta do instrumento ocorreu no primeiro dia e na modalidade presencial para todos os participantes. Alguns participantes tiveram a segunda coleta (a partir da sétima sessão presencial) e todos tiveram a coleta no final, através do Google Formulários;

- CGI: dois motivos levaram à interrupção: (a) mesmo com os pais presentes na maior parte do tempo, o pesquisador optou pelo encerramento da coleta, pela mudança abrupta causada na rotina dos pais. Essa situação poderia enviesar a observação dos pais sobre os filhos; e (b) devido ao item sobre a observação dos pais a respeito da melhora das habilidades sociais dos filhos em outros contextos. A impossibilidade de realizar essa observação poderia prejudicar a análise dos pais;

- TC-GAS: a coleta foi interrompida, pois as tarefas dadas pelos responsáveis geralmente atribuíam outros comportamentos fora do contexto domiciliar, ou seja, eram exigidos alguns comportamentos no contexto escolar e tarefas sociais em outros contextos. Por variar o setting da sessão, a coleta também foi interrompida.

Para analisar o desempenho dos grupos, a análise constituiu-se em tabulação e análise dos dados das diferentes escalas: IHSA, GCQ, TC-GAS e CGI. Para facilitar a compreensão dos dados coletados, foi criado um diagrama para explicitar o momento das coletas de IHSA, GCQ, CGI e TC-GAS. Vale lembrar que a coleta do GCQ ocorreu junto com CGI e TC. 
Figura 16 - Representação da coleta dos instrumentos IHSA e GCQ para cada participante da pesquisa

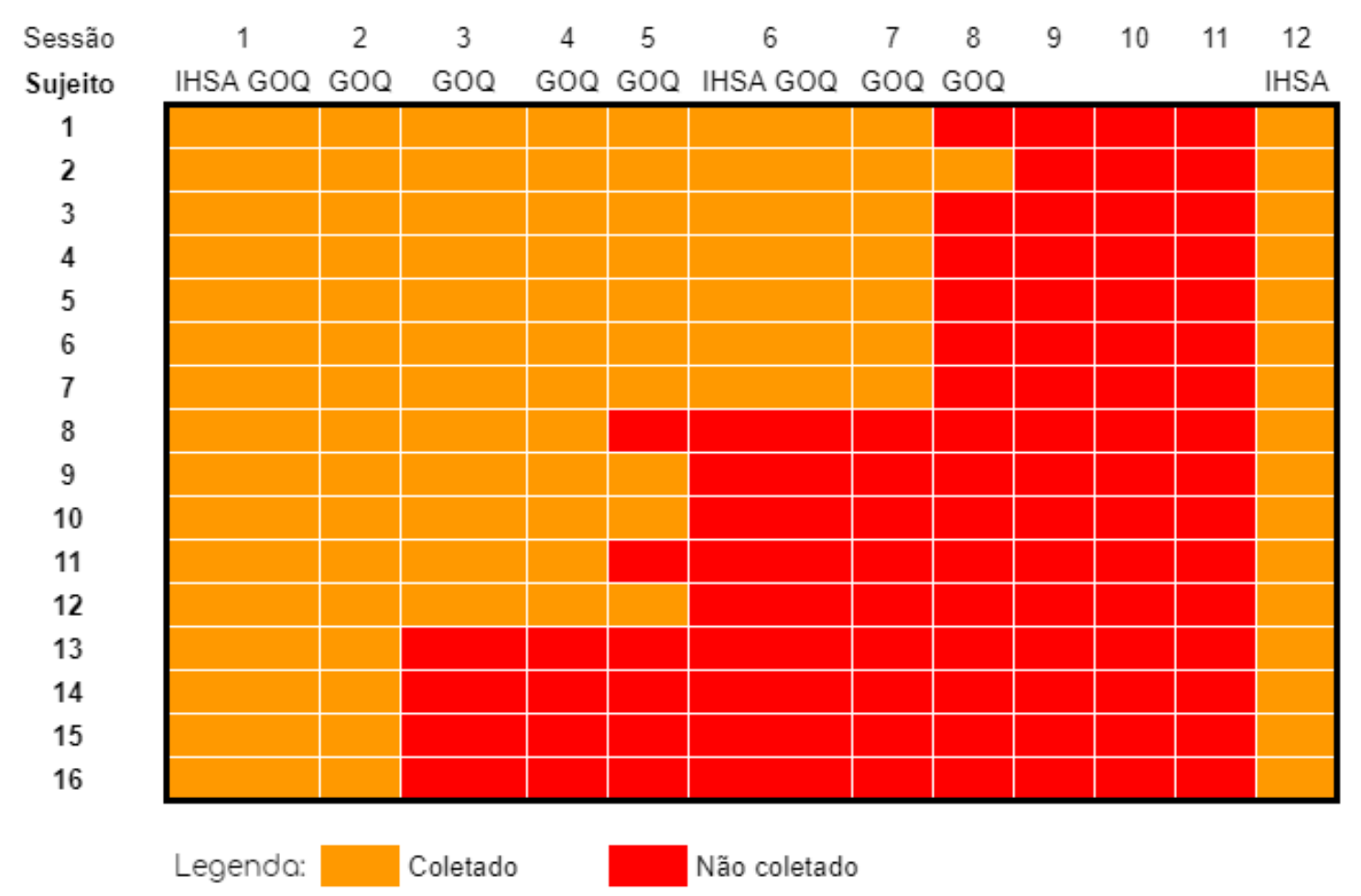

Fonte: $\mathrm{O}$ autor.

\subsection{IHSA PARA OS SETE SUJEITOS E A AMOSTRA TODA}

Neste item, os dados foram analisados separadamente, em dois grupos e, por fim, a discussão sobre os resultados. Devido à pandemia, os resultados serão divididos e apresentados em dois subtítulos.

\section{1) Os sete sujeitos}

De toda a amostra - 16 participantes, ao todo -, sete sujeitos realizaram seis ou sete sessões presenciais no primeiro e no segundo teste do IHSA, ou seja, a comparação entre esses dois testes poderá mostrar se as sessões presenciais tiveram algum impacto no teste.

Para esse primeiro teste, foi excluído o sujeito 7, pois, por se tratar de TEA, no final do segundo teste, o experimentador fez algumas perguntas sobre a sessão. Esse sujeito teve uma sessão de maior dificuldade no jogo, admitiu ter ficado nervoso por não ter recebido as recompensas desejadas na sessão do dia do teste e, então, preencheu o IHSA relatando que estava "frustrado". Logo, ele foi considerado como um dado aberrante ou outlier.

Sobre o teste IHSA, ele avalia em escore total e mais 6 categorias (F1 - Empatia, F2 Autocontrole, F3 - Civilidade, F4 - Assertividade, F5 - Abordagem afetiva, F6 - Desenvoltura 
social). Todos esses itens são separados em frequência e dificuldade. Quanto maior a pontuação no quesito frequência e menor na dificuldade, mais adequado é o comportamento social, logo, quando é menor a frequência e maior a dificuldade, vice-versa.

Para todas as categorias do IHSA, houve aumento da frequência categorias do teste e uma diminuição da dificuldade; não houve diferença significativamente para todas as categorias $(\mathrm{p}<0,05)$.

Foi utilizado o teste de Friedman, que é um teste para amostra pareada e não paramétrico para análise da avaliação de 3 momentos. Se houvesse algum resultado com $p<0,05$, seria utilizado um teste post-hoc para verificar em qual momento que aconteceu a diferença significativa.

A seguir, a tabela com os dados do IHSA com os 6 sujeitos da pesquisa:

Tabela 4 - Média, desvio-padrão, variância e nível de significância do escore total e as seis categorias da frequência e dificuldade para os 6 sujeitos da pesquisa nos 3 diferentes momentos da pesquisa pré (Ava 1), meio (Ava 2) e pós-intervenção (Ava 3)

\begin{tabular}{|c|c|c|c|c|c|c|c|c|c|}
\hline \multirow[b]{2}{*}{ Tipo } & \multirow[b]{2}{*}{ Categoria } & \multicolumn{2}{|c|}{ Ava 1} & \multicolumn{2}{|c|}{ Ava2 } & \multicolumn{2}{|c|}{ Ava 3} & \multirow[b]{2}{*}{$\mathrm{X} 2$} & \multirow[b]{2}{*}{$\mathbf{p}$} \\
\hline & & Média & SD & Média & SD & Média & SD & & \\
\hline \multirow{7}{*}{ Frequência } & Escore total & 86,33 & 28,23 & 98,67 & 25,23 & 87,33 & 48,05 & 1,33 & 0,51 \\
\hline & Empatia & 22 & 9,01 & 22,5 & 8,96 & 18,83 & 10,61 & 2,33 & 0,31 \\
\hline & Autocontrole & 11 & 6,32 & 16,5 & 6,32 & 15,33 & 9,29 & 2,33 & 0,31 \\
\hline & Civilidade & 17,5 & 6,06 & 18,83 & 5,88 & 16 & 9,08 & 1,52 & 0,47 \\
\hline & Assertividade & 13,83 & 4,45 & 17,83 & 5,98 & 17,17 & 8,38 & 2,17 & 0,34 \\
\hline & Abordagem afetiva & 11,17 & 4,22 & 12 & 4,82 & 10,83 & 7,63 & 1 & 0,61 \\
\hline & Desen. Social & 10,83 & 4,58 & 11 & 3,58 & 9,17 & 7,52 & 1,33 & 0,51 \\
\hline \multirow{7}{*}{ Dificuldade } & Escore Total & 60 & 24,27 & 38,5 & 19,31 & 48 & 33,53 & 4,96 & 0,08 \\
\hline & Empatia & 16 & 12,31 & 7 & 4,73 & 10,17 & 8,64 & 1,65 & 0,44 \\
\hline & Autocontrole & 13 & 4,299 & 10,83 & 5,74 & 14,5 & 8,69 & 1,45 & 0,48 \\
\hline & Civilidade & 9,33 & 5,2 & 4 & 3,58 & 4,33 & 4,46 & 2,17 & 0,34 \\
\hline & Assertividade & 7,67 & 4,93 & 5,83 & 3,6 & 4,33 & 4,18 & 0,09 & 0,96 \\
\hline & Abordagem afetiva & 6,17 & 2,14 & 5,5 & 3,21 & 8,67 & 6,09 & 1,65 & 0,44 \\
\hline & Desen. Social & 7,83 & 4,02 & 5,33 & 3,78 & 6 & 4,73 & 0,61 & 0,74 \\
\hline
\end{tabular}

Fonte: Elaborada pelo autor.

Para os gráficos dos resultados dos escores totais de frequência e dificuldade, os resultados mostraram que a média da frequência, inicialmente, subiu de 86,33 para 98,67 e, depois, caiu para 87,33. No item da dificuldade, houve uma diminuição de 60 para 38,50 e um 
aumento para 48. Quanto ao desvio-padrão, os dados para frequência e dificuldade apresentaram maior desvio na terceira avaliação.

São apresentados os gráficos do escore total e de cada categoria:

Figura 17 - Escore total da frequência e da dificuldade do IHSA ao longo das três avaliações pré, meio e pós-intervenção, e a indicação sobre a modalidade de atendimento da sessão entre os testes
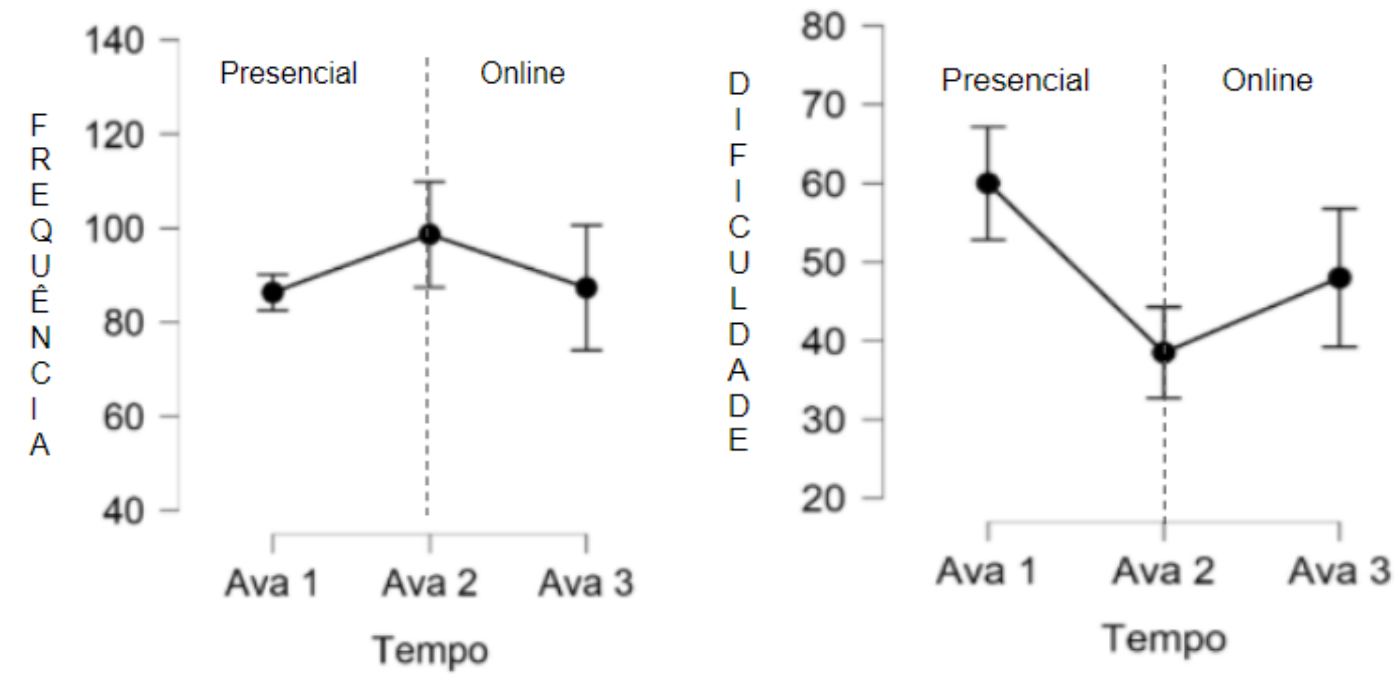

Fonte: Elaborada pelo autor.

É notável que, após seis ou sete sessões de intervenção presencial em grupo, houve um aumento da frequência no escore sobre comportamentos desejáveis nos itens de autorrelato. No aspecto da dificuldade em realizar tal comportamento adequado, houve diminuição no autorrelato dos comportamentos adequados.

Devido à pandemia, as demais sessões realizadas a partir da sexta sessão foram na modalidade online. A média da frequência entre a segunda e a terceira avaliação diminuiu, e a dificuldade aumentou.

Observando os gráficos (Figura 18), nota-se que o escore em todas as categorias de frequência aumentou e a dificuldade diminuiu, mesmo não havendo diferença estatisticamente significativa. Destacam-se o escore da frequência na categoria autocontrole, que apresentou maior variação, e o quesito dificuldade, em que houve maior diferença na categoria empatia e civilidade.

Outro detalhe interessante é que, do Ava2 para Ava3, houve piora em todos os escores, exceto para categoria Dificuldade - Assertividade, isto é, diminuição da frequência e aumento da dificuldade em todas as categorias. 
Figura 18 - Escore de frequência e dificuldade para todas as categorias do IHSA para os seis sujeitos no pré, meio e pós-teste

F1 - Empatia

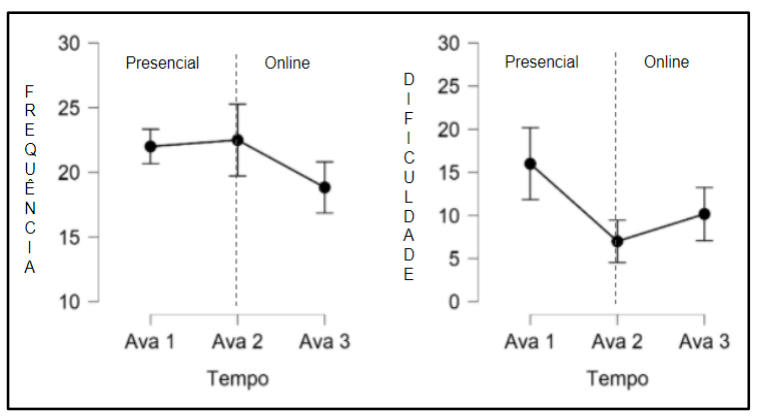

F3 - Civilidade

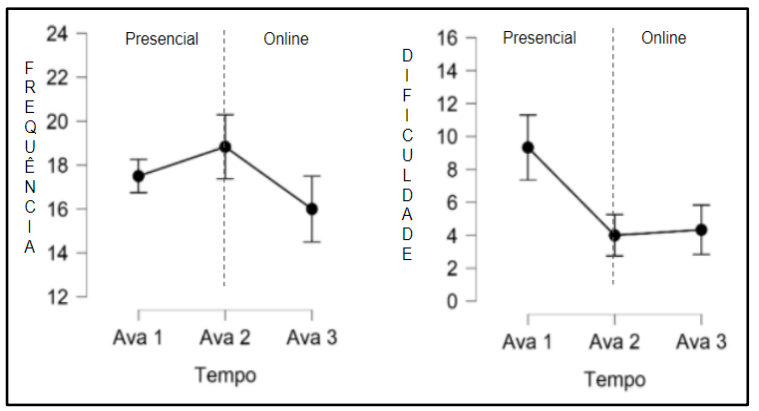

F5 - Abordagem afetiva

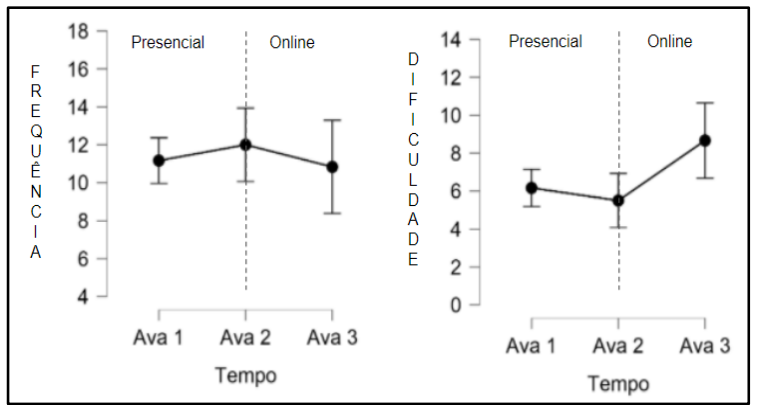

Fonte: Elaborada pelo autor.
F2 - Autocontrole

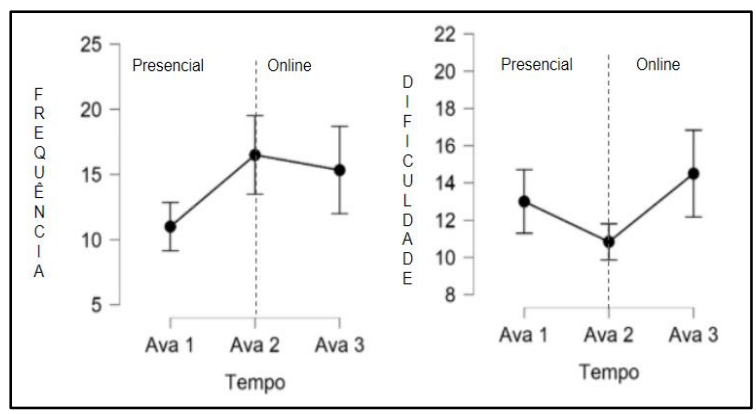

F4 - Assertividade

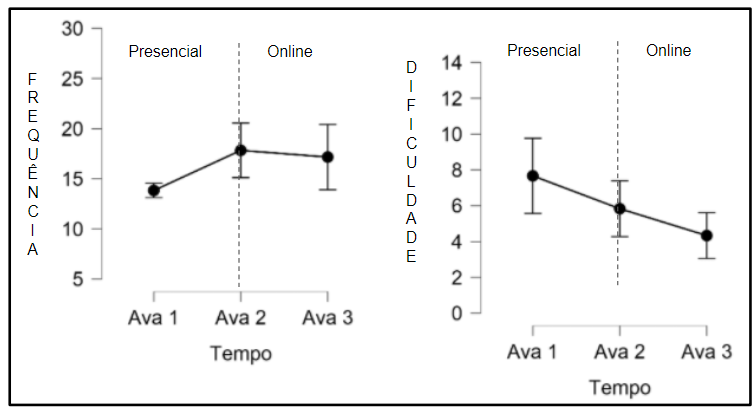

F6 - Desenvoltura social

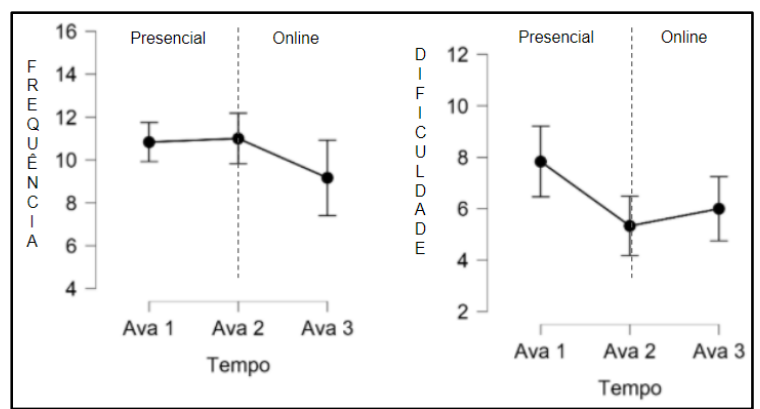

\section{2) Resultados para os 16 sujeitos}

Com o objetivo de analisar os efeitos da intervenção para os 16 participantes da pesquisa, foram analisadas e comparadas todas as categorias do IHSA. Vale ressaltar que 7 sujeitos da amostra tiveram a metade das sessões programadas na modalidade online. Os outros 9 tiveram entre 2 e 5 sessões presenciais, e o restante das sessões foram online.

Mesmo assim, foi realizada a comparação entre pré (Ava 1) e pós-intervenção (Ava 3) para todos os sujeitos. Nota-se que, em geral, o escore sobre a frequência dos comportamentos adequados diminuiu e a dificuldade aumentou.

A Tabela 5 analisa dois momentos de teste: 
Tabela 5 - Teste de Wilcoxon pareado, média e desvio-padrão de cada categoria para frequência e dificuldades nos 2 momentos de teste (pré e pós) com os 16 sujeitos da pesquisa

\begin{tabular}{c|c|cccccc}
\multicolumn{1}{c}{} & \multicolumn{7}{c}{ Ava 1 Ava 3 } \\
\hline Tipo & Categoria & Média & SD & Média & SD & W & p \\
\hline \multirow{5}{*}{ Frequência } & Escore total & 79.25 & 27.54 & 77.19 & 34.52 & 65.00 & 0.80 \\
& Empatia & 18.88 & 7.55 & 17.19 & 9.10 & 84.00 & 0.42 \\
& Autocontrole & 14.19 & 6.63 & 14.63 & 6.72 & 67.00 & 0.98 \\
& Civilidade & 16.06 & 4.33 & 14.19 & 6.18 & 77.00 & $0.03^{*}$ \\
& Assertividade & 13.13 & 6.63 & 14.44 & 7.47 & 49.00 & 0.85 \\
& Abordagem afetiva & 7.50 & 4.87 & 7.63 & 6.02 & 59.50 & 1.00 \\
& Desen. Social & 9.50 & 5.34 & 9.13 & 5.38 & 65.50 & 0.78 \\
\hline \multirow{5}{*}{ Dificuldade } & Escore Total & 51.38 & 22.69 & 52.75 & 26.91 & 47.00 & 0.48 \\
& Empatia & 13.50 & 8.99 & 11.63 & 6.59 & 72.00 & 0.86 \\
& Autocontrole & 10.56 & 4.66 & 12.63 & 6.72 & 38.00 & 0.22 \\
& Civilidade & 5.81 & 5.26 & 5.56 & 4.46 & 59.00 & 0.98 \\
& Assertividade & 6.75 & 5.47 & 5.88 & 4.49 & 54.50 & 0.92 \\
& Abordagem afetiva & 8.44 & 3.56 & 10.56 & 4.82 & 16.50 & $0.03 *$ \\
& Desen. Social & 6.31 & 3.93 & 6.50 & 3.95 & 43.00 & 0.57 \\
\hline
\end{tabular}

Fonte: Elaborada pelo autor.

* Diferenças significativas foram encontradas para Frequência/Civilidade e Dificuldade/Abordagem afetiva.

Não houve diferença significativa para todos as categorias comparadas, exceto para frequência do F3 (Civilidade) e dificuldade do F5 (Abordagem afetiva).

Analisando os dados de cada categoria, nota-se que, ao contrário dos resultados com os 6 sujeitos, houve maior dispersão de dados. Ao observar a frequência de cada categoria, algumas delas apresentaram aumento, estagnação e diminuição na comparação com Ava3, o que não aconteceu com os resultados dos 6 sujeitos. Percebeu-se que houve diminuição significativa da frequência da categoria Civilidade.

No quesito Dificuldade, o mesmo padrão de maior dispersão também ocorreu. Em cada categoria, houve aumento, estagnação ou diminuição. Na categoria Abordagem Afetiva, a dificuldade foi maior no Ava3, o que representa uma piora.

\subsection{GCQ PARA OS CINCOS GRUPOS}

Ao contrário da aplicação de uma pré e pós-intervenção, que é comum para a maioria das pesquisas clínicas, o objetivo do GOQ é ser uma aplicação para avaliação do processo clínico, ou seja, nesse caso, sobre o clima das sessões no decorrer do tempo. 
Vale frisar que, para a apresentação dos dados, a amostra será dividida em cada um dos grupos terapêuticos. Para cada grupo foi realizada uma análise da média de cada medida e o intervalo da variabilidade de cada dado.

Figura 19 - Escore de cada grupo do instrumento GCQ e o intervalo de variância de cada categoria de engajamento, conflito e esquiva em todas as sessões
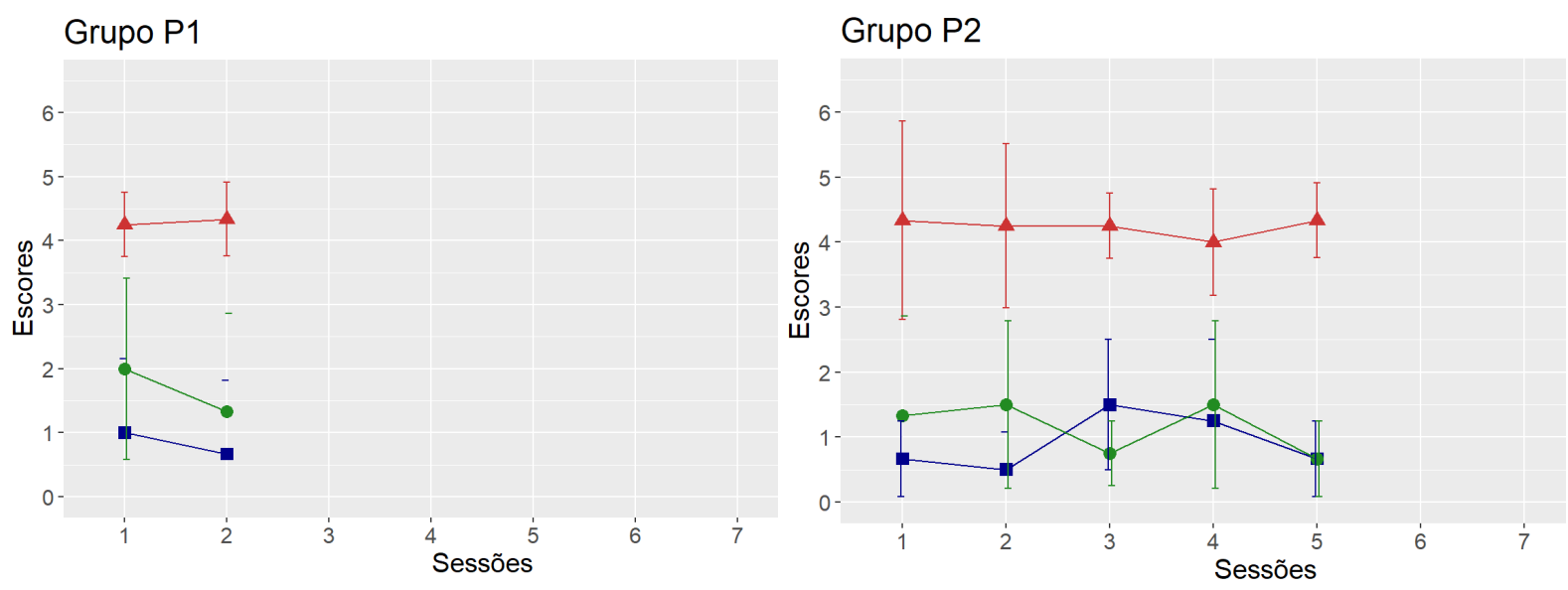

\section{Grupo P3}

\section{Grupo P4}
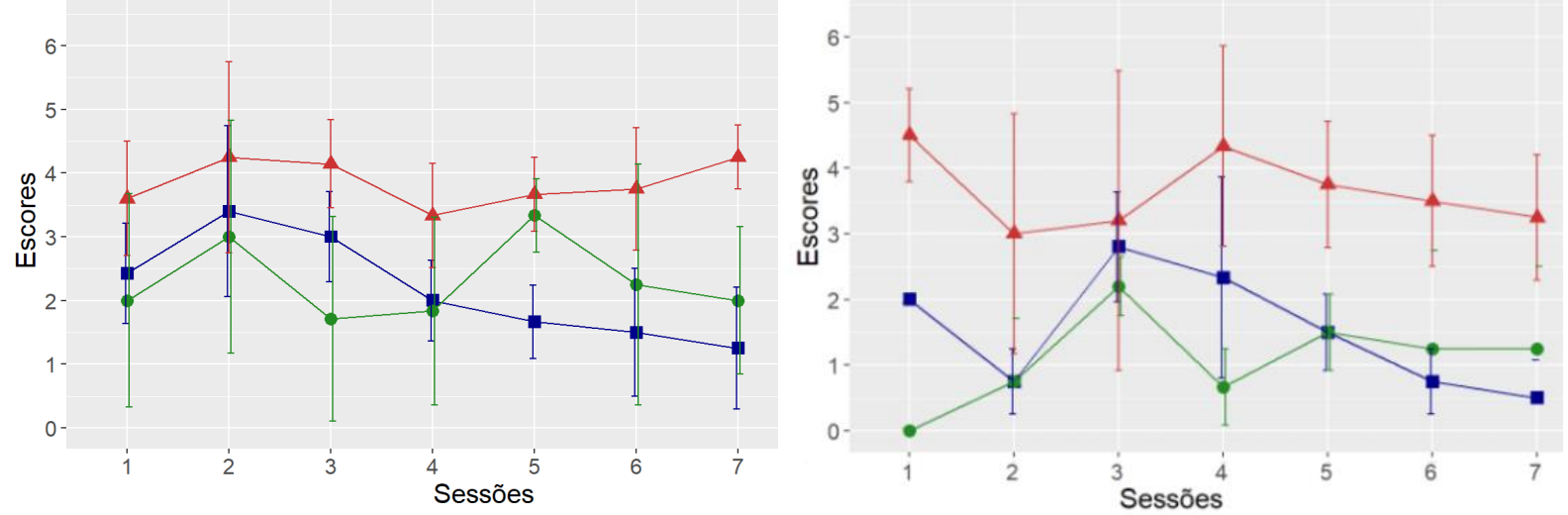

Grupo P8

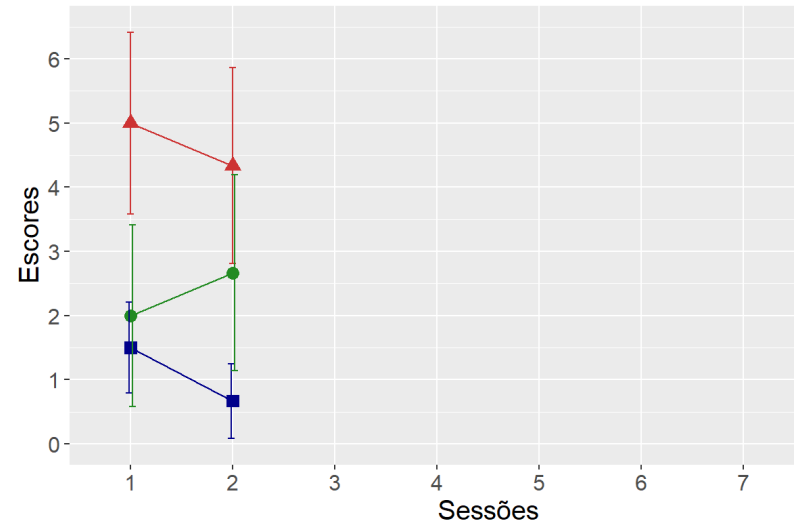

Fonte: Elaborada pelo autor. 
Sobre os grupos P1 e P8, a coleta teve apenas duas sessões, pois os sujeitos desses grupos fizeram aniversário no mês de novembro e entraram na faixa etária adequada para a aplicação do teste. Como foram poucas sessões, esses grupos não foram analisados.

Sobre o grupo P3, o perfil psicológico é predominantemente TEA, o que, em algumas sessões mais tensas, apresentou maior desregulação emocional e maiores discussões entre os membros. A variação das categorias Engajamento foi de 4,3 até 3,3; Conflito de 1,7 até 4,0; e Esquiva de 1,8 até 3,3. Dentre os grupos analisados, foi o que apresentou maior variação e menor diferenças entre as subescalas.

O grupo P4 apresentou maior variação de Engajamento, em comparação com os demais grupos, de 4,5 até 3,0; Conflito variou de 0,8 até 2,8; e Esquiva foi de 0 até 2,2.

Sobre o grupo P2, observa-se uma maior padronização e estabilidade no processo. $\mathrm{O}$ item Engajamento apresenta uma oscilação menor, entre 4,3 e 3,8. Já o item Esquiva oscila de 1,8 até 0,8; e Conflito, de 0,7 até 1,2. Como se trata de um grupo de neurotípicos, talvez haja um padrão das sessões: Engajamento em torno de 4,0 e Conflito/Esquiva abaixo de 2,0.

\subsection{CGI DE TODOS OS PAIS}

Durante a intervenção, foi enviado aos pais dos participantes, via Google Formulários, o questionário sobre a percepção dos responsáveis a respeito da gravidade e do progresso das Habilidades Sociais (HS) e Atividade Vida Diária (AVD) ao longo das semanas.

A Tabela 6 sintetiza a taxa de resposta do questionário enviado para todos os responsáveis dos participantes dos grupos.

Tabela 6 - Taxa de respostas dos pais dos participantes, agrupados pelos grupos terapêuticos, e o total das mensagens enviadas/respondidas a partir de 25/10/2019 até 13/03/2020

\begin{tabular}{ccc}
\hline Grupos & Número de envios & $\begin{array}{c}\text { Número e Porcentagem } \\
\text { de respostas }\end{array}$ \\
\hline P1 & 24 & $3(12,5 \%)$ \\
P2 & 24 & $4(16,6 \%)$ \\
P3 & 30 & $6(20 \%)$ \\
P4 & 30 & $7(23,3 \%)$ \\
P8 & 6 & $2(33,3 \%)$ \\
Total & 114 & $22(19,3 \%)$ \\
\hline
\end{tabular}

Fonte: Elaborada pelo autor. 
É importante ressaltar que a taxa de respostas dos pais é $19,3 \%$ e que, portanto, a próxima análise é um recorte da percepção dos pais sobre o tratamento e quadro clínico.

Outro dado analisado até o momento é a distribuição das respostas dos pais sobre a severidade do quadro clínico e a melhora desses sintomas ao longo do tratamento. Os dados foram tabulados e comparados, para facilitar o entendimento da percepção dos pais sobre o tratamento.

O objetivo da Figura 20 é apresentar uma comparação entre a percepção dos pais sobre a gravidade dos sintomas. Observa-se que a diferença das respostas é pequena (diferença de 23 respostas no item grave, leve e muito leve).

Figura 20 - Frequência de resposta dos pais sobre a severidade da queixa à respeito dos AVD e HS dos filhos 15

AVD HS

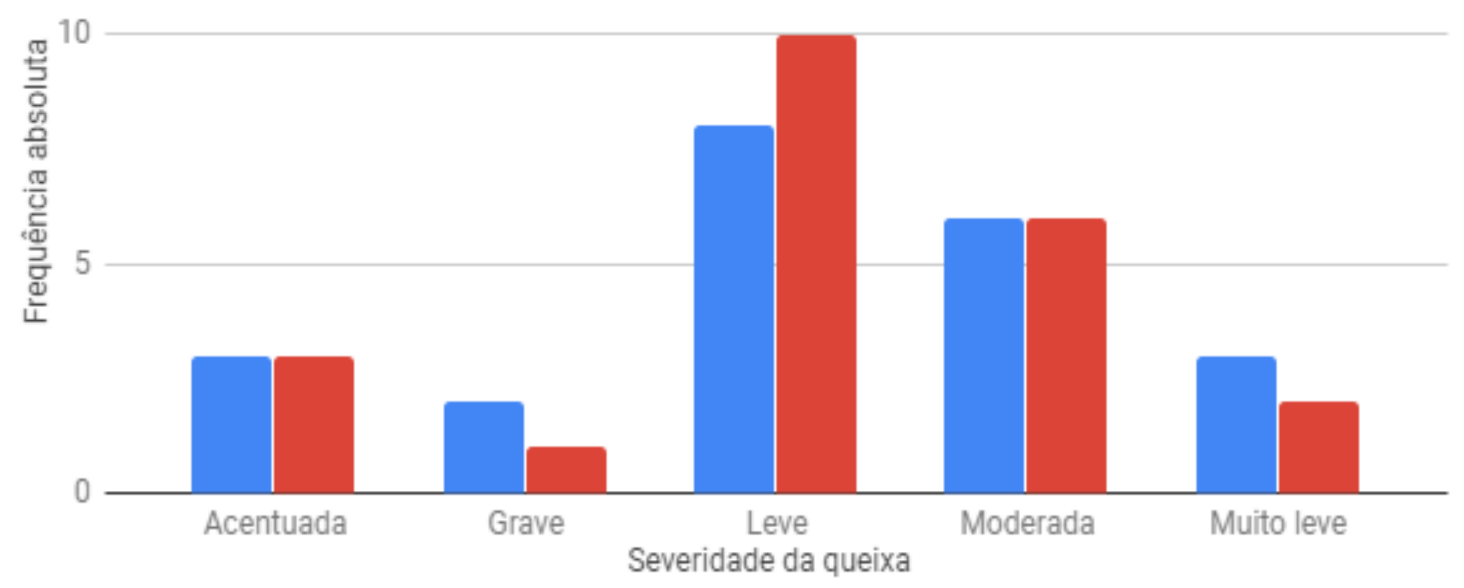

Fonte: Elaborada pelo autor.

Já na Figura 21, nota-se um padrão diferente. O item avaliado é a melhora do participante, ou seja, se os pais perceberam alguma alteração em relação à semana anterior. Percebe-se que repostas como "Sem alteração" foram mais frequentes para AVD e maior número de resposta para "Levemente melhor" no item HS. Esse dado sugere que os pais estão mais sensíveis com os ganhos sociais do que para os AVDs. 
Figura 21 - Frequência de resposta dos pais sobre a avaliação do processo terapêutico a respeito de AVD e HS dos filhos

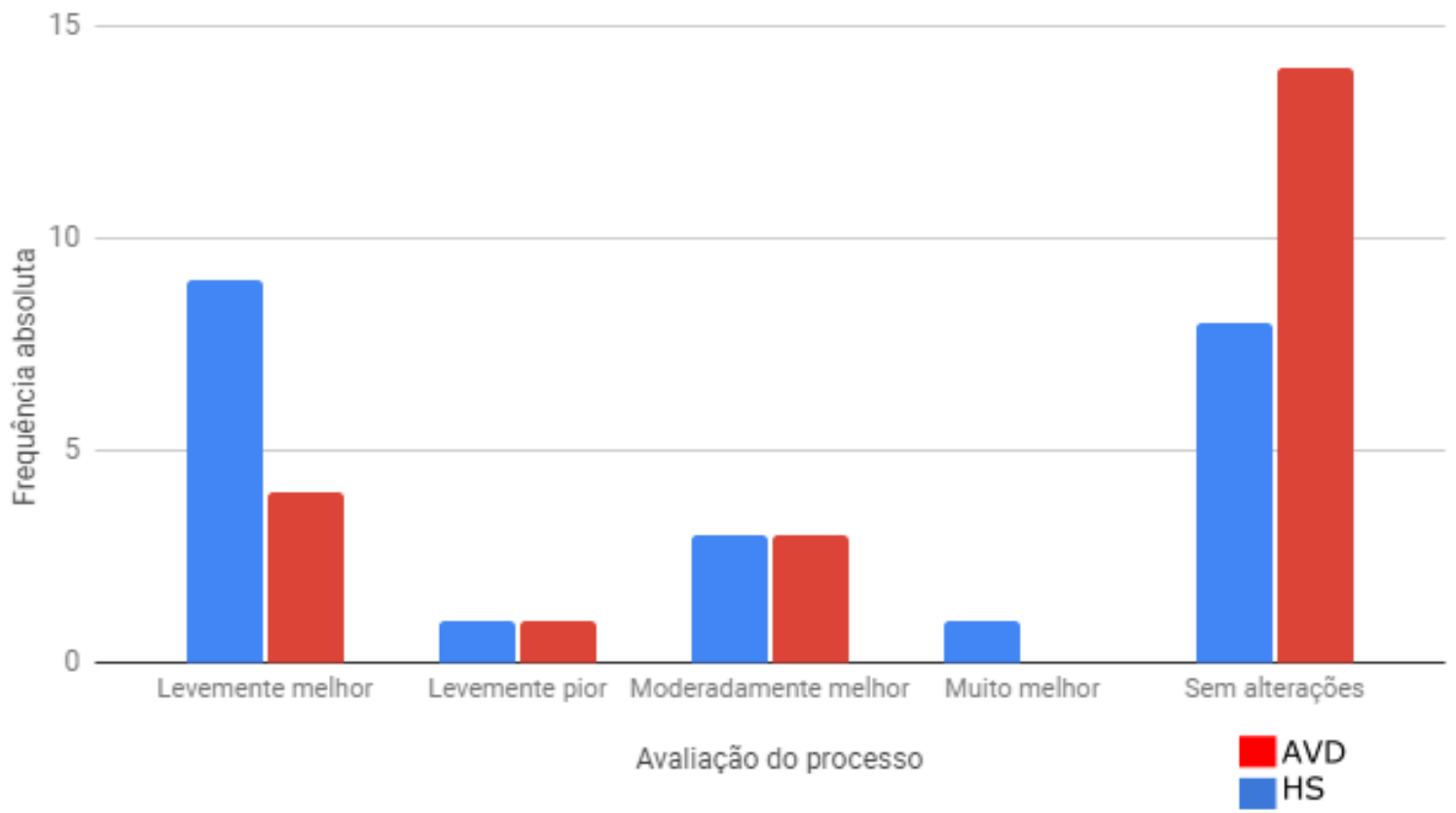

Fonte: Elaborada pelo autor.

\subsection{TC-GAS}

No final de todas as sessões de grupo, os terapeutas entregavam aos participantes as folhas para os pais preencherem em casa, com as Tarefas de Casa (TC). Na sessão seguinte, o participante a devolvia aos terapeutas, com as tarefas realizadas e registradas pelos pais. Como parte da contingência, o " $\mathrm{X}$ " da tarefa deveria ser registrado e confirmado pelos pais.

A Figura 22 ilustra a proporção das tarefas elaboradas e requeridas pelos pais. Vale ressaltar que são as tarefas trazidas pelos participantes, ou seja, não estão contabilizadas as tarefas dos participantes que não as trouxeram à sessão. Para a análise, todas as tarefas entregues foram separadas em três categorias, Habilidades Sociais (HS), Habilidades Acadêmicas (HA) e Atividade de Vida Diária (AVD):

- Habilidades Sociais: cumprimentar pessoas no elevador, conversar no jantar com a família, ser gentil com a irmã, não ficar no celular quando estiver com uma pessoa por perto, conversar com os meninos do grupo através do WhatsApp, entre outros;

- Habilidades Acadêmicas: arrumar a mochila da escola, fazer lição, estudar para a prova, ler um livro de literatura, ir para o reforço escolar, entre outros;

- Atividade de Vida Diária: escovar os dentes, arrumar a cama, tomar banho, passear com o cachorro, comer à mesa, tirar a mesa, lavar a louça, entre outros. 
Figura 22 - Porcentagem do tipo de tarefas requisitadas pelos pais nas TC-GAS, separadas em HA, HS e AVD

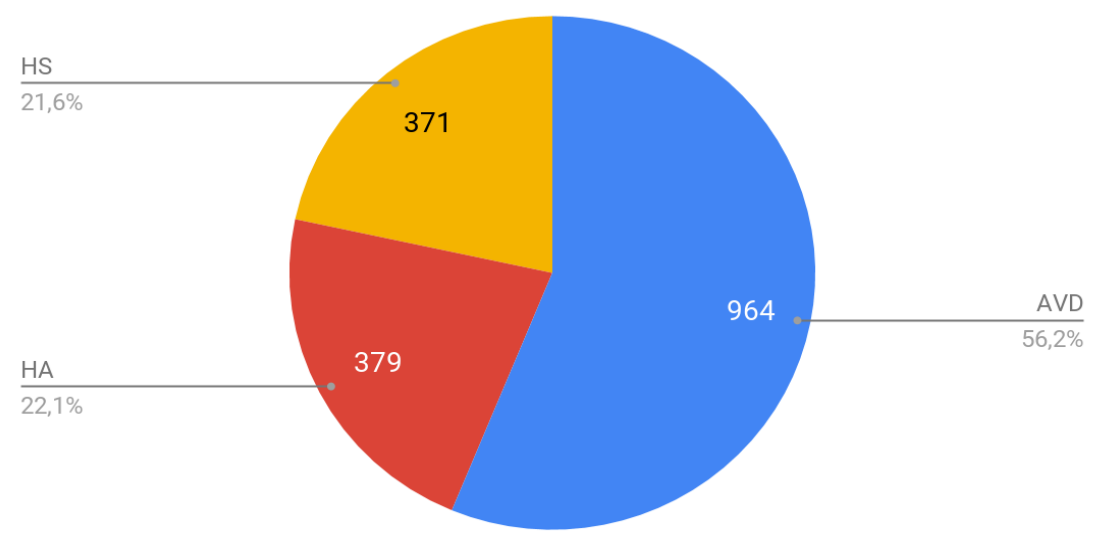

Fonte: Elaborada pelo autor.

A Figura 22 revela, também, que 56\% das tarefas de casa compunham AVDs. Por outro lado, HS e HA mantiveram proporções semelhantes (21-22\%). Ou seja, esses dados sugerem que os pais focaram mais em AVDs do que nas demais demandas, inclusive HS, sendo que este é o principal motivo para buscar o tratamento em grupo, ou seja, o foco principal da proposta dos grupos é o desenvolvimento das habilidades sociais.

A partir da entrega das TCs, as respostas foram tabuladas e medido o coeficiente das tarefas realizadas, ou seja, qual foi a taxa de realização das atividades.

Figura 23 - Taxa de realização da tarefa por todos os participantes da pesquisa, separados em AVD, HA, HS, IND

$100,00 \%$

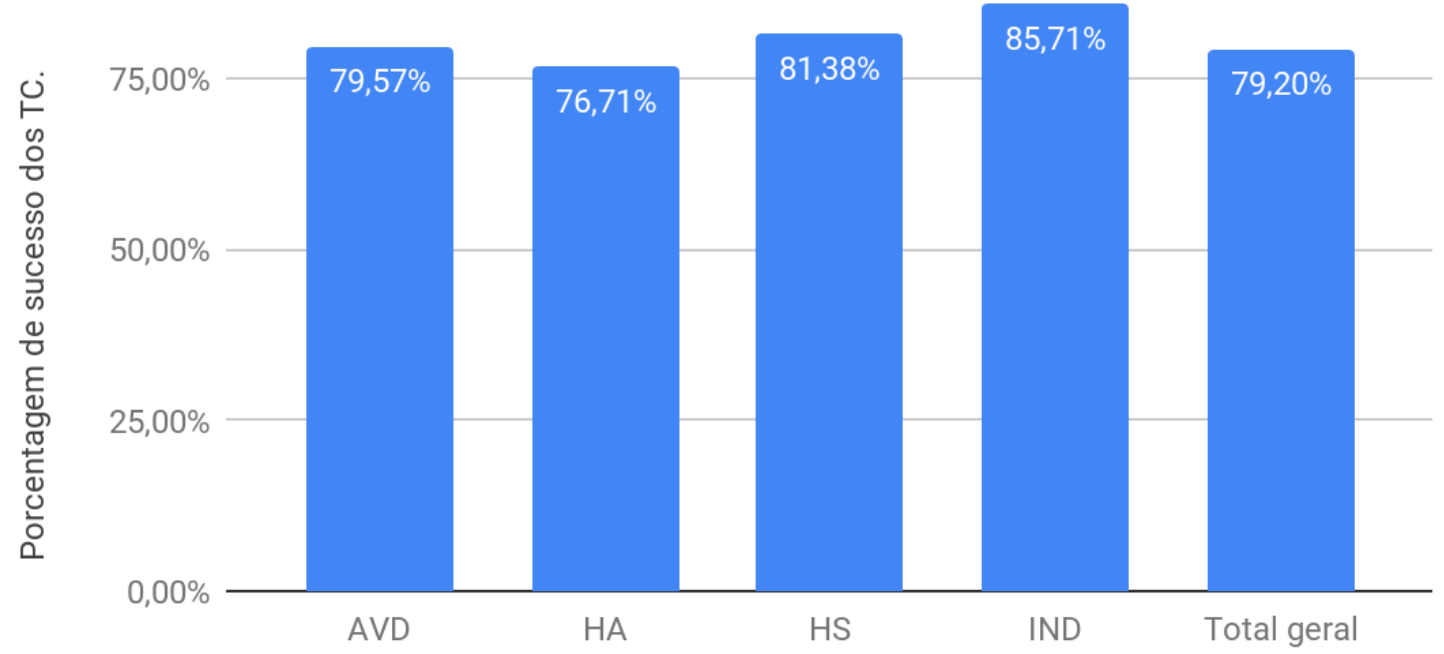

Fonte: Elaborada pelo autor. 
A Figura 23 mostra que a taxa para realização das tarefas não varia significativamente de acordo com o tipo de tarefa exigida, ou seja, para o cliente, não há diferença se a tarefa é AVD, HA ou HS. A média da taxa de tarefa realizada com sucesso é de $78 \%$.

Foi separada o tipo de tarefa por cada grupo para verificar se havia diferença no tipo de tarefa exigida para o perfil de cada grupo.

Figura 24 - Porcentagem da realização de cada tipo de tarefa distribuída em cada grupo, com a linha média da taxa de realização de toda a amostra

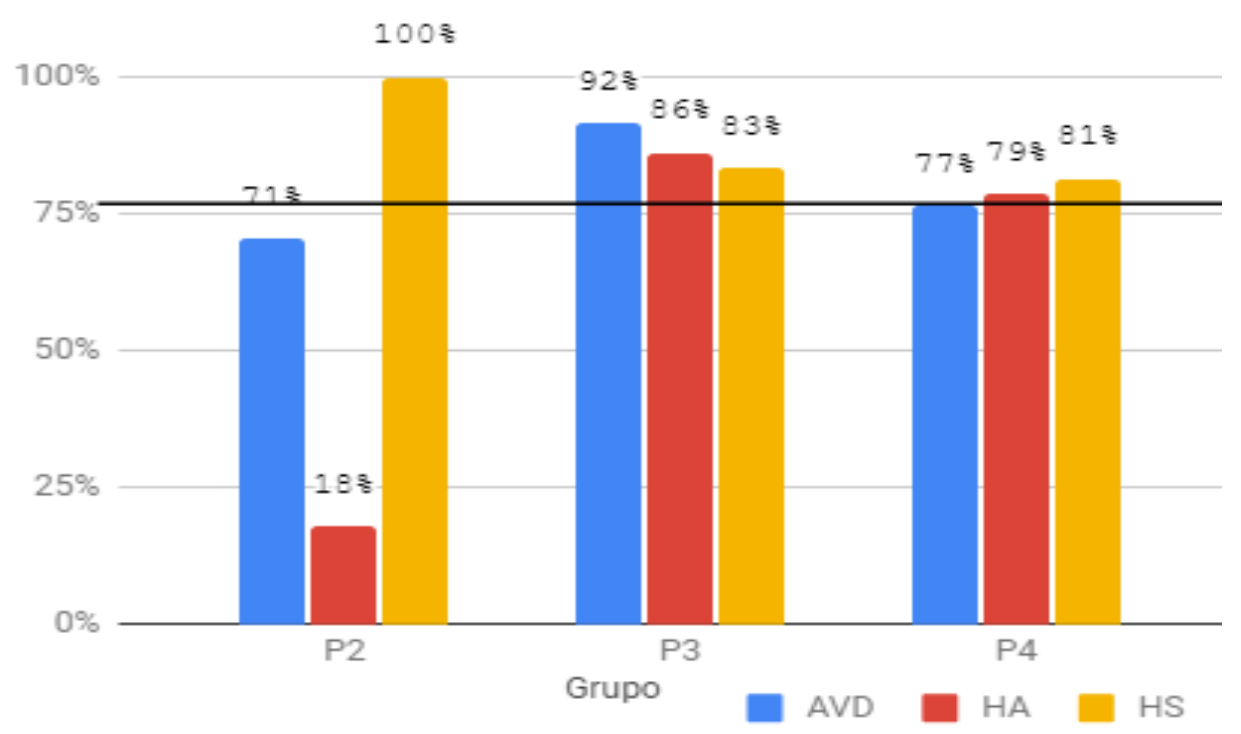

Fonte: Elaborada pelo autor.

A Figura 24 explicita alguns dados sobre a taxa de realização das tarefas separada em tipo de tarefa e grupo. Nota-se que o P2, por ser um grupo mais homogêneo e neurotípico, apresentou a menor taxa de realização de tarefas quando envolvia tarefas acadêmicas, e maior taxa de desempenho de tarefas sociais. Já o grupo P3, constituído por TEA, apresentou as maiores taxas de realização para todas as tarefas, estando acima da média. E o P4, por ser um grupo mais heterogêneo (TEA e TDAH), apresentou taxas mais próximas à média de realização das tarefas. 


\section{DISCUSSÃO}

Talvez o principal aspecto da pesquisa seja a mudança abrupta do setting terapêutico que, inicialmente, foi planejada para a realização de atendimentos na modalidade presencial. A pandemia impôs uma mudança de intervenção não prevista. Portanto, houve um período de adaptação para uma nova tecnologia, com uso de uma plataforma social chamada Discord. Então, o impacto da pandemia na execução do cronograma pode ter afetado o resultado da pesquisa, pois metade das sessões programadas foram realizadas na modalidade online. Mesmo assim, os dados puderam ser discutidos e analisados, assim como o impacto dessa tecnologia nova para o setting terapêutico online.

O primeiro aspecto a ser discutido é a adesão dos participantes, que pode trazer pistas sobre a motivação com a intervenção. O número de participantes que iniciou a pesquisa foi de 20 participantes e, destes, 16 ficaram até o final da pesquisa, mais ou menos 1 ano depois. A taxa de adesão foi de $80 \%$, sendo que, na literatura, a taxa encontrada em clínica-escola foi de 49\%. Vale ressaltar que, desses 4 participantes que desistiram, 2 saíram por conta da dificuldade em utilizar a plataforma. Portanto, a taxa de adesão poderia ser maior, caso fosse mantida a intervenção presencial.

Já quando a taxa de adesão dos adolescentes é comparada com a taxa de resposta do CGI dos pais - que é a participação dos pais no tratamento -, a taxa de respostas sobre a progresso da terapia foi relativamente baixa $(19,3 \%)$, se comparada com a de adesão dos filhos à pesquisa $(80 \%)$.

Considerando a taxa de realização das Tarefas de Casa pelos adolescentes (78\%), em muitos momentos houve situações em que os participantes relataram que eles próprios cobravam os pais para verificarem a realização das tarefas e registrar na folha. Esse fato foi interessante, pois revela uma alta motivação dos meninos pelo compromisso com a terapia.

Ainda sobre a análise entre a Tarefa de Casa e o CGI, interessante é notar que, inicialmente, os pais buscam esse tipo de terapia no consultório para tratar especificamente os déficits de HS. Mas a porcentagem dos tipos de tarefas de casa escolhidas pelos próprios pais foram 56,2\% para atividade da vida diária (AVD); 22,1\% para tarefas acadêmicas e 21,6\% para tarefas interpessoais. Por si só, esse é um dado interessante, pois, se a busca pela terapia foi o déficit das HS, qual foi o motivo para prevalecer o alto índice de escolhas pelas tarefas de AVD? Esse fenômeno poderia ser estudado em futuras pesquisas.

Outro fato interessante sobre esses dados é a taxa de realização entre os tipos de tarefas de casa. A taxa de realização das tarefas de AVD foi 79,57\%; de HA, 76,71\%; e de HS, 81,38\%, 
ou seja, as taxas entre as categorias foram semelhantes, o que surpreendeu a premissa de que o tipo de tarefa poderia impactar o rendimento das atividades.

Também um fato relevante é que, com a alta taxa de realização para qualquer tipo de TC, a percepção dos pais foi diferente para cada tipo de tarefa. Através do instrumento CGI, foi possível observar que, mesmo com a alta taxa de resolução das tarefas de casa AVD e HS, os pais tiveram diferentes percepções sobre o progresso. Segundo os pais, 66\% dos AVD não apresentaram alteração ao longo das semanas, e 30\% dos AVD apresentaram pouca alteração. No caso das HS, 30\% apresentaram nenhuma alteração e 70\% apresentaram uma leve mudança ao longo das semanas. Porém, a taxa de resolução entre as diferentes atividades foi semelhante. Futuras pesquisas poderiam investigar esse ponto. Esse dado pode levar à interpretação sobre o estigma que o filho tem ao longo da vida, pois "para os pais, ele sempre será bagunceiro".

Sobre os dados obtidos pelo IHSA, a análise foi dividida em 2 partes:

- Houve 6 sujeitos que realizaram 6 ou 7 sessões presenciais entre duas avaliações do IHSA. Como resultado, teve um aumento do escore para frequência e uma diminuição da dificuldade dos comportamentos adequados. Esse resultado foi positivo para 6 sessões do tratamento, porém, pelo tamanho da amostra e pelo número de sessões, a diferença não foi significativa, quando aplicado o teste de Friedman;

- Para a amostra total do estudo, dos 20 participantes, 16 concluíram o cronograma da pesquisa; porém exatamente a metade das sessões foram executadas na modalidade online, além de uma interrupção das sessões até a adaptação na plataforma online. Portanto, como as sessões estavam ocorrendo, foi aplicado o IHSA através da plataforma Google Formulários. Aplicando o teste de Wilcoxon pareado, os resultados mostraram que não houve diferença estatisticamente significativa; e analisando os resultados das subcategorias, os dados foram bem dispersos. Vale ressaltar que, dos 6 sujeitos da amostra que fizeram a aplicação intermediária do IHSA, todos obtiveram piores resultados da segunda para terceira avaliação.

Por mais que o impacto da pandemia tenha sido relevante, houve uma piora do IHSA em praticamente todas as categorias, o que pode levar à conclusão sobre a limitação dos atendimentos online no THS. Porém, essa observação pode ser questionada por dois fatores:

a) Talvez o IHSA possa não ser adequado para a avaliação de um contexto virtual, por se tratar de um questionário de autorrelato. Lembrando que a aplicação do questionário é para o participante lembrar as últimas 10 situações e, caso não tenha acontecido, o que supostamente faria. A pandemia iniciou-se em março de 2020 e a 
coleta do IHSA em setembro de 2020; logo, a aplicação do IHSA é questionável, pois os próprios participantes não se submeteram em condições naturais descritas nos itens do próprio questionário. Sendo assim, talvez a conclusão possa ser a de que o IHSA não seja a melhor ferramenta para a avaliação do repertório social quando há pouca ou nenhuma exposição social (que é o caso na quarentena);

b) A plataforma digital em que foi realizada as sessões de grupo trouxe inúmeros resultados inesperados, que devem ser uma fonte de dados interessantes a respeito, principalmente, quando se trata de generalização das habilidades sociais.

A plataforma digital Discord possibilitou uma variabilidade de intervenções que, ao longo dos meses, foram sendo aprimorados e, atualmente, é considerada uma ferramenta imprescindível para o THS. A plataforma permite, aos programadores do servidor, a configuração de inúmeros bots (robôs que executam uma tarefa automatizada) que exercem a manutenção de reforçadores com objetivo de estimular a socialização. Segundo o planejamento realizado pela clínica, os bots têm três funções: aumentar o valor reforçador do RPG, reforçar interações sociais nos canais de texto e de voz e registrar os comportamentos sociais. Portanto, foi percebido, com dados quantitativos não publicados por enquanto, um aumento das interações sociais para além das sessões de grupo, o que aponta uma vasta área de pesquisa dentro do campo da generalização do comportamento aprendido em sessão. Por exemplo, dados encontrados sugerem que os usuários têm o dobro de tempo de participação no servidor em horários além da sessão de grupo.

Os achados do GCQ, dentro da perspectiva da avaliação do processo terapêutico, representaram, em forma de gráfico de linha, o processo terapêutico de cada grupo. Nos 3 grupos selecionados para a análise, é possível ver as linhas de engajamento, conflito e esquiva. A linha do engajamento prevaleceu, em comparação com as demais linhas, e fazendo uma análise da média do grupo, é notável uma diferença do grupo P4 com os demais. O grupo P4 foi composto por clientes neurotípicos e, portanto, é notável uma maior estabilidade e menos oscilação nas três categorias, Engajamento, Conflito e Esquiva. Já nos grupos P2 e P3, é evidente uma variação maior, pois, durante as sessões, os integrantes apresentaram mais respondentes e falta de repertório de autocontrole diante das situações de escassez de reforçadores.

Uma observação a ser feita a respeito do GCQ é sobre os itens do questionário. Os itens avaliados parecem mais adequados para as intervenções focadas em questões mais subjetivas, como análise de traumas, ou em algum quadro clínico. Para a amostra da pesquisa adolescentes com queixas ligadas a déficit de habilidades sociais, alto interesse por RPG, por 
cultura de games e geek -, talvez não seja este o questionário ideal para avaliar as habilidades sociais na perspectiva de processo. Nesse sentido, falta na literatura algum inventário de habilidades sociais com foco no processo terapêutico, e não apenas no pré e pós-intervenção.

Com relação à amostra e ao cronograma da pesquisa, ela foi planejada para 20 participantes sem histórico de psicoterapia, para serem distribuídos em 4 ou 5 grupos. Porém, a coleta da pesquisa foi antecipada para realizar o estudo preliminar - iniciado em agosto - dos inventários traduzidos e realizar as adaptações necessárias. Assim, o planejamento, ao longo da coleta, era substituir os participantes experientes por pacientes novos ao tratamento. Com a ameaça da pandemia, optou-se por iniciar a coleta dos instrumentos e, na medida do possível, tentar cumprir o cronograma oficial da pesquisa. Portanto, os resultados do GCQ já apontavam um padrão sem oscilações significativas, pois os grupos já estavam em andamento. Para pesquisas futuras e com um cronograma maior, sugere-se a aplicação desses instrumentos com participantes sem tratamento prévio.

Sobre a frequência da intervenção, a frequência das sessões de THS, encontradas na literatura, são semanais. O modelo apresentado da TGS é realizar sessões mistas (sessões individuais e de grupo), de modo que o THS seja semanal. O objetivo das sessões individuais é realizar o treino de alguma habilidade social específica, além de trabalhar questões subjetivas, e o objetivo do grupo é desenvolver a competência social ou generalização do comportamento. Portanto, as sessões do TGS são intercaladas entre sessões individuais e de grupo para contemplar a complexidade do THS. Em alguns casos, sugere-se a intervenção com acompanhante terapêutico para aumentar a intervenção em contexto natural. Essas intervenções geralmente foram eventos realizados pela clínica e o número de participantes era aumentado, pois contemplava todos os outros demais clientes.

Esse planejamento das sessões traz uma intervenção com elementos de jogos diretamente relacionada com os conceitos da gamificação e uso do RPG como uma ferramenta terapêutica. Esse modo de intervenção, no contexto individual e de grupo, não foi encontrado na literatura.

Sobre a estrutura das sessões, a TGS segue a perspectiva da prática controlada aplicada à THS na abordagem analítico-comportamental, ou seja, as sessões individuais e de grupo são planejadas de acordo com as queixas trazidas pelo cliente e pelos pais. A cada sessão, são estabelecidas as metas e a medida necessária para mensurar e avaliar o progresso. Porém, uma crítica feita aqui é que, quando se trata de intervenção baseada na demanda trazida do cliente, muitas vezes pode haver algumas classes de comportamentos sociais que não serão trabalhadas. Por exemplo, um dos clientes tem déficit no repertório de civilidade, mas, como é demanda 
para os pais e não dele, tal treino não ocorre na terapia. Desta maneira, uma sugestão para pesquisas futuras é utilizar intervenções estruturadas e protocoladas para os atendimentos individuais e, para as sessões de grupo, continuar com as intervenções com foco em manutenção, generalização e treino dos comportamentos sob demanda do caso clínico.

Com relação à prática controlada, quando se trata de habilidades sociais, esse tipo de intervenção possibilita uma adaptação da intervenção de acordo com as demandas do cliente, o que geralmente acontece com clientes neurotípicos. Por exemplo, em um período, pode haver problemas conjugais, e a terapia muda o seu objetivo, que é tratar de questões conjugais. Esse tipo de intervenção baseada na prática controlada pode ser uma alternativa de tratamento, desde que o terapeuta esteja preparado com o conhecimento necessário do campo de estudo das habilidades sociais. Desse modo, o terapeuta pode criar medidas de mensuração para mostrar ao cliente as suas conquistas. Portanto, cabe uma sugestão para pesquisas futuras verificarem a eficiência desse tipo de intervenção aplicada às habilidades sociais.

Sobre os inventários utilizados, a pesquisa optou pelo uso do IHSA por ser uma avaliação presente em diversos estudos da literatura brasileira; no contexto internacional, existem outros inventários que utilizaram SSRS, por exemplo; porém ambos seguem o tipo de avaliação pré e pós-teste. O propósito de utilizar GCQ foi buscar uma avaliação de processo terapêutico no contexto de grupo, mas, como o questionário não foi formulado especificamente para mensurar as habilidades sociais, pelo menos deu pistas sobre o processo do clima de cada sessão de grupo. Portanto, como proposta para futuras pesquisas, seria interessante, para o campo das habilidades sociais, algum instrumento que possa avaliar a evolução do repertório social de cada sessão de grupo. Por exemplo, o instrumento OQ-45 é um instrumento de autorrelato e é utilizado para avaliação do sofrimento do cliente adulto. Ao plotar os dados, o cliente e o terapeuta podem avaliar como a terapia está se desenvolvendo. Então, como proposta de pesquisas futuras, a criação de uma escala de processo das habilidades sociais, tanto no contexto individual quanto no contexto de grupo, poderia auxiliar as terapias com foco nas habilidades sociais. 


\section{CONCLUSÃO}

A intervenção proposta e avaliada neste estudo apresenta uma complexidade de variáveis. O objetivo da pesquisa foi apresentar a intervenção para avaliar os efeitos desse tipo de prática de terapia de grupo e, sob a perspectiva de avaliação de alguns instrumentos, analisar o THS.

A respeito dos dados quantitativos, a partir dos resultados dos instrumentos IHSA, GCQ, CGI e TC-GAS, há algumas limitações para os instrumentos.

Na literatura, o IHSA é utilizado como pré e pós-treino; porém, no contexto de pandemia, verificou-se que o resultado desse instrumento pode ser limitado. A razão mais clara é que a pandemia não possibilita interações no contexto natural, o que torna os itens do questionário irreais. Estudos futuros poderiam investigar se esse instrumento é válido para situações semelhantes à da pandemia.

Ainda sobre o IHSA, o questionário é de autorrelato, o que é comum para muitos instrumentos, mas a instrução dada no instrumento é hipotético-dedutiva. O participante deve responder, com base em cada dez últimas situações, quantas vezes se comportou e, se aquilo não aconteceu, é para imaginar o que faria. Mesmo aplicando o tal instrumento validado para adolescentes, alguns participantes acharam incômodo e "nada a ver" (nas palavras deles) os itens específicos a respeito do uso de camisinha e de conversa com os pais sobre sexo. Alguns participantes afirmaram aos terapeutas: "Eu não sei o que responder nesse item. Isso não passa pela minha cabeça". Outro item criticado por eles foi "Demonstrar aborrecimento se o irmão/irmã mexer nas coisas". Muitos dos participantes não tinham irmãos, logo "imaginar um irmão" não parece uma boa forma de investigar as habilidades sociais.

Além dessas questões, o IHSA não é um questionário para avaliar processo terapêutico ao longo de cada sessão, daí o uso do GCQ para investigar se era possível utilizar em THS. Os resultados mostraram que o instrumento GCQ faz uma leitura acerca da dinâmica do grupo de acordo com o perfil dos participantes e com a dinâmica das sessões, porém o instrumento é mais adequado para um setting mais tradicional de terapia de grupo devido a muitas perguntas sobre sentimentos. Por exemplo: "Os membros revelaram informações pessoais sensíveis ou sentimentais". Como se trata de THS com uso de gamificação e com temática de jogo, questões de autorrevelação e sentimentais raramente aconteciam em sessão, o que, provavelmente, faz mais sentido na terapia de grupo mais tradicional.

Outro ponto do GCQ é que alguns itens do questionário não investigam especificamente as habilidades sociais. Futuras pesquisas poderiam criar instrumentos para mensurar as 
habilidades sociais aprendidas e os efeitos no grupo ao longo do processo das sessões terapêuticas, através de instrumentos de autorrelato logo após a sessão. Assim, a menor distância temporal entre o fim da sessão e o preenchimento do questionário é mais fidedigna aos acontecimentos ocorridos na sessão.

Os instrumentos CGI e TC-GAS foram importantes para implementar procedimentos para aumentar a adesão dos pais à terapia, de modo a treinar o olhar deles sobre os filhos. Uma proposta é implementar uma parte da intervenção proposta, como no protocolo PEERS (LAUGENSON; FRANKEL, 2010). Nesse protocolo, os pais tinham sessões de orientação ao mesmo tempo que as sessões dos filhos aconteciam.

Sobre TC-GAS, o instrumento é importante para ampliar a efetividade do treino em contextos fora do treino, como aponta Andreozzi (2017). A possibilidade de adaptar o instrumento à demanda do paciente é uma forma otimizar os treinos no consultório e promover a generalização dos comportamentos, tanto para AVD como para HA e HS. Assim como em Starling (2010), a prática controlada é um dos modelos de terapia que se adequa aos princípios da terapia analítico-comportamental.

A prática controlada é um dos fundamentos da TSG, pois os planejamentos da intervenção são construídos a partir de um levantamento das queixas dos clientes e, utilizando as categorias de habilidades sociais de Del Prette e Del Prette (2017), os comportamentos-alvo são estabelecidos. Ao utilizar elementos de jogos, a motivação dos participantes é construída, otimizando a intervenção. Muitos participantes relatam que "não sentem que estão em uma clínica de psicologia”. O uso desses elementos pode otimizar o potencial do treino, como é visto na alta taxa de adesão ao tratamento (80\%).

Ainda sobre prática controlada e a possibilidade de criar uma intervenção específica para cada cliente, quando se trata de THS, é primordial que o cliente traga a queixa à clínica. Assim, tem-se um dilema, pois existem déficits comportamentais de HS que não são trazidos ao consultório; logo, corre-se o risco de não desenvolver tais comportamentos sociais. Desta maneira, os protocolos de THS têm a sua importância, porque eles garantem ao participante a possibilidade de trabalhar todas as categorias de HS. Por outro lado, as queixas dos clientes que passaram por esses treinamentos protocolados de HS é que são monótonos e que não fizeram amizade ao fim do programa. Portanto, é importante estudar os efeitos de uma intervenção mista entre um THS protocolado com objetivo de desenvolver a maioria das HS e um outro THS não protocolado, baseado na prática controlada e gamificada, com objetivo de trabalhar as queixas, as competências sociais (generalização do comportamento com pares) e a motivação para se manter em terapia de grupo. 
A respeito dos dados qualitativos, a intervenção TSG faz uso do aspecto lúdico e da gamificação para tornar a intervenção mais tentadora para o público jovem e contemporâneo. A análise proposta por Chou (2014) deixa clara a motivação da adesão das pessoas através da gamificação, do mundo lúdico e do RPG. Por exemplo, no começo de novembro de 2020, foi publicado o primeiro livro sobre as sessões de RPG contadas pelos próprios participantes, disponível na Amazon. Os participantes escreveram histórias e fizeram vários desenhos para tentar passar o que acontece nas sessões de RPG (CARVALHEIRA; SBERVELIERI; MARSIGLIA NETO, 2020).

A intervenção vai além do RPG, pois a gamificação é utilizada em intervenções que, muitas vezes, não envolveria o RPG. A construção dos sistemas de planilhas de Google Sheets, as filipetas com missões ou desafios, muitas vezes, não tinham consequência direta com as sessões de grupo. Alguns participantes já relataram que a terapia promovida no consultório se parecia com um jogo e era divertido cumprir as tarefas. Portanto, inúmeros encontros entre os participantes ocorreram ao longo dos meses e pelos mais diferentes motivos. Assim, coloca-se o termo gamificação no princípio da intervenção e o RPG é uma das ferramentas poderosas disponíveis.

Quanto ao impacto da pandemia e o uso de plataformas online, os efeitos da pandemia com o THS possibilitaram, em um primeiro momento, várias limitações quanto à ausência do contato físico, de visualização das expressões visuais, de discriminação das nuances do tom de voz, entre outros componentes paralinguísticos. Portanto, o treino presencial das HS não pode ser totalmente descartado. Porém, uma nova vasta área de estudo pode ter sido aberta, pois o processo de adaptação das intervenções para a modalidade online possibilitou o uso de ferramentas digitais que podem ser úteis para o estudo da generalização do comportamento social. Como no protocolo PEERS, o uso de ferramentas digitais e das redes sociais é uma etapa do protocolo de THS. Assim, a plataforma digital Discord permitiu uma variabilidade de intervenções, tornando-se uma ferramenta imprescindível para o TSG.

Por fim, ao fazer uso do RPG como ferramenta terapêutica, no estudo de Kōhei (2019), a intervenção ganha no aspecto da motivação; mas a proposta aqui é utilizar os conhecimentos do campo das habilidades sociais para desenvolver classes de comportamento, descritas por Del Prette e Del Prette (2017) e, através da análise funcional, aplicar uma intervenção individualizada e adequada, ou seja, o uso dos elementos do RPG e da gamificação para consequenciar e aprimorar as classes de habilidades sociais complexas.

Quando se trata de registros de comportamentos, a proposta aqui é implementar a prática controlada como um dos pilares da intervenção tanto no registro do progresso clínico das 
habilidades sociais dos participantes quanto no registro com os pais. Como futura pesquisa, serão testados e implementados registros de progresso dos ganhos das habilidades sociais adquiridas, e não apenas um teste pré e pós-intervenção.

Sobre as competências sociais (ou generalização do comportamento), a TSG propõe a implementação de intervenções fora do consultório através dos seus eventos ou das plataformas de rede social Discord. Para o desenvolvimento das HS, há a intervenção individualizada e, como resultado dessa pesquisa, há possibilidades futuras de implementação de sessões estruturadas e protocoladas de THS, como sugerido no tratamento PEERS, para trabalhar outros comportamentos não trazidos ao consultório. Desta forma, os comportamentos adquiridos nos tratamentos podem ser mantidos através do RPG ou de outras estratégias com foco na gamificação, como apresentado nas TC-GAS.

Portanto, conciliar a área do RPG, dos jogos, da gamificação, da terapia e do campo das habilidades sociais exige conhecimento técnico e aprimorado da área clínica. O conhecimento técnico da saúde mental não pode ser substituído por qualquer outra área, em sua totalidade, se a finalidade é utilizar RPG ou gamificação como ferramenta terapêutica. Existe o compromisso ético com a saúde mental dos clientes e o conhecimento técnico sobre os quadros clínicos descritos no DSM e no CID, além dos investimentos necessárias como parte da formação do terapeuta clínico. 


\section{ANÁLISE DOS ASPECTOS ÉTICOS}

O presente estudo foi conduzido com os devidos cuidados éticos, nos termos da Resolução 466 do Conselho Nacional de Saúde (BRASIL, 2013). A pesquisa somente será iniciada após ter sido submetida à apreciação e aprovada pela Comissão de Ética da Universidade de São Paulo. Após a aprovação ser concedida, os clientes assinarão o Termo de Consentimento Livre e Esclarecido, autorizando a utilização dos dados obtidos. O pesquisadorterapeuta e o observador independente assinarão o Termo de Responsabilidade. Quando da publicação e/ou apresentação dos resultados da pesquisa, os dados de identificação do cliente não serão divulgados, considerando o devido cuidado para o sigilo. Para garantir tal sigilo, haverá alteração dos dados que, de alguma forma, possam identificar o cliente e a ocultação de dados desnecessários para os diversos meios de divulgação científica. Além disso, após a utilização dos dados coletados para a presente pesquisa, as mídias contendo as gravações das sessões dos clientes serão guardadas em local seguro, pertencente ao laboratório. O cliente será informado disso e a destruição das mídias poderá ser solicitada pelo cliente, sem que nenhum prejuízo esteja implicado.

O pesquisador foi responsável pelo andamento da pesquisa e pela aplicação dos procedimentos e avaliação do bem-estar do cliente durante o andamento da coleta de dados. Se for identificado qualquer problema e/ou desconforto do cliente, o pesquisador-terapeuta conversará com o cliente e com os responsáveis e, se for o caso, tem a liberdade de interromper o tratamento. A interrupção da pesquisa também poderá ser solicitada a qualquer momento pelo cliente, sendo que seu direito ao atendimento continuará sendo garantido. Caso o cliente solicite a não inclusão dos dados na presente pesquisa, o direito de atendimento será garantido e nenhum prejuízo estará implicado. O próprio pesquisador-terapeuta continuará o atendimento por pelo menos 6 meses, sendo que, após esse período, o cliente poderá ser encaminhado para atendimento com outro terapeuta.

Caso um cliente selecionado para a pesquisa não concorde com as disposições do Termo de Consentimento Livre e Esclarecido, o pesquisador-terapeuta garante o direito de atendimento por pelo menos 6 meses e, após este período, o cliente poderá ser encaminhado a outro terapeuta, dependendo da disponibilidade do pesquisador.

O projeto será supervisionado pelo orientador do departamento de Pós-Graduação em Psicologia Clínica. 


\section{REFERÊNCIAS}

ALBERTI, R. E.; EMMONS, M. L. Your perfect right: A guide to assertive behavior. Atascadero, CA: Impact, 1970.

ANDREOZZI, G. C. Ensino em grupo de habilidades sociais para pessoas com autismo: uma revisão da literatura. 2017. Dissertação (Mestrado em Psicologia Experimental: Análise do Comportamento) - Pontifícia Universidade Católica de São Paulo, São Paulo, 2017.

ARAUJO, R. B.; OLIVEIRA, M. M. de A.; CEMI, J. Desenvolvimento de role-playing game para prevenção e tratamento da dependência de drogas na adolescência. Psicologia: Teoria e Pesquisa, v. 27, n. 3, p. 347-355, set. 2011. doi: https://doi.org/10.1590/S0102$\underline{37722011000300010 .}$.

ARGYLE, M. Social interaction. London, UK: Methuen, 1969.

ARGYLE, M. Comunicação e dinâmica de grupo: bases psicológicas. Tradução Agostinho Minicucci. São Paulo: Ibrasa, 1974.

ARGYLE, M. The Psychology of interpersonal behavior. 5. ed. Londres, UK: Penguin Books, 1994 [1967].

ARGYLE, M.; KENDON, A. The Experimental analysis of social performance. Advances in Experimental Social Psychology, v. 3, p. 55-98, Dec. 1967.

ARNESON, D.; GYGAX, G. Dungeons \& Dragons. Lake Geneva, WI: TSR, 1974.

BANDELOW, B.; BALDWIN, D. S.; DOLBERG, O. T.; ANDERSEN, H. F.; STEIN, D. J. What is the threshold for symptomatic response and remission for major depressive disorder, panic disorder, social anxiety disorder, and generalized anxiety disorder? The Journal of Clinical Psychiatry, v. 67, n. 9, 1428-1434, Sept. 2006. doi: 10.4088/jcp.v67n0914.

BARBOSA, A. de S.; TERROSO, L. B.; ARGIMON, I. I. de L. Epistemologia da terapia cognitivo-comportamental: casamento, amizade ou separação entre as teorias? Boletim Academia Paulista de Psicologia, v. 34, n. 86, p. 63-79, 2014.

BARTLE, R. Hearts, clubs, diamonds, spades: Players who suit MUDs. The Journal of Virtual Environments, v. 1, n. 1, 1996. Disponível em: https://mud.co.uk/richard/hcds.htm.

BECHELLI, L. P. de C.; SANTOS, M. A. dos. Psicoterapia de grupo: como surgiu e evoluiu. Revista Latino-Americana de Enfermagem, v. 12, n. 2, p. 242-249, 2004. doi: https://doi.org/10.1590/s0104-11692004000200014.

BEDELL, J. R.; LENNOX, S. S. Handbook for communication and problem solving skills trainning: A cognitive behavioral approach. Nova York, NY: Willey, 1997.

BOLSONI-SILVA, A. T.; CARRARA, K. Habilidades sociais e análise do comportamento: compatibilidades e dissensões conceitual-metodológicas. Psicologia em Revista, Belo Horizonte, v. 16, n. 2, p. 330-350, ago. 2010. Disponível em: 
http://pepsic.bvsalud.org/scielo.php?script=sci_arttext\&pid=S1677$11682010000200007 \& \operatorname{lng}=\mathrm{pt} \& \mathrm{nrm}=\mathrm{iso}$.

BORNSTEIN, M. R.; BELLACK, A. S.; HERSEN, M. Socials skills training for unassertive children: A multiple baseline analysis. Journal of Applied Behavior Analysis, v. 10, p. 183195, 1977.

BOWMAN, S. L.; LIEBEROTH, A. Psychology and role-playing games. In: ZAGAL, J. P.; DETERDING, S. (ed.). Role-Playing Game Studies: transmedia foundations. New York, NY: Routledge, 2018. p. 245-264.

BRASIL. Ministério da Saúde. Conselho Nacional de Saúde. Resolução nº 466, de 12 de dezembro de 2012. Aprova as diretrizes e normas regulamentadoras de pesquisas envolvendo seres humanos e revoga as Resoluções CNS nos. 196/96, 303/2000, 404/2008. Diário Oficial da União, Brasília, DF, 13 jun. 2013.

BROWN, D. A.; EFFGEN, S. K.; PALISANO, R. J. Performance following ability-focused physical therapy intervention in individuals with severely limited physical and cognitive abilities. Physical Therapy, v. 78, p. 934-947, 1998.

BURLINGAME, G. M.; FUHRIMAN, A.; JOHNSON, J. Cohesion in group psychotherapy. In: NORCROSS, J. C. (ed.). A guide to psychotherapy relationships that work. New York, NY: Oxford University Press, 2003. p. 71-87.

BUSNER, J.; TARGUM, S. D. The clinical global impressions scale: applying a research tool in clinical practice. Psychiatry, Edgmont, v. 4, n. 7, p. 28-37, July 2007. Disponível em: https://www.ncbi.nlm.nih.gov/pmc/articles/PMC2880930/.

CABALLO, V. E. O treinamento em habilidades sociais. In: CABALLO, V. E. (org.). Manual de técnicas de terapia e modificação do comportamento. São Paulo: Santos, 1996. p. 3-42.

CABALLO, V. E. Manual de avaliação e treinamento das habilidades sociais. São Paulo: Santos, 2003.

CARDOSO, B. L. A.; DEL PRETTE, Z. A. P. Habilidades sociais conjugais: uma revisão da literatura brasileira. Revista Brasileira de Terapia Comportamental e Cognitiva, v. 19, n. 2, p. 124-137, 2017.

CARNEIRO, R. S. A relação entre habilidades sociais e qualidade de vida na terceira idade. Revista Brasileira de Terapias Cognitivas, Rio de Janeiro, v. 2, n. 1, p. 45-54, jun. 2006. Disponível em: http://pepsic.bvsalud.org/scielo.php?script=sci_arttext\&pid=S180856872006000100005\&lng=pt\&nrm=iso. Acesso em: 31 dez. 2020.

CASSARO, M.; SVALDI, G. D.; CALDELA, L. Tormenta RPG. Porto Alegre: Jambô, 2013. (ilustr. Erica Awano et al.).

CAVAQUINHO, N.; VALE, E. do. Caridade. Intérprete: Nelson Cavaquinho. In: Nelson Cavaquinho. Depoimento do poeta. Rio de Janeiro: Selo Castelinho, 1970. 1 LP. Faixa 9. 
ÇEKER, E.; ÖZDAML, F. What "gamification" is and what it's not. European Journal of Contemporary Education, v. 6, n. 2, p. 221-228, 2017.

CHOU, Y.-k. Actionable Gamification: beyond points, badges, and leaderboards. [S.1.]: Createspace Independent Publishing Platform, 2014.

CHRISTIANS, G. The Origins and future of gamification. 2018. Theses (Senior Theses) University of South Carolina, Los Angeles, CA, 2018.

CHUNG, T.-s. Table-top role playing game and creativity. Thinking Skills and Creativity, v. 8, n. 1, p. 56-71, 2013. doi: https://doi.org/10.1016/j.tsc.2012.06.002.

COONRADT, C. A. The game of work: how to enjoy work as much as a play. Salt Lake City, UT: Shadow Mountain, 1984.

CORDOVA, J. V.; JACOBSON, N. S. Crise de casais. In: BARLOW, D. H. (org.). Manual clínico dos transtornos psicológicos. Tradução M. R. B. Osório. Porto Alegre: Artmed, 1999. p. 535-567.

CROCCO, F. The RPG classroom: re-purposing game mechanics for the gamification of education. In: BYERS, A.; CROCCO, F. (ed.). The Role-Playing Society: Essays on the Cultural Influence of RPGs. Jefferson, NC: McFarland, 2016. p. 278-302.

DEL PRETTE, A., DEL PRETTE, Z. A. P. Habilidades sociais: biologia evolucionária, sociedade e cultura. In: GUIHARDI, H. J.; MADI, M. B. B. P.; QUEIROZ, P. P.; SCOZ, M. C. (org.). Sobre comportamento e cognição: vol. 8. Expondo a variabilidade. Santo André: ESETec, 2001. p. 65-75.

DEL PRETTE, A., DEL PRETTE, Z. A. P. Inventário de Habilidades Sociais para Adolescentes (IHSA-Del-Prette): manual de aplicação, apuração e interpretação São Paulo: Casa do Psicólogo, 2009.

DEL PRETTE, A.; DEL PRETTE, Z. A. P. Competência Social e Habilidades Sociais: manual teórico-prático. Petrópolis: Vozes, 2017.

DEL PRETTE, Z. A. P.; DEL PRETTE, A. Desenvolvimento interpessoal e educação escolar: o enfoque das habilidades sociais. Temas em Psicologia, v. 6, n. 3, p. 205-215, 1998.

DEL PRETTE, Z. A. P.; DEL PRETTE, A. Psicologia das habilidades sociais: terapia e educação. Petrópolis, RJ: Vozes, 1999.

DEL PRETTE, Z. A. P.; DEL PRETTE, A. Inventário de habilidades sociais (IHSDelPrette): manual de apuração e interpretação. São Paulo: Casa do Psicólogo, 2001a.

DEL PRETTE, Z. A. P.; DEL PRETTE, A. Inventário de habilidades sociais (IHSDelPrette): manual de apuração e interpretação. São Paulo: Casa do Psicólogo, 2001b.

DEL PRETTE, Z. A. P.; DEL PRETTE, A. No contexto da travessia para o ambiente de trabalho: treinamento de habilidades sociais com universitários. Estudos de Psicologia, v. 8, n. 3, p. 413-420, 2003. 
DEL PRETTE, Z. A. P.; DEL PRETTE, A. Habilidades sociais e análise do comportamento: proximidade histórica e atualidades. Perspectivas, São Paulo, v. 1, n. 2, p. 104-115, 2010. Disponível em: http://pepsic.bvsalud.org/scielo.php?script=sci_arttext\&pid=S217735482010000200004\&lng=pt\&nrm=iso. Acesso em: 19 mar. 2021.

DEL PRETTE, Z. A. P.; FALCONE, E. M. O.; MURTA, S. G. Contribuições do campo das habilidades sociais para a compreensão, prevenção e tratamento dos transtornos de personalidade. In: CARVALHO, L. F.; PRIMI, R. (org.). Perspectivas em psicologia dos transtornos da personalidade: implicações teóricas e práticas. São Paulo: Casa do Psicólogo, 2013. p. 326-358.

DEL PRETTE, Z. A. P.; DEL PRETTE, A. Inventário de Habilidades Sociais (IHS-DelPrette): manual de aplicação, apuração e interpretação. 6. ed. São Paulo: Casa do Psicólogo, 2016 [2001].

DETERDING, S.; SICART, M.; NACKE, L.; O’HARA, K.; DIXON, D. Gamification: Using game-design elements in non-gaming contexts. In: 2011 ANNUAL CONFERENCE EXTENDED ABSTRACTS ON HUMAN FACTORS IN COMPUTING SYSTEMS, 11. Vancouver, CA. Proceedings... 2011, p. 2425-2428. doi: https://doi.org/10.1145/1979742.1979575.

EKSTRÖM, L.; JOHANSSON, E.; GRANAT, T.; CARLSBERG, E. Functional therapy for children with cerebral palsy: An ecological approach. Developmental Medicine and Child Neurology, v. 47, p. 613-619, 2005.

FORTUNA, T. R. A formação lúdica docente e a universidade: contribuições da ludobiografia e da hermenêutica filosófica. 2011. Tese (Doutorado em Educação) Universidade Federal do Rio Grande do Sul, Porto Alegre, 2011.

GALASSI, J. P.; GALASSI, M. D.; VEDDER, M. J. Perspectives on assertion as a social skills model. In: WINE. J. D.; SMYE, M. D. (ed.). Social Competence. New York, NY: Guilford Press, 1981. p. 287-345.

GARCIA, A. Privilege, Power, and Dungeons \& Dragons: How systems shape racial and gender identities in tabletop role-playing games. Mind, Culture, and Activity, v. 24, n. 3, p. 232-246, 2017. doi: https://doi.org/10.1080/10749039.2017.1293691.

GERDENITSCH, C.; SELLITSCH, D.; BESSER, M.; BURGER, S.; STEGMANN, C.; TSCHELIGI, M.; KRIGLSTEIN, K. Work gamification: Effects on enjoyment, productivity and the role of leadership. Electronic Commerce Research and Applications, v. 43, Sept./Oct. 2020. doi: https://doi.org/10.1016/j.elerap.2020.100994.

GRESHAM, F. M.; ELLIOTT, S. N. Social skills assessment and training in emotional and behavioral disorders. In: WALKER, H. M.; GRESHAM, F. M. (ed.). Handbook of evidencebased practices for emotional and behavioral disorders: Applications in schools. New York, NY: The Guilford Press, 2014. p. 152-172.

GRESHAM, F.; ELLIOTT, S.; METALLO, S. Psychometric Fundamentals of the social skills improvement system: Social-emotional learning edition rating forms. Assessment for 
Effective Intervention, v. 45, n. 3, p. 194-209, 2020. Disponível em: https://doi.org/10.1177/1534508418808598.

GROENING, C.; BINNEWIES, C. “Achievement unlocked!” - The impact of digital achievements as a gamification element on motivation and performance. Computers in Human Behavior, v. 97, p. 151-166, 2019. doi: https://doi.org/10.1016/j.chb.2019.02.026.

HARO, J. M. et al. The Clinical Global Impression-Schizophrenia Scale: A simple instrument to measure the diversity of symptoms present in schizophrenia. Acta Psychiatrica

Scandinavica, v. 107, n. s416, p. 16-23, 2003. doi: 10.1034/j.1600-0447.107.s416.5.x.

HARTER, J. Historic drop in employee engagement follows record rise. In: Gallup. 02 July 2020. Disponível em: https://www.gallup.com/workplace/313313/historic-drop-employeeengagement-follows-record-rise.aspx.

HENNING, G.; ANDRADE, M. T. Developing Social Skills with group therapy using RPG. In: WORLD CONGRESS ON BRAIN, BEHAVIOR AND EMOTIONS, 2015, Porto Alegre. (Apresentação de Trabalho).

HORTA, A. M. O uso do RPG na sala de aula. 2005. Monografia (Licenciatura em Desenho e Plástica da Escola de Design) - Universidade do Estado de Minas Gerais, Belo Horizonte, 2005.

HUIZINGA, J. Homo ludens. São Paulo: Perspectiva, 1996.

INGERSOLL, B.; GERGANS, S. The effect of a parent-implemented imitation intervention on spontaneous imitation skills in young children with autism. Research in Developmental Disabilities, v. 28, n. 2, p. 163-175, 2007.

JAQUES, R. R. Educação e linguagem: as situações enunciativas do role-playing game (RPG) como ferramenta pedagógica de constituição da alteridade. 2016. Dissertação (Mestrado em Educação) - Universidade de Caxias do Sul, Caxias do Sul, 2016.

KADOURI, A.; CORRUBLE, E.; FALISSARD, B. The improved Clinical Global Impression Scale (iCGI): Development and validation in depression. BMC Psychiatry, v. 7, art. n. 7, Feb. 2007. doi: 10.1186/1471-244X-7-7.

KIM, Y. J.; SHUTE, V. J. Chapter 5 - Opportunities and challenges in assessing and supporting creativity in video games. In: GREEN, G. P.; KAUFMAN, J. C. (ed.). Video games and creativity. San Diego, CA: Academic Press, 2015. p. 99-117. doi:

https://doi.org/10.1016/B978-0-12-801462-2.00005-9.

KING, G.; McDOUGALL, J.; TUCKER, M.; GRITZAN, J.; MALLOY-MILLER, T.; ALAMBETS, P.; GREGORY, K.; THOMAS, K.; CUNNING, D. An evaluation of functional, school-based therapy services for children with special needs. Physical and Occupational Therapy in Pediatrics, v. 19, p. 5-29, 1999.

KIRESUK, T. J.; SHERMAN, R. E. Goal attainment scaling: A general method for evaluating comprehensive community mental health programs. Community Mental Health Journal, v. 4, n. 6, p. 443-453, 1968. doi: https://doi.org/10.1007/BF01530764. 
KIVLIGHAN, D. M.; GOLDFINE, D. C. Endorsement of therapeutic factors as a function of stage of group development and participant interpersonal attitudes. Journal of Counseling Psychology, v. 38, p. 150-158, 1991.

KLIMICK, C.; BETTOCCHI, E. O lugar do virtual no RPG, o lugar do RPG no design. In: SIMPÓSIO DO LARS: Atopia, Departamento de Artes e Design, 2., 2003, Rio de Janeiro. (Apresentação de Trabalho).

KŌHEI, K. Employing Tabletop Role-Playing Games (TRPGs) in social communication support measures for children and youth with Autism Spectrum Disorder (ASD) in Japan: A hands-on report on the use of leisure activities. Japanese Journal of Analog Role-Playing Game Studies, v. 0, p. 23-28, 2019.

KUPCHAN, C. A. The origins and future of NATO enlargement. Contemporary Security Policy, v. 21, n. 2, p. 127-148, 2000. doi: https://doi.org/10.1080/13523260008404259.

LANDERS, R. N. Developing a Theory of Gamified Learning: Linking serious games and gamification of learning. Simulation \& Gaming, v. 45, n. 6, p. 1-17, 20145. doi: https://doi.org/10.1177/1046878114563660.

LAUGESON, E.A.; FRANKEL, F. Social skills for teenagers with developmental and autism spectrum disorders: The PEERS treatment manual. New York: Routledge, 2010.

LAZARUS, A. A. Behaviour rehearsal vs. Non-directive therapy vs. Advice in effecting behaviour change. Behaviour Research and Therapy, v. 4, n. 3, p. 209-212, Aug. 1966. Disponível em: https://www.sciencedirect.com/science/article/abs/pii/0005796766900088.

LAZARUS, A. A. On assertive behavior: A brief note. Behavior Therapy, v. 4, p. 697-699, 1973.

LEME, V. B. R.; CAMPOS, J. R.; COIMBRA, S.; DEL PRETTE, A.; DEL PRETTE, Z. A. P. Social skills inventory for adolescents: evidence of construct validity and reliability. Psico, v. 47, n. 3, p. 171-178, 2016. doi: https://doi.org/10.15448/1980-8623.2016.3.20942.

LEUCHT, S.; ENGEL, R. R. The relative sensitivity of the Clinical Global Impressions Scale in the Brief Psychiatric Rating Scale in antipsychotic drug trials.

Neuropsychopharmacology, v. 31, n. 2, p. 406-412, Feb. 2006. doi: 10.1038/sj.npp.1300873.

LHULLIER, A. C.; NUNES, M. L. T.; HORTA, B. L. Preditores de abandono de psicoterapia em pacientes de clínica-escola. In: SILVARES, E. F. M. (org.). Atendimentos psicológicos em clínica-escola. Campinas: Alínea; 2006. p. 229-46.

LIBERMAN, R. P.; KING, L. W.; DERISI, W. J.; McCANN, M. Personal Effectiveness. Champaign, IL: Research Press, 1975.

LIMA, L. D. de; NOMURA, M. T.; VELASCO, P. D. N. O RPG no ensino de filosofia: diálogo e imaginação. In: SIMPÓSIO DO PIBID/UFABC 2012, Santo André. Anais... Santo André: UFABC, 2012. p. 43-45. 
LIMBERGER, L. S.; SILVA, J. C. Os role playing games (RPGS) como uma ferramenta em psicoterapia: um estudo de caso. Boletim de Psicologia, v. 63, n. 139, p. 193-200, dez. 2013.

LINEHAN, M. M. Interpersonnal effectiveness in assertive situations. In: BLEECHMAN, E. E. (ed.). Behavior modification with women. New York, NY: Guilford Press, 1984. p. 3452.

LÖHR, S. S. Estimulando o desenvolvimento de habilidades sociais em idade escolar. In: DEL PRETTE, A.; DEL PRETTE, Z. A. P. (org.). Habilidades sociais, desenvolvimento e aprendizagem: questões conceituais, avaliação e intervenção. Campinas: Alínea, 2003. p. 293-310.

MacKENZIE, K. R. The clinical application of a group climate measure. In: DIES, R. R.; MacKENZIE, K. R. (ed.). Advances in group psychotherapy: Integrating research and practice New York, NY: International Universities Press, 1983. p. 159-170.

MacKENZIE, K. R.; DIES, R. R.; COCHE, E.; RUTAN, J. S.; STONE, W. N. An analysis of AGPA Institute groups. International Journal of Group Psychotherapy, v. 37, p. 55-74, 1987.

MacMAHON, C. M.; LERNER, M. D.; BRITTON, N. Group-based social Skills interventions for adolescents with higher-functioning autism spectrum disorders: a review and looking to the future. Adolescent Health, Medicine and Therapeutics, v. 4, p. 23-38, 2013.

MALONE, T. W. How make things fun to learn: a study of intrinsically motivating computer games. Palo Alto, CA: Xerox, 1980.

MANTOVANI, C. C. P.; MARTURANO, E. M.; SILVARES, E. F. M. Abandono do atendimento em uma clínica-escola de psicologia infantil: variáveis associadas. Psicologia em Estudo, v. 15, n. 3, p. 527-535, set. 2010.

MARKWAY, B. G.; CARMIN, C. N.; POLLARD, C. A.; FLYNN, T. Morrendo de vergonha: um guia para tímidos e ansiosos. Tradução S. Augusto. São Paulo: Summus, 1999.

McDOUGALL, J.; KING, G. Goal Attainment Scaling: Description, utility, and applications in pediatric therapy services. 2nd ed. London, Ontario: Thames Valley Children's Centre, 2007. Disponível em: http://elearning.canchild.ca/dcd_pt_workshop/assets/planninginterventions-goals/goal-attainment-scaling.pdf.

McFALL, R. M. Behavioral training: a skill-acquisition approach to clinical problems. In: SPENCE, J. T.; CARSON, A.; CARSON. R. C.; THIBAUT, J. N. (org.). Behavioral approaches to Therapy. Morristow, NJ: General Learning Press, 1976. p. 227-259.

McKINNON, K.; KREMPA, J. L. Social skills solutions: A hands-on manual for teaching social skills to children with autism. New York, NY: DRL Books, 2002.

MELLO, M. F. de. Terapia Interpessoal: um modelo breve e focal. Revista Brasileira de Psiquiatria, São Paulo, v. 26, n. 2, p. 124-130, June 2004. doi:

http://dx.doi.org/10.1590/S1516-44462004000200010. 
MITCHELL, R.; SCHUSTER, L.; JIN, H. S. Gamification and the impact of extrinsic motivation on needs satisfaction: Making work fun?, Journal of Business Research, v. 106, p. 323-330, Jan. 2020. doi: https://doi.org/10.1016/j.jbusres.2018.11.022.

NEUFELD, C. B.; MALTONI, J.; LONGHINI, L. Z.; AMARAL, J. A. G. Estratégias de manejo terapêutico com adolescentes. In: NEUFELD, C. B. (org.). Terapia cognitivocomportamental para adolescentes: uma perspectiva transdiagnóstica e desenvolvimental. Porto Alegre: Artmed, 2017. p. 156-77.

O’DONOGHUE, W.; FERGUSON, E. (ed.). Handbook of professional ethics for psychologists: Issues, questions, and controversies. Thousand Oaks, CA: Sage Publications, 2003.

PALISANO, R. J.; HALEY, S. M.; BROWN, D. A. Goal attainment scaling as a measure of change in infants with motor delays. Physical Therapy, v. 72, p. 432-437, 1992.

PEREIRA-GUIZZO, C. de S.; DEL PRETTE, A.; DEL PRETTE, Z. A. P.; LEME, V. B. R. Programa de habilidades sociais para adolescentes em preparação para o trabalho. Psicologia Escolar e Educacional, v. 22, n. 3, p. 573-581, 2018. doi: https://doi.org/10.1590/2175$\underline{35392018035449 .}$.

PETERMANN, F.; MÜLLER, J. Clinical Psychology and single-case evidence: Practical approach to treatment planning and evaluation. Chichester, UK: John Wiley \& Sons, 2001.

PHILLIPS, E. L. Social skills: History and prospect. In: L'ABATE, L.; MILAN, M. A. (ed.). Handbook of social skills training and research. Nueva York, NY: John Wiley \& Sons, 1985. p. 3-19.

RANDI, M. A. F.; CARVALHO, H. F. Uma abordagem para a educação ativa. Revista Brasileira de Educação Médica, v. 37, n. 1, p. 80-88, 2013.

RANGÉ, B. Programa de treinamento à distância para tratamento de transtorno do pânico e agorafobia. In: MARINHO, M. L.; CABALLO, V. E. (org.). Psicologia clínica e da saúde. Granada (ES); Londrina (BR): APICSA; EDUEL, 2001. p. 153-175.

RATHUS, S. A.; FOX, J. A.; DE CRISTOFARO, J. Perceived structure of aggressive and assertive behaviors. Psychological Reports, v. 4, n. 3, p. 695-698, June 1979. doi: https://doi.org/10.2466/pr0.1979.44.3.695.

ROCHA, J. F. da; BOLSONI-SILVA, A. T.; VERDU, A. C. M. A. O uso do treino de habilidades sociais em pessoas com fobia social na terapia comportamental. Perspectivas em Análise do Comportamento, v. 3, n. 1, p. 38-56, 2012.

RODRIGUES, A. da S.; FEITOSA, F. B.; WAGNER, M. F.; PEDROSO, R. Social Skills Training in the promotion of self-esteem in adolescentes. Research Society and Development, v. 10, n. 2, e10710212212. doi: 10.33448/rsd-v10i2.12212.

ROMANCZYK, R. G.; GILLIS, J. M. Treatment approaches for autism: Evaluating options and making informed choices. In: ZAGER, D. (ed.). Autism spectrum disorders: Identification, education, and treatment. Mahwah, NJ: Lawrence Erlbaum, 2005. p. 515-535. 
SALDANHA, A. A.; BATISTA, J. R. M. A concepção do role-playing game (RPG) em jogadores sistemáticos. Psicologia: Ciência e Profissão, v. 29, n. 4, p. 700-717, 2009. doi: https://doi.org/10.1590/s1414-98932009000400005.

SALTER, A. Conditioned reflex therapy. New York, NY: Farrar, Strauss and Giroux, 1949.

SAMPAIO, A. A. S.; ANDERY, M. A. P. A. Comportamento social, produção agregada e prática cultural: uma análise comportamental de fenômenos sociais. Psicologia: Teoria e Pesquisa, v. 26, n 1, p. 183-192, 2010. Disponível em: https://doi.org/10.1590/S0102$\underline{37722010000100020 .}$.

SANTOS, P. S. A. Adaptação transcultural da Goal Attainment Scaling (GAS) para a língua portuguesa brasileira: uma ferramenta para dimensionar o cumprimento de metas em programas de reabilitação. 2018. Trabalho de Conclusão de Curso (Bacharelado em Fisioterapia) - Universidade Brasília, Brasília, 2018.

SCORSOLINI-COMIN, F.; INOCENTE, D. F.; MIURA, I. K. Avaliação de programas de treinamento, desenvolvimento e educação no contexto organizacional: modelos e perspectivas. Revista Psicologia: Organizações e Trabalho, v. 11, n. 1, p. 37-53, 2011.

SEGRIN, C. Social skills deficits and psychosocial problems: antecedent, concomitant, or consequent? Journal of Social and Clinical Psychology, v. 12, p. 336-353, 1993.

SKINNER, B. F. Verbal Behavior. New York, NY: Applenton-Century-Crofts, 1957.

SOARES, A. N.; GAZZINELLI, M. F.; SOUZA, V. de; ARAÚJO, L. H. L. Role playing game (RPG) como estratégia pedagógica na formação do enfermeiro: relato da experiência de criação do jogo. Texto e Contexto Enfermagem, v. 24, n. 2, p. 600-608, 2015. doi: https://doi.org/10.1590/0104-0707201500107201457.

SPEARING, M.; POST, R. M.; LEVERICH, G. S.; BRANDT, D.; NOLEN, W. Modification of the Clinical Global Impressions (CGI) Scale for use in bipolar illness (BP): The CGI-BP. Psychiatry Research, v. 73, n. 3, p. 159-171, Dec. 1997. doi: https://doi.org/10.1016/S01651781(97)00123-6.

SPIELMANS, G. I.; McFALL, J. P. A comparative meta-analysis of Clinical Global Impressions change in antidepressant trials. The Journal of Nervous and Mental Disease, v. 194, n. 11, p. 845-852, Nov. 2006. doi: 10.1097/01.nmd.0000244554.91259.27.

STARLING, R. R. Prática controlada: medidas continuadas e produção de evidências empíricas em terapias analítico-comportamentais. 2010. Tese (Doutorado em Psicologia) Universidade de São Paulo, São Paulo, 2010. doi: https://doi.org/10.11606/T.47.2010.tde29032010-163308.

STEENBEEK, D.; MEESTER-DELVER, A.; BECHER, J.; LANKHORST, G. The effect of botulinum toxin type A treatment of the lower extremity on the level of functional abilities in children with cerebral palsy: evaluation with goal attainment scaling. Clinical

Rehabilitation, v. 19, p. 274-282, 2005. 
SUGG, N. K.; THOMPSON, R. S.; THOMPSON, D. C.; MAIURO, R.; RIVARA, F. P. Domestic violence and primary care. Attitudes, practices, and beliefs. Archives of Family Medicine, v. 8, n. 4, p. 301-306, July/Aug. 1999. doi: 10.1001/archfami.8.4.301.

SUITS, B. What is a game? Philosophy of Science, v. 34, n. 2, p. 148-156, 1967. Disponível em: https://philpapers.org/rec/SUIWIA.

TANCINI, P. E. G. Temporalidades contemporâneas ressignificadas: lógicas de consumo e representações de passado e futuros no cenário ficcional de Tormenta RPG. 2018. Dissertação (Mestrado em Comunicação e Práticas de Consumo) - Escola Superior de Propaganda e Marketing, São Paulo, 2018.

TAYLOR, B. A. Improving the social behavior of children with autism. In: BONDY, A.; WEISS, M. J. (ed.). Teaching social skills to people with autism: best practices in individualizing interventions. Bethesda, MD: Woodbine House, 2013. p. 1-46.

TAYLOR, S. E. Psicología de la salud. México, DF: McGraw-Hill Interamericana, 2007.

TREIBLMAIER, H.; PUTZ, L.-M. Gamification as a moderator for the impact of intrinsic motivation: Findings from a multigroup field experimente. Learning and Motivation, v. 71, Aug. 2020. doi: https://doi.org/10.1016/j.lmot.2020.101655.

TROWER, P. (ed.). Social behavior in context. Londron, UK: Lawrence Erlbaum, 1984.

TROWER, P. Adult social skills: State of the art and future directions. In: O'DONOHUE, W.; KRASNER, L. (ed.). Handbook of Psychological Skills Training: Clinical techniques and applications. New York, NY: Allyn and Bacon, 1995. p. 54-80.

TROWER, P.; BRYANT, B.; ARGYLE, M. Social skills and mental health. London, UK: Methuen, 1978.

VIALE-VAL, G.; ROSENTHAL, R. H.; CURTISS, G.; MAROHN, R. C. Dropout from adolescent psychotherapy: A preliminary study. Journal of the American Academy of Child Psychiatry, v. 23, n. 5, p. 562-568, Sept.1984. doi: https://doi.org/10.1016/S00027138(09)60347-2.

WIERZBICKI, M.; PEKARIK, G. A meta-analysis of psychotherapy dropout. Professional Psychology: Research and Practice, v. 24, n. 2, 190-195, 1993.

WILKINSON, J.; CANTER, S. Social skills training manual. Assessment, programme design and management of training. Hoboken, NJ: Wiley, John \& Sons, 1982.

WOLPE, J. Psychotherapy by reciprocal inhibition. Stanford, CA: Stanford University Press, 1958.

WOLPE, J. The practice of Behavior Therapy. Oxford, UK: Pergamon, 1969.

WOLPE, J.; LAZARUS, A. A. Behavior Therapy techniques: A guide to the treatment of neuroses. Toronto, CA: Pergamon of Canada, 1966. 
ZAIDER, T. I.; HEIMBERG, R. G.; FRESCO, D. M.; SCHNEIER, F. R.; LIEBOWITZ, M. R. Evaluation of the Clinical Global Impression Scale among individuals with social anxiety disorder. Psychological Medicine, v. 33, n. 4, p. 611-622, May 2003. doi:

$\underline{10.1017 / \mathrm{s} 0033291703007414 .}$.

ZIGLER, E.; PHILLIPS, L. Social effectiveness and symptomatic behaviors. Journal of Abnormal and Social Psychology, v. 61, p. 231-232, 1960. 


\section{APÊNDICE A - TERMO DE CONSENTIMENTO LIVRE E ESCLARECIDO}

\section{HOSPITAL DAS CLÍNICAS DA FACULDADE DE MEDICINA DA UNIVERSIDADE DE SÃO PAULO-HCFMUSP TERMO DE CONSENTIMENTO LIVRE E ESCLARECIDO}

\section{DADOS DA PESQUISA}

Título da pesquisa - O Método D20 na terapia das habilidades sociais e competência social em grupo para adolescentes e jovens.

Pesquisador principal: Germano Henning

Departamento/Instituto - Hospital das Clínicas da USP Instituto de Psiquiatria / Instituto de Psicologia da USP

De acordo com a resolução 466/2012 os seguintes conteúdos devem fazer parte das explicações sobre a pesquisa:

Convidamos o(a) Sra. para participar desta pesquisa com o título de "O Método D20 na terapia das habilidades sociais e competência social em grupo para adolescentes e jovens.", isto é, analisar cientificamente a eficiência deste método do RPG, aliada com terapia, para promover engajamento dos participantes a mudarem o seu comportamento e compreender a generalização dos comportamentos aprendidos.

Justificativa e objetivos do estudo: É descobrir se, através do Método D20, aumentar o engajamento e repertório social dos clientes nas sessões de grupo e, também, capaz de motivar o participante a mudar o comportamento fora do contexto do consultório.

Procedimentos que serão realizados e métodos que serão empregados: Os participantes participação de 12 até 16 sessões da terapia de grupo, além de sessão da entrevista inicial com os pais e uma outra com o participante para avaliação. Os encontros serão quinzenais e os grupos serão formados com pares semelhantes. Vale a pena frisar que, na entrevista inicial com os pais, será verificado a possibilidade do seu filho participar da pesquisa, pois dependerá do perfil, idade e interesse pela cultura pop ou nerd.

Será pedido para os participantes de grupo preencher dois questionários: (a) o IHSA (Inventário de Habilidades Sociais para Adolescentes) no começo, meio e final do estudo; (b) o GOQAdaptado no final de cada sessão de grupo.

Para os pais, será enviado, por WhatsApp, o link para o CGI (Impressão Clínica Global) toda a semana.

Não será utilizada nenhuma ação farmacológica durante toda a pesquisa

Explicitação de possíveis desconfortos e riscos decorrentes da participação na pesquisa:

Não há riscos. Talvez um leve desconforto pelas sessões por serem longas, mas, qualquer incômodo será informado aos pais, durante todo o processo.

Benefícios esperados para o participante:

Desenvolvimento do repertório social, assim como possibilidade de alterar comportamentos dentro de casa e/ou maiores encontros fora do consultório com os demais participantes.

Esclarecimento sobre a forma de acompanhamento e assistência a que terão direito os participantes da pesquisa:

Durante a pesquisa, os pais terão comunicação com os terapeutas através do WhatsApp para 
tirar algumas dúvidas e/ou terapeutas alinharem as demandas para as Tarefas Interpessoais de Casa, a partir da perspectiva dos pais.

Garantias de plena liberdade ao participante de recusar-se a participar ou retirar o seu consentimento em qualquer fase da pesquisa sem penalização alguma, de sigilo e privacidade

Garantia de que o participante receberá uma via do termo de consentimento

Após à aprovação da pesquisa no comitê, possivelmente haverá uma segunda versão do TCLE que deverá ser entregue aos pais.

Explicitação das garantias de ressarcimento por despesas decorrentes da pesquisa e explicitação da garantia de indenização por eventuais danos decorrentes da pesquisa

Se houver algum prejuízo decorrente da pesquisa, será discutida com o pesquisador responsável e com a equipe de pesquisa para avaliar quais poderão ser os possíveis reparos como terapias individuais extras, orientação de pais e outros.

Em qualquer etapa do estudo, você terá acesso aos profissionais responsáveis pela pesquisa para esclarecimento de dúvidas. O principal investigador é o Germano Henning que pode ser encontrado no endereço Rua João Moura, 627, cjto 183 Telefone 11 96111-7644, e-mail germano.henning@gmail.com. Se você tiver alguma consideração ou dúvida sobre a ética da pesquisa, entre em contato com o Comitê de Ética em Pesquisa (CEP) - Rua Ovídio Pires de Campos, 225 - 5o andar - tel: (11) 2661-7585, (11) 2661-1548, (11) 2661-1549; e-mail: cappesq.adm@hc.fm.usp.br

Fui suficientemente informado a respeito do estudo “ ".

Eu discuti as informações acima com o Pesquisador Responsável ( ou pessoa(s) por ele delegada(s) ( ) sobre a minha decisão em participar nesse estudo. Ficaram claros, para mim, os objetivos, os procedimentos, os potenciais desconfortos e riscos e as garantias. Concordo voluntariamente em participar deste estudo, assino este termo de consentimento e recebo um via rubricada pelo pesquisador.

Assinatura do participante /representante legal

$$
\text { Data: }
$$

I

Assinatura do responsável pelo estudo

Data: l

DADOS DE IDENTIFICAÇÃO (OU ETIQUETA INSTITUCIONAL DE IDENTIFICAÇÃO) DO PARTICIPANTE DA PESQUISA OU RESPONSÁVEL LEGAL

1. NOME:

DOCUMENTO DE IDENTIDADE No: SEXO : .M $\square \mathrm{F} \square$

DATA NASCIMENTO: I I

ENDEREÇO No APTO:

BAIRRO: CIDADE CEP

TELEFONE: DDD ( ) 
2.RESPONSÁVEL LEGAL

NATUREZA (grau de parentesco, tutor, curador etc.)

DOCUMENTO DE IDENTIDADE No :

SEXO : .M $\square \mathrm{F} \square$

DATA NASCIMENTO:

I.

I

ENDEREÇO

APTO:

BAIRRO:

CIDADE

CEP

TELEFONE: DDD 


\section{APÊNDICE B - ENTREVISTA INICIAL COM PAIS V1.0}

\section{Formulário para Entrevista Clínica Inicial}

Identificação/Localização

*Nome da cliente:

*Nascimento:

Endereço:

Bairro:

*Escola:

*Coordenadora:

\section{*Dados do Núcleo Familiar}

\begin{tabular}{|l|l|l|l|}
\hline Nome & Parentesco & Idade & Profissão \\
\hline & & & \\
\hline & & & \\
\hline & & & \\
\hline & & & \\
\hline & & & \\
\hline
\end{tabular}

\section{Informações Adicionais}

*Encaminhado por:

Fez algum tratamento médico? ( )Sim ( )Não

Especifique:

Já fez algum tratamento psicológico ou psiquiátrico? ( )Sim ( )Não

Histórico de encaminhamentos (Quem deu o diagnóstico final?)

Diagnóstico atual:

Últimos relatórios de neuropsi, avaliações...: 
Informações da Entrevista

Queixa (descrição, frequência, duração, exemplos, implicações para a criança e para as outras pessoas, tentativas de mudanças já realizadas, diagnóstico)

Relacionamento familiar (relacionamento da criança com os pais, irmãos e outros familiares; relacionamento conjugal dos pais, brigas)

Vida escolar (relação com os colegas e professores, rendimento acadêmico, motivação)

Sintomas (Sono, Alimentação...):

O que gosta de fazer:

Aspectos sociais (assertividade, relacionamentos, dentre outros)

Expectativas em relação ao atendimento (o que acham que eu posso oferecer)

\section{Metas claras:}


APÊNDICE C - LISTA DE INTERESSE V2.09

v2.09

Data:

Nome:

Idade:

\section{GAMES}

Frequência de jogar na semana? (1x, 2x, etc):

\section{PLATAFORMA DOS GAMES}

Quais plataformas você joga? (Nintendo, Xbox, Celular, PS4, etc)

\section{Jogos ATUAIS}

Quanto gosta?

\begin{tabular}{|c|c|c|c|c|c|}
\hline Jogos / Console & 1 & 2 & 3 & 4 & 5 \\
\hline & & & & & \\
\hline & & & & & \\
\hline & & & & & \\
\hline & & & & & \\
\hline & & & & & \\
\hline & & & & & \\
\hline & & & & & \\
\hline & & & & & \\
\hline & & & & & \\
\hline Tormenta RPG & & & & & \\
\hline
\end{tabular}

\section{JOGOS HISTÓRICOS}

Jogos que você mais curtiu ... do mais recente para mais antigo

\begin{tabular}{|l|l|}
\hline NOME DO JOGO / PLATAFORMA & Joga atualmente? \\
\hline & \\
\hline & \\
\hline & \\
\hline & \\
\hline
\end{tabular}




\begin{tabular}{|l|l|}
\hline & \\
\hline & \\
\hline & \\
\hline & \\
\hline & \\
\hline
\end{tabular}

EDITORAS DE HQ (assinale as que você curte)

Marvel DC Comics Animes

Dark Horse

Cartoon
Vertigo

Turma da Mônica
Mangás

\section{LIVROS}

Qual Gênero/Autor/Título:

\section{RELACIONAMENTOS}

Tem colegas? $\mathrm{R}$ : Tem amigos? R: Tem namorada? R: Tem amigos de verdade? $R$ :

Se encontra fora da escola?

Locais:

Gosta de flertar? R: Gostaria de namorar? R: Tem Crush? R:

\section{REDES SOCIAIS}

Quais aplicativos/site? Qts vezes por semana?

Participar de quantos grupos de whatsapp?

Quais os temas dos grupos?

\section{YOUTUBE}

Quais os canais você curte?

\section{MÚSICA}

Ouve música? R: Frequência por semana? R:

Faz aula de música? R:__ Qual instrumento?

Toca em grupo? R:

Gostaria de aprender a tocar? R:

Qual instrumento gostaria? R:

Gênero que ouvir: 
ESPORTES E E-SPORTS

\begin{tabular}{|c|c|c|c|c|c|c|}
\hline \multicolumn{7}{|c|}{ Quanto você gosta? } \\
\hline Nome do esporte & Joga? & 1 & 2 & 3 & 4 & 5 \\
\hline & & & & & & \\
\hline & & & & & & \\
\hline & & & & & & \\
\hline & & & & & & \\
\hline & & & & & & \\
\hline & & & & & & \\
\hline & & & & & & \\
\hline
\end{tabular}

\section{Hobbies}

Outras coisas que gosta de fazer? 
APÊNDICE D - CGI - IMPRESSÃO CLÍNICA GLOBAL

Nome do responsável:

Data:

Nome do adolescente:

Sessão:

\section{ESCALA DE IMPRESSÃO CLÍNICA GLOBAL - Severidade da doença (CGI-S)}

1) Sobre queixas de habilidades sociais e competência social:

Considerando sua experiência com este tipo de problema, qual o grau de severidade dessa questão deste paciente neste momento?
$0 . \quad$ ( ) Não avaliado
4. ( ) Moderada
1. ( ) Não está doente
5. ( ) Acentuada
2. ( ) Muito leve
6. ( ) Grave
3. ( ) Leve
7. ( ) Extremamente grave

\section{ESCALA DE IMPRESSÃO CLÍNICA GLOBAL - Melhora da doença (CGI-I)}

Comparado à semana anterior, como se encontra o paciente neste momento? (Aponte a melhoria global mesmo que esta não tenha decorrido completamente ao tratamento).
0. ( ) Não avaliado
4. ( ) Sem alterações
1. ( ) Muito melhor
2. ( ) Moderadamente melhor
5. ( ) Levemente pior
3. ( ) Levemente melhor
6. ( ) Moderadamente pior
7. ( ) Muito pior

O que mudou?: 